\title{
The Biological and Chemical Diversity of Tetramic Acid Compounds from Marine-Derived Microorganisms
}

\author{
Minghua Jiang ${ }^{1,2,+} \mathbb{D}$, Senhua Chen ${ }^{1,2,3, *,+} \mathbb{D}$, Jing Li ${ }^{1,2,3}$ and Lan Liu $1,2,3, *(\mathbb{D})$ \\ 1 School of Marine Sciences, Sun Yat-sen University, Guangzhou 510006, China; \\ jiangmh23@mail2.sysu.edu.cn (M.J.); lijing356@mail.sysu.edu.cn (J.L.) \\ 2 South China Sea Bio-Resource Exploitation and Utilization Collaborative Innovation Center, \\ Guangzhou 510006, China \\ 3 Southern Laboratory of Ocean Science and Engineering (Guangdong, Zhuhai), Zhuhai 519000, China \\ * Correspondence: chensenh@mail.sysu.edu.cn (S.C.); cesllan@mail.sysu.edu.cn (L.L.); \\ Tel.: +86-020-84725459 (S.C. \& L.L.) \\ + These authors contributed equally to this work.
}

Received: 25 January 2020; Accepted: 14 February 2020; Published: 15 February 2020

\begin{abstract}
Tetramic acid (pyrrolidine-2,4-dione) compounds, isolated from a variety of marine and terrestrial organisms, have attracted considerable attention for their diverse, challenging structural complexity and promising bioactivities. In the past decade, marine-derived microorganisms have become great repositories of novel tetramic acids. Here, we discuss the biological activities of 277 tetramic acids of eight classifications (simple 3-acyl tetramic acids, 3-oligoenoyltetramic acids, 3-decalinoyltetramic acid, 3 -spirotetramic acids, macrocyclic tetramic acids, $N$-acylated tetramic acids, $\alpha$-cyclopiazonic acid-type tetramic acids, and other tetramic acids) from marine-derived microbes, including fungi, actinobacteria, bacteria, and cyanobacteria, as reported in 195 research studies up to 2019.
\end{abstract}

Keywords: tetramic acid; bioactivity; marine natural product; marine-derived microorganisms

\section{Introduction}

Secondary metabolites bearing a tetramic acid (pyrrolidine-2, 4-dione) motif have been isolated from various terrestrial and marine species, such as bacteria, actinobacteria, cyanobacteria, fungi, and sponges. The tetramic acid scaffold can be modified by unusual and intricate substituents to form complex, diverse chemical structures with multiple stereogenic centers. Intriguingly, an increasing number of tetramic acid products have shown a remarkable diversity of bioactivities, including antitumor, antibacterial, antifungal, and antiviral activities [1-5]. Due to their intricate structures and potent biological activity, natural tetramic acids have attracted a great deal of attention for their biosynthesis mechanisms, medicinal potential, and chemical synthesis in the biological, chemical, and pharmaceutical fields. Up to 2013, there were several reviews covering numerous aspects of naturally occurring tetramate products, such as isolation, biological activity, and synthesis, published by Royles [1], Ghisalberti [2], Gossauer [3], Schobert and Schlenk [4], and Ju et al. [5]. Many reviews have discussed the biosynthetic mechanisms of the PKS-NRPS biosynthesis pathways of tetramic acids in detail [2,5-9].

Marine natural products (MNPs) are considered an unexploited treasure trove of new bioactive NPs for the 21st century. Among them, marine microorganism-derived NPs have become the primary source of new MNPs, from less than 20\% of newly discovered MNPs in 2006 to 57\% in 2017 (based on a summary of a series of reviews "Marine Natural Products" published by Blunt and his colleagues during 2008-2019 [10,11]. While there have been no special reviews about tetramic acid compounds from marine microbes, especially in the past six years, numerous examples of new tetramate molecules from 
marine-derived microorganisms, and their related bioactivities, have been reported (up to 94 articles, $48 \%$ of the total 195 research articles from 1970-2019). In the current review, we focus our attention on the isolation, structural features, and biological activities of natural tetramate products isolated from marine-derived microorganisms (fungi, actinobacteria, bacteria, and cyanobacteria) reported up to September 2019. Notably, three broad groups of compounds (cytochalasins, 4-O-substituted derivatives (i.e., tetronates), and 2-pyridones), from putative tetramic acid-related biosynthesis pathways have been covered in numerous reviews [4,6-8,12-16] and are excluded from this review.

A total of 195 research papers describing 277 tetramate compounds from marine-derived microbes were analyzed for this review (Supplementary Table S1). The assignments of a given compound to a certain category were based on their particular structural features and biogenetic pathways. The compounds were characterized into eight groups of chemical structures, as shown in Figure 1: simple 3-acyl-tetramic acids (3-ATAs), 3-oligoenoyltetramic acids (3-OTAs), 3-decalinoyltetramic acids (3-DTAs), 3-spirotetramic acids (3-STAs), macrocyclic tetramic acids (MTAs), $N$-acylated tetramic acids, $\alpha$-cyclopiazonic acid (CPA)-type tetramic acids, and other tetramic acids. Furthermore, the macrocyclic tetramic acids were distributed into two subcategories: polycyclic tetramate macrolactams (PTMs) from marine actinobacteria and bacteria, and pyrrocidine tetramate alkaloids (PTAs) from marine fungi. The pie chart in Figure 1 provides deeper insight into the diversity and complexity of TAs from marine-derived microbes, revealing the complexity and diversity of molecules characterized as the dominating compounds. MTAs (21.0\%) comprised the largest proportion of TAs from marine microbes, followed by $N$-acylated TAs (16.0\%), 3-DTAs (13.0\%), 3-STAs (12\%), CPA-type TAs (9\%), 3-ATAs (9\%), and 3-OTAs (5\%). As is known, structures can determine properties; thus, the complex and diverse structures of TAs will lead to the diversity of their bioactivities. Therefore, this review aims to give an overview of the naturally occurring tetramate products from marine-derived microbes and their biological activities, as reported in the literature until September 2019, to illustrate their biodiversity, chemical diversity, and bioactive diversity. The origins of the strains and the diversity and biological properties of the compounds, as well as the relevant publication details are also summarized (Supplementary Table S1).

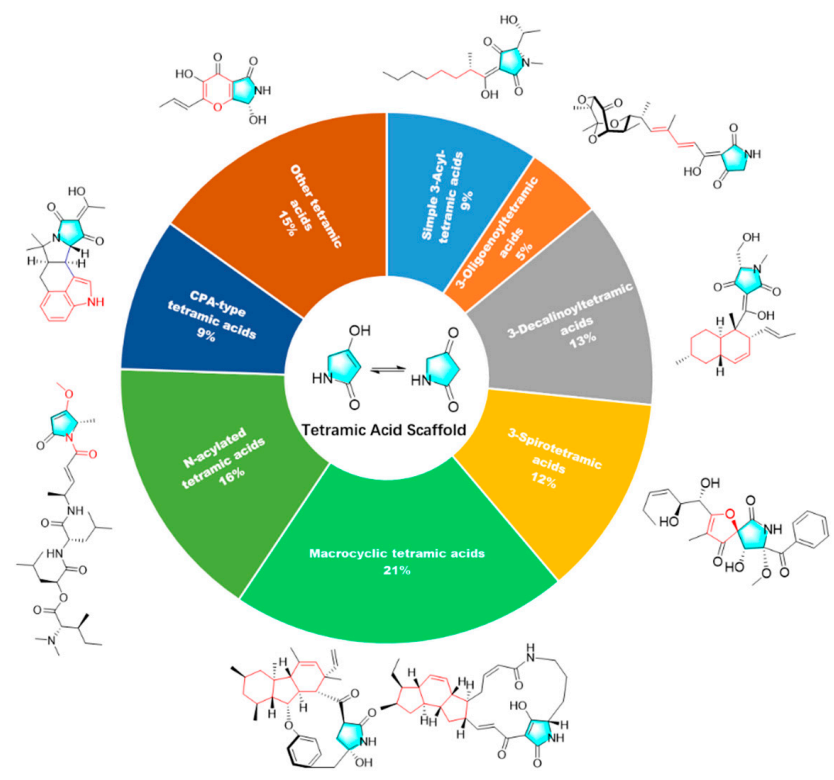

Figure 1. Classification of the 277 tetramic acids (TAs) from marine microorganisms into eight classes. Some examples of typical molecules belonging to these classes are illustrated: simple 3-acyl-tetramic acids (penicillenol $\mathrm{A}_{1}$ ), 3-oligoenoyltetramic acids (tirandamycin A), 3-decalinoyltetramic acids (equisetin), 3-spirotetramic acids (pseurotin A), macrocyclic tetramic acids (from left to right, ikarugamycin, GKK1032 $\mathrm{A}_{2}$ ), $N$-acylated tetramic acids (symplostatin 4 ), $\alpha$-cyclopiazonic acid (CPA)-type tetramic acids ( $\alpha$-cyclopiazonic acid), and other tetramic acids (vermelhotin). The main characteristics of each chemical class are highlighted in red. 


\section{Isolation, Structure, and Bioactivities of Tetramic Acid Products from Marine Microbes}

\subsection{Simple 3-acyl Tetramic Acid}

Simple 3-acyl tetramic acids (3-ATAs), which contain an acyl substituent at C-3, are the most common tetramate derivatives in nature. However, only 26 simple 3-ATAs (featuring C-3-acyl-linear side chains) have been discovered from marine microorganisms (Figure 2).

Magnesidin A (1), a mixture of the magnesium chelates of the $\mathbf{1 a}$ (3-hexanoyl) and $\mathbf{1 b}$ (3-decanoyl), was first isolated in 1973 from the marine bacterium Pseudomonas magnesiorubra and re-isolated in 1994 from another marine bacterium, Vibrio gazogenes, and displayed significant activity against eight Gram-positive bacteria (MIC $=2-7 \mu \mathrm{g} / \mathrm{mL}$ ) $[17,18]$. Epicoccamide (2), an unusual $O$-glycosylated tetramic acid with a $\beta$-D-mannose moiety and an aliphatic chain, was reported from a marine fungus Epicoccum purpurascens originating from the jellyfish Aurelia aurita, and was devoid of antimicrobial and cytotoxic activities [19].

The bioassay-guided investigation of the fermentation culture of Penicillium sp. GQ-7, which was collected from an endophytic fungus associated with the mangrove plant Aegiceras corniculatum, led to the isolation of six tetramic acids, penicillenols $A_{1}, A_{2}, B_{1}, B_{2}, C_{1}$, and $C_{2}$ (3-8) [20]. Subsequently, the penicillenol analogues penicillenol $D$ (9) [21] and penicillenols $D_{1}$, and $D_{2}$ (10 and 11) [22] were discovered from the marine sediment-derived fungi Trichoderma citrinoviride and Penicillium citrinum, respectively. The stereochemistry (3-8) of C-9 in the 3-acyl side chain was assigned as $S$ by total synthesis [23]. In the cytotoxicity bioassay, compound 3 showed potent cytotoxicity against five human tumor cell lines (HTCLs) (A-549, BEL-7402, P388, HL-60, and A375) with IC 50 values of $23.80,13.03,8.85,0.76$, and $12.80 \mu \mathrm{M}$, respectively [20,24], while 4, 5, and 6 displayed cytotoxicity against the HL-60 cell line, with an $\mathrm{IC}_{50}$ ranging from 3.20 to $16.26 \mu \mathrm{M}$ [20]. Further, compounds 9 , 10, and 11 showed moderate or weak cytotoxicity against A-375 ( $\mathrm{IC}_{50}=32.6 \mu \mathrm{M}$ for 9 ), A549, and HL-60 ( $\mathrm{IC}_{50}=43.5-66.5 \mu \mathrm{M}$ for 10 and 11) [21]. Penicillenol $\mathrm{A}_{1}(3)$ also showed cytotoxicity against cisplatin-resistant HT-29, antibacterial activity against Staphylococcus aureus, and antituberculous (anti-TB) activity, with a $96.1 \%$ inhibition ratio at $10 \mu \mathrm{M}$ [25]. In seeking anti-biofilm agents, these molecules (3-8) were re-obtained from the deep-sea fungus Aspergillus restrictus DFFSCS006 and were used to inhibit biofilm formation and eradicate the pre-developed biofilms of Candida albicans [26]. The mechanistic basis of compounds $\mathbf{4}$ and $\mathbf{5}$ is to decrease hyphal growth, thereby suppressing the transcripts of specific genes, inhibiting the expression of extracellular polymeric substance and reducing phospholipase activity [26]. The structure-activity relationships (SARs) of these penicillenols suggest that the saturation of the hydrocarbon chain at C-8 and the trans-configuration of the double bond between C-5 and C- 6 might significantly affect their activities; further, a different configuration of C-5 is important for anti-biofilm $(R)$ and antitumor $(S)$ activities $[20,26]$.

Penicitrinine A (12), bearing a unique 5-spiro tetramate skeleton and considered to be a Diels-Alder reaction product of compound 3 and citrinin, was purified from a strain of P. citrinum (also producing compounds 3-6 [24]), and displayed antiproliferative activities on multiple HTCLs, especially human malignant melanoma cell A-375 [27]. The mechanism of action was via inducing apoptosis by regulating Bcl-2 and Bax secretion and inhibiting cell metastasis through suppressing MMP-9 activity and upregulating its specific inhibitor TIMP-1 [27].

Four simple 3-ATAs, chaunolidines A-C (13-15) and a known F-14329 (16) were isolated from the marine fungus Chaunopycnis sp. (CMB-MF028) associated with a pulmonate false limpet Siphonaria sp. [28]. All have the capability to form metal chelates nonselectively, though only $\mathbf{1 6}$ exhibits cytotoxic activity and was previously reported to inhibit the absorption of neutral lipids in mice $[28,29]$. The three tetramate analogues tolypocladenol $\mathrm{A}_{1}, \mathrm{~A}_{2}$, and C (17-19) were obtained from sponge-derived Tolypocladium geodes sp. MF458 using the "one strain many compounds" (OSMAC) method and do not exhibit cytotoxicity [30]. Seven 3-ATAs (cladosporiumins E-H, N-O, and $\mathrm{L}$ as an $\mathrm{Mg}$ complex) (20-23, 24-25, and 26) were isolated from Cladosporium sp. SCSIO z0025 [31] and Cladosporium sphaerospermum EIODSF 008 [32] was derived from deep-sea sediment. 


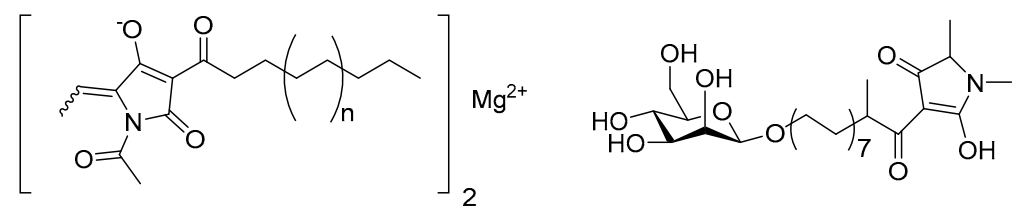

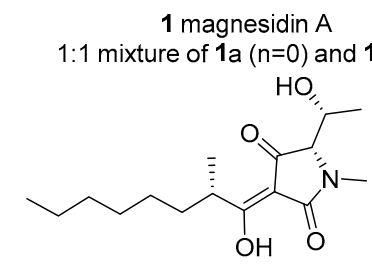

3 penicillenol $A_{1}$

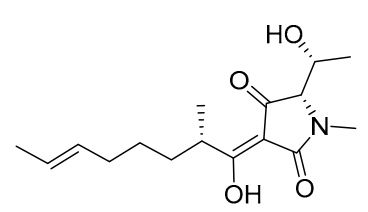

7 penicillenol $\mathrm{C}_{1}$<smiles>CCCCCC[C@H](C)C(O)=C1C(=O)[C@@H]([C@H](C)O)N(C)C1=O</smiles>

4 penicillenol $A_{2}$

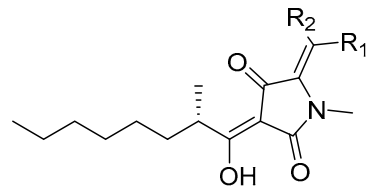

5 penicillenol $\mathrm{B}_{1} \mathrm{R}_{1}=\mathrm{CH}_{3} \mathrm{R}_{2}=\mathrm{H}$ 6 penicillenol $B_{2} \mathrm{R}_{1}=\mathrm{H} \quad \mathrm{R}_{2}=\mathrm{CH}_{3}$<smiles>[R2]C([R2])=C1C(=O)/C(=C(/O)C(C)CCC/C=C/C)C(=O)N1C</smiles>

10 penicillenol $D_{1} \mathrm{R}_{1}=\mathrm{CH}_{3} \mathrm{R}_{2}=\mathrm{H}$ 11 penicillenol $D_{2} R_{1}=H \quad R_{2}=C_{3}$

$\mathrm{HO}$<smiles>C/C=C/CCC[C@H](C)/C(O)=C1\C(=O)[C@@H]([C@H](C)O)N(C)C1=O</smiles>

8 penicillenol $\mathrm{C}_{2}$

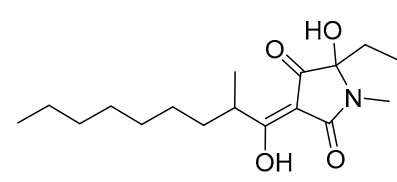

9 penicillenol D

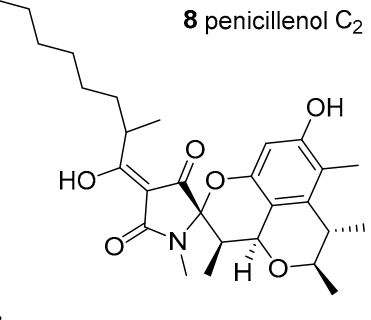<smiles>[R]C/C=C/C[C@H](C)C[C@@H](C)/C(O)=C1/C(=O)N[C@H]([C@H](O)c2ccc(O)cc2)C1=O</smiles>

12 penicitrinine $A$ $\mathrm{R}=\mathrm{H}, \quad 2 \mathrm{~S}$

13 chaunolidine $A \quad \mathrm{R}=\mathrm{H}, \quad 2 ' R$<smiles>C/C=C\C[C@H](C)C[C@H](C)/C(O)=C1/C(=O)NC(=C/c2ccc(O)cc2)/C1=C(/O)[C@@H](C)C[C@@H](C)C/C=C\C</smiles>

15 chaunolidine $C \quad 17$ tolypocladenol $A_{1} \quad 18$ tolypocladenol $A_{2} \quad 19$ tolypocladenol $C$<smiles>CC(C)=C1NC(=O)C(=C(O)C=CC[C@@H](C)O)C1=O</smiles><smiles>CC(C)=C1NC(=O)C(=C(O)CC(O)CC(C)O)C1=O</smiles><smiles>CC(O)C/C=C/C(O)=C1C(=O)N[C@@H](C(C)C)C1=O</smiles><smiles>COC(=CCC(C)O)CC(O)=C1C(=O)N[C@@H](C(C)C)C1=O</smiles><smiles>CC(O)C/C=C/C(O)=C1/C(=O)N[C@@H](C(C)C)C1=O</smiles>

20 cladosporiumin E 21 cladosporiumin F (anti C-11,C-13)

22 cladosporiumin G

23 cladosporiumin $\mathrm{H} \quad \mathbf{2 4}$ cladosporiumin $\mathrm{N}$ a:(anti C-11, C-13)<smiles>CC(C)=C1NC(=O)/C(=C(O)/C=C/C[C@H](C)O)C1=O</smiles>

25 cladosporiumin $\mathrm{O}$

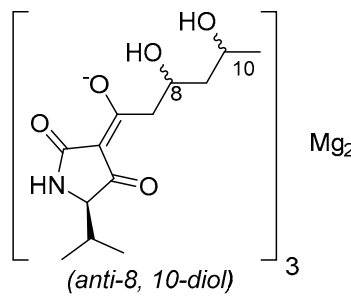

26 cladosporiumin L

Figure 2. Chemical structures of simple 3-acyl tetramic acids (1-26). 


\subsection{3-Oligoenoyltetramic Acids}

To date, only 13 members of 3-oligoenoyltetramic acids (3-OTAs) (Figure 3) possessing a 1-oxopentadienyl substituent at $\mathrm{C}-3$ in the tetramate ring have been discovered from marine microorganisms-three of them from fungi and ten of them from actinobacteria Streptomyces.<smiles>[R]C/C=C(/C=C(C)/C=C/C=C/C=C(/C)C(=O)C1CC(=O)NC1=O)C(=O)OC</smiles><smiles>C=CC(C)=C1NC(=O)C(C(O)=CC=CC)C1=O</smiles>

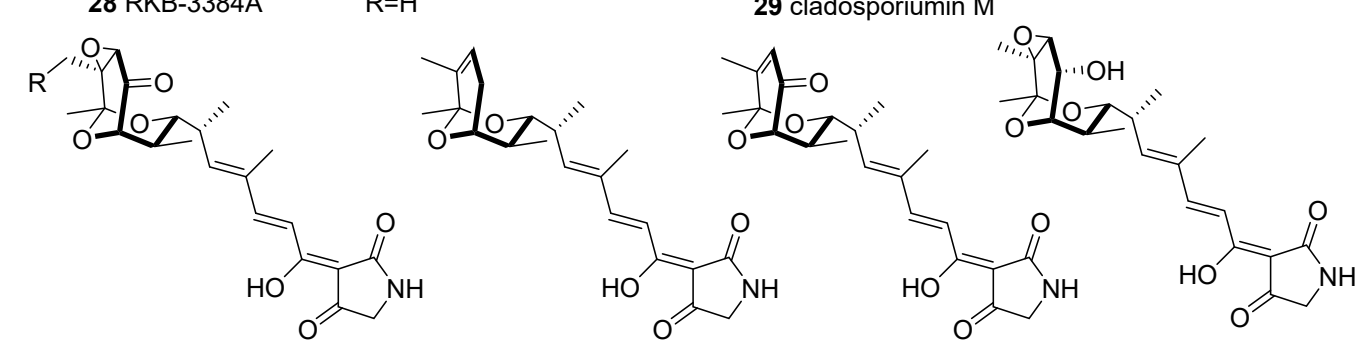

30 tirandamycin $\mathrm{A} \mathrm{R}=\mathrm{H}$ 31 tirandamycin $\mathrm{B} \mathrm{R}=\mathrm{OH}$ 32 tirandamycin C 33 tirandamycin D 35 tirandamycin $\mathrm{E}$

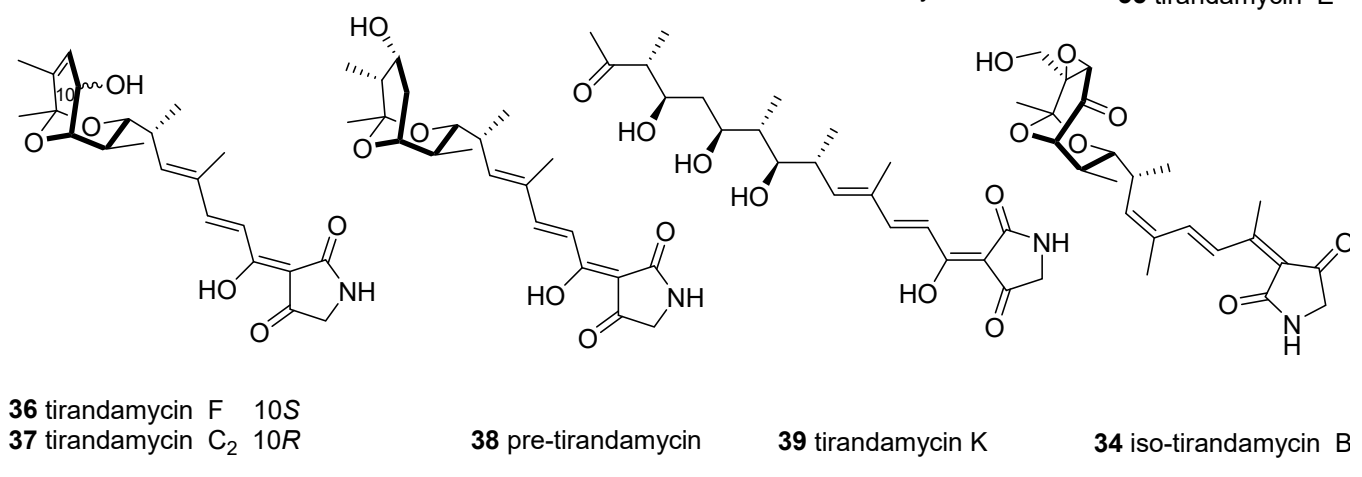

Figure 3. Chemical structures of 3-oligoenoyltetramic acids (27-39).

The fermentation broth of the mangrove soil-derived fungus Aspergillus sp. OUCMDZ-1914 yielded two 3-oligoenoyltetramic acids, RKB-3884A (27) and its analogue 18-OH-RKB-3884A (28). Molecule 27 showed potent inhibition of the $\mathrm{H} 1 \mathrm{~N} 1$ influenza virus $\left(\mathrm{IC}_{50}=116.2 \mu \mathrm{M}\right)$, equal to the positive control ribavirin $\left(\mathrm{IC}_{50}=138.1 \mu \mathrm{M}\right)$ [33]. Another 3-OTA, cladosporiumin $\mathrm{M}$ (29), was isolated from the deep-sea-derived fungus Cladosporium sphaerospermum EIODSF 008, and was devoid of cytotoxic and antibacterial activities [32].

Tirandamycins (TAMs) are a subgroup of Streptomyces-derived 3-dienoyltetramic acid antibiotics that exhibit broad biological activities, such as bacterial RNA polymerase inhibition [34], inhibition of mitochondria oxidative phosphorylation [35], and effects on the futalosine pathway [36]. By screening new MNPs with anti-vancomycin-resistant Enterococcus faecalis (VRE) activity, researchers have reported tirandamycins A-D (30-33), isolated from the marine environmental isolate Streptomyces sp. 307-9, among which 30 showed the highest activity (MIC $2.25 \mu \mathrm{M}$ ) [37]. The SARs of these tirandamycins suggest that the C-10 ketone and C-11/C-12 epoxide confer increased potency, but this effect can be attenuated by the hydroxy group at C-18 [37]. Compounds 30 and 31 are considered as the main antibacterial constituents of marine Streptomyces sp. [38,39]. Moreover, tirandamycin B (31) was reported to be a new lead scaffold for anti-filarial activity, as it can selectively inhibit Brugia malayi 
AsnRS (BmAsnRS) $\left(\mathrm{IC}_{50}=30 \mu \mathrm{M}\right)$ and efficiently kill adult $B$. malayi parasite $\left(\mathrm{IC}_{50}=1 \mu \mathrm{M}\right)$ in vitro without general cytotoxicity to human hepatic cells [40,41]. An assessment of the anti- $V R E$ activity and BmAsnRS inhibition of TAMs revealed that these bioactivities were strongly dependent on the structure of the dioxabicyclo[3.3.1]nonane ring unit [37]. Isotirandamycin B (34), together with tirandamycins A and B, were identified from the marine-derived Streptomyces sp. SCSIO 41399 and displayed potent bacteriostatic activity against Streptococcus agalactiae (MIC $=5.7-11.5 \mu \mathrm{M}$ ) [42]. Using a biosynthetic approach, tirandamycins C (32), E (35), F (36), C2 (37), and pre-tirandamycin (38), were isolated from the genetically engineered strains of Streptomyces sp. 307-9 and Streptomyces sp. SCSIO1666 [43-45]. Similarly, the first linear 7,13;9,13-diseco-tirandamycin derivative tirandamycin K (39) was obtained from a mutant strain $(\Delta \mathrm{tamI})$ of marine Streptomyces sp. 307-9 [46]. Furthermore, studies on the biological activity of $\mathbf{3 9}$ and other TAMs confirmed that the bicyclic ketal ring of TAMs is the key pharmacophore [46].

\subsection{3-Decalinoyltetramic Acids}

The class of 3-decalinoyltetramic acids (3-DTAs) derived from microorganisms features a tetramate unit at position $\mathrm{N}-1$ connected to $\mathrm{H}$ or $\mathrm{CH}_{3}$, and $\mathrm{C}-3$ connected to "decalin" with multiple chiral centers. Up to 35 members of 3-DTAs (Figure 4) have been uncovered from marine fungi and actinobacteria.<smiles>C/C=C/[C@H]1C=C[C@H]2C[C@@H](C)CC[C@H]2[C@]1(C)/C(O)=C1/C(=O)C(CO)N(C)C1=O</smiles>

40 equisetin $5 S$ 41 epi-equisetin $5 R$

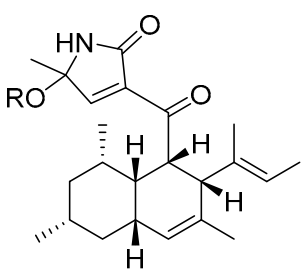

42 ascosalipyrrolidinone $A \quad \mathrm{R}=\mathrm{CH}_{2} \mathrm{CH}_{2} \mathrm{CH}_{2} \mathrm{CH}_{3}$ 43 ascosalipyrrolidinone $\mathrm{B} \mathrm{R}=\mathrm{CH}_{3}$<smiles>[R]C(C)C(O)(CC1C(=O)/C(=C(O)/C=C/[C@@H]2[C@H]3CCCC[C@H]3C=C[C@@H]2C)C(=O)N1C)C(=O)O</smiles>

44 zopfiellamide $\mathrm{A} \quad \mathrm{R}=\mathrm{CH}_{3}$ 45 zopfiellamide $B \quad \mathrm{R}=\mathrm{CH}_{2} \mathrm{CH}_{3}$

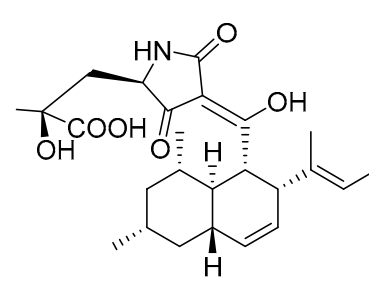

$46 \operatorname{sch} 210972$<smiles>C/C=C/C=C/C1C(C)=C[C@H]2C[C@@H](C)CC[C@H]2[C@H]1/C(O)=C1/C(=O)NC(CO)C1=O</smiles>

47 beauversetin<smiles>CCC(C)C[C@H]1C(=O)/C(=C(/O)[C@H]2C(C[C@@]3(C)O[C@@H]3C)C(C)=C[C@H]3CCC[C@H](C)[C@H]32)C(=O)N1C</smiles>

48 trichobotrysin A<smiles>CC1=C[C@H]2CCC[C@@H](C)[C@H]2[C@H](/C(O)=C2\C(=O)N(C)[C@H](CC(C)C)C2C[C@@]2(C)O[C@@H]2C)C1=O</smiles>

49 trichobotrysin B

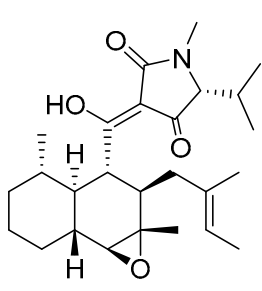

50 trichobotrysin C<smiles>C/C=C(\C)C[C@H]1C(C)=C[C@H]2CCC[C@@H](C)[C@H]2[C@H]1/C(O)=C1\C(=O)[C@@H](CC(C)C)N(C)C1=O</smiles>

51 trichobotrysin D

52 trichobotrysin E<smiles>CC1=C[C@H]2CC(C)CC[C@]2(C)[C@H](/C(O)=C2/C(=O)NC(Cc3ccccc3)C2=O)[C@H]1/C(C)=C/C(=O)O</smiles>

53 lindgomycin

Figure 4. Cont. 


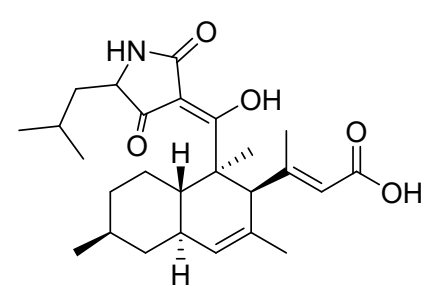

54 ascosetin<smiles>CC1NC(=O)/C(=C(/O)[C@H]2C3CC[C@@H](O)CC3C=C[C@@H]2O)C1=O</smiles>

55 iqalisetin $\mathrm{A}$<smiles>CC1NC(=O)/C(=C(/O)[C@H]2C3CC(O)C(=O)C[C@H]3C=C[C@@H]2O)C1=O</smiles>

56 iqalisetin $B$

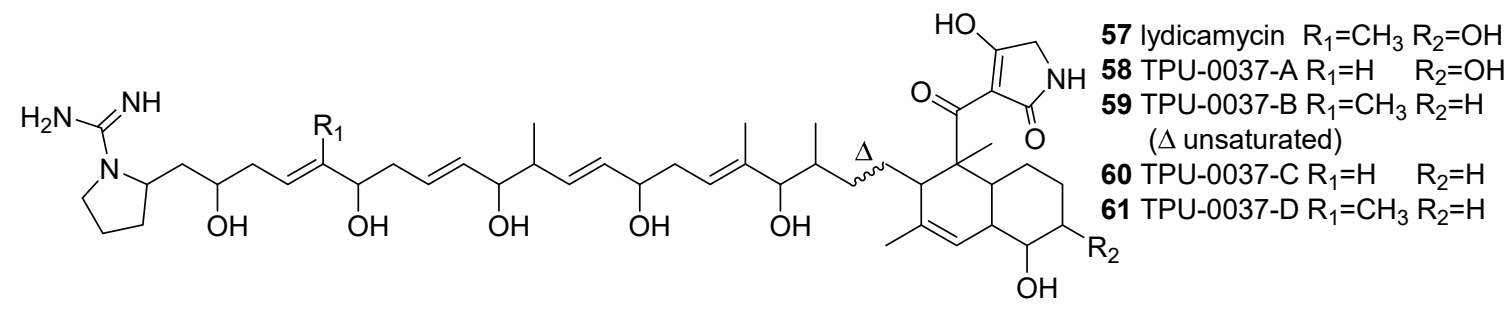<smiles>CC[C@H]1CC(=O)[C@]2(C)C(O)C(C)=CC[C@H]2[C@]1(C)C(=O)C1=C(O)NCC1=O</smiles>

62 streptosetin A

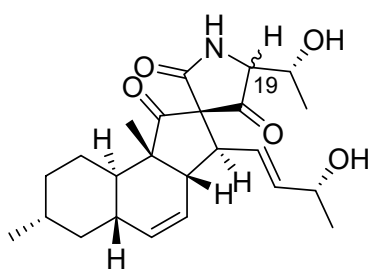

66 altercrasin A $19 S$ 67 altercrasin B $19 R$

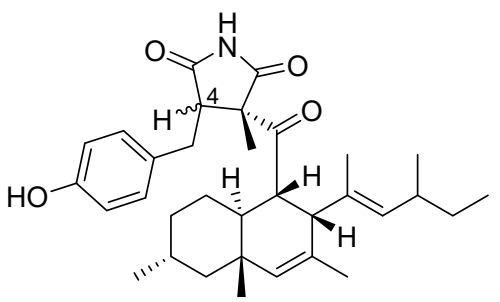

63 cladosporitin A $4 R$ 64 cladosporitin B $4 S$

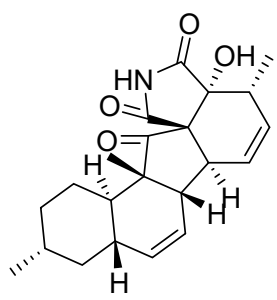

68 altercrasin C

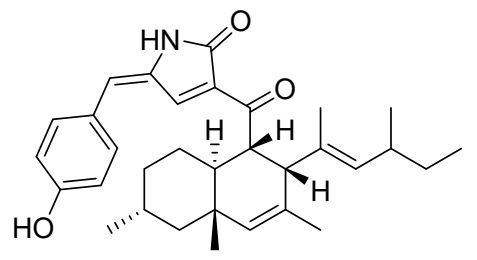

65 talaroconvolutin A

69 altercrasin D $20 S$ 70 altercrasin $\mathrm{E} 20 R$

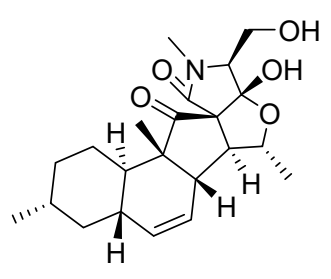

71 fusarisetin $A$

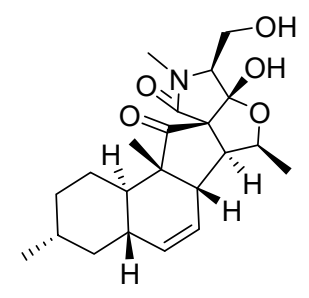

72 fusarisetin B

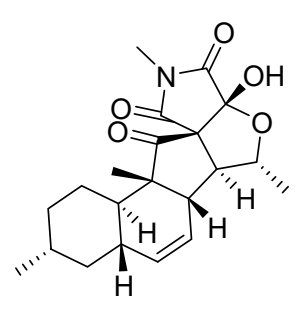

73 fusarisetin C

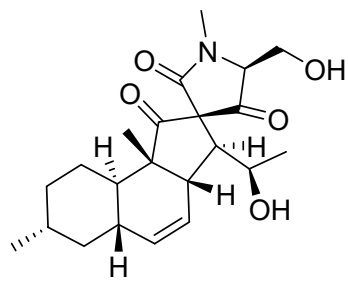

$\mathbf{7 4}$ fusarisetin $D$

Figure 4. Chemical structures of 3-decalinoyltetramic acids (40-74).

The typical 3-DTA, equisetin (40) and epi-equisetin (41), were isolated initially from terrestrial Fusarium genera and displayed various biological activities, such as antimicrobial, anti-HIV, cytotoxicity, and phytotoxicity activities [1]. These two molecules were also later isolated from the marine-derived fungi Fusarium sp. 152 and F. equiseti D39 [47] and displayed potent anti-phytopathogenic bacterial and fungal activities [47]. Notably, equisetin (40) exhibited potent anti-methicillin-resistant Staphylococcus aureus (MRSA) activity (MIC $=1 \mu \mathrm{g} / \mathrm{mL}$, equivalent to vancomycin) and antimicrobial activities against 
Pseudomonas syringae and Rhizoctonia cerealis (MIC $=1.1$ and $8.4 \mu \mathrm{M}$, respectively) superior to the positive control and could be exploited as a potential antimicrobial drug candidate [48].

Ascosalipyrrolidinones A and B (42 and 43), possessing a rare cis-decalin scaffold, were isolated from an obligate marine fungus, Ascochyta salicorniae, collected from the green alga Ulva sp. [49]. Compound 42 displayed moderate antiplasmodial activity towards the Plasmodium falciparum strains K-1 and NF-54, antimicrobial activity, the inhibition of tyrosine kinase $\mathrm{p} 56^{\mathrm{lck}}$, and significant antiprotozoal activity against Trypanosoma cruzi and T. brucei, as well as cytotoxic activity against rat skeletal muscle myoblast cells and mouse peritoneal macrophages [49]. Another two 3-decalinoyltetramic acids, zopfiellamides A and B (44 and 45), were isolated from the culture broth of a marine soil-derived ascomycete Zopfiella latipes CBS 611.97 [50]. These metabolites (44 and 45) displayed antifungal activity against the yeasts Nematospora coryli and Saccharomyces cerevisiae at MIC $=2 \mu \mathrm{g} / \mathrm{mL}$ and were devoid of cytotoxicity against four HTCLs [50]. One of the compounds, 44, displayed moderate antibacterial activity against ten bacterial strains (MIC $=2-10 \mu \mathrm{g} / \mathrm{mL}$ ), which was about five times more active than that of 45, showing that the extra methyl group of zopfiellamides influences antibacterial properties [50]. The seaweed-derived fungus Microdiplodia sp. yielded sch210972 (46), which could inhibit human leucocyte elastase (HLE), with an $\mathrm{IC}_{50}$ value of $1.04 \mu \mathrm{g} / \mathrm{mL}$, and revealed moderate inhibition of the growth of Bacillus megaterium [51]; 46 can also be considered a chemokine receptor CCR-5 inhibitor, with an $\mathrm{IC}_{50}$ of $79 \mathrm{nM}$ [52]. Another marine-sponge-derived fungus, Beauveria bassiana, afforded a 3-DTA named beauversetin (47), which exhibited moderate cytotoxicity against a panel of six cell lines, with a mean $\mathrm{IC}_{50}=3.09 \mu \mathrm{g} / \mathrm{mL}$ for a monolayer assay, but it was devoid of antimicrobial activity [51]. A class of new 3-DTAs, trichobotrysins A-E (48-52), were discovered from the culture of a deep-sea-derived fungus Trichobotrys effuse DFFSCS021 [53]. Among them, compounds 48, 49, and 51 showed significant selective inhibition of the proliferation of carcinoma KG-1 $\alpha$ HTCL $\left(\mathrm{IC}_{50}=5.44,8.97\right.$, and $\left.6.16 \mu \mathrm{M}\right)$ and prominent antiviral activity towards HSV-1 $\left(\mathrm{IC}_{50}=3.08,9.37\right.$, and $\left.3.12 \mu \mathrm{M}\right)$ [53]. Lindgomycin (53), with its unique 5-benzyl-3-decalin-tetramate skeleton, and ascosetin (54) were obtained from two marine-derived Lindgomycetaceae strains and showed moderate antibiotic activities against six Gram-positive bacteria, including $M R S A$ and two pathogenic fungi with $\mathrm{IC}_{50}=2.2-17.8 \mu \mathrm{M}[54,55]$. Chemical investigation of the crude extracts from the marine sediment-derived fungus Tolypocladium sp. yielded two new 3-DTAs, iqalisetins A and B (55 and 56), which lacked the tested activities [56].

The fermentation broth of a marine actinomycete Streptomyces platensis (TP-A0598) provided lydicamycin (57) and four new analogues, TPU-0037 A-D (58-61) possessing octahydrodecalin skeletons [57]. The lydicamycins (57-61) showed significant bioactivity against five Gram-positive bacteria (including MRSA), with MIC values in the range of $0.39-12.5 \mu \mathrm{g} / \mathrm{mL}[57,58]$. Among them, molecule 60 displayed the most potent bioactivity, while 59 showed the lowest level of bioactivity, indicating that the C14-C15 olefin may diminish antibacterial activity [57]. During screening, human class III histone deacetylase (SIRT) inhibitors from the marine actinomycete streptosetin A (62) were discovered from the broth of Streptomyces sp. CP13-10 and displayed weak inhibitory activity towards yeast Sir2p, human SIRT1, and SIRT2, with IC 50 values of $2.5,3.7$, and $4.5 \mu \mathrm{M}$, respectively [59].

Recently, a chemical analysis of the culture broth of the mangrove-derived fungus Cladosporium sp. HNWSW-1 resulted in the discovery of two new succinimide-containing derivatives, cladosporitins $A$ and B (63 and 64), together with talaroconvolutin A (65) [60]. Compound 64 showed moderate cytotoxicity against three HTCLs, with $\mathrm{IC}_{50}$ values from 25.6 to $41.7 \mu \mathrm{M}$, whereas 65 exhibited moderate cytotoxicity towards two HTCLs $\left(\mathrm{IC}_{50}=14.9\right.$ and $\left.26.7 \mu \mathrm{M}\right)$, as well as significant inhibitory activity against $\alpha$-glycosidase $\left(\mathrm{IC}_{50}=78.2 \mu \mathrm{M}\right)[60]$.

Altercrasins and fusarisetins are 3-DTA derivatives with a unique structure, some of which exhibited unusual bioactivities. Altercrasin A (66), a novel decalin derivative with spirotetramic acid, was reported from a strain of Alternaria sp. OUPS-117D-1, originally associated with the sea urchin Anthocidaris crassispina, and displayed moderate inhibitory activity against three HTCLs [61,62]. Other studied metabolites of this fungal strain, altercrasins B-E (67-70), were obtained in 2019 [62]. Two pairs of stereoisomers 66/67 and $69 / 70$ were characterized by an unusual 6/6/5/5 tetracyclic ring system, while 68 was identified as 
a 6/6/5/6/5 pentacyclic ring [62]. These isolated compounds 66-70 had moderate or potent cytotoxicity against three leukemia HTCLs $\left(\mathrm{IC}_{50}=6.1-61 \mu \mathrm{M}\right)$, two of which, 69 and 70, bear a diene moiety (C-6 to C-8) and exhibited significant cytotoxicity against $\mathrm{HL}-60$, with $\mathrm{IC}_{50}$ values of 6.1 and $6.2 \mu \mathrm{M}$, respectively, similar to that of 5-fluorouracil $\left(\mathrm{IC}_{50}=4.5 \mu \mathrm{M}\right)$ [62]. Using the bioassay-LCMS- ${ }^{1} \mathrm{H}$ NMR-screening technology, four 3-DTA derivatives, namely fusarisetins A-D (71-74), were discovered from a marine-derived fungus Fusarium equiseti D39 and displayed phytotoxicity [47]. Interesting, fusarisetins A-C possess a rare carbon skeleton with a 6/6/5/5/5 pentacyclic ring system, while fusarisetin $\mathrm{D}$ is the first-discovered fusarisetin with an unusual 6/6/5/5 tetracyclic ring framework. It was reported that fusarisetin A also has acinar morphogenesis inhibitory activity [63]. Interestingly, fusarisetins A and B are considered as a novel class of potent cancer migration inhibitors with a new mechanism of action $[64,65]$. The SAR of the fusarisetins revealed that the decalin motif, serine amino acid, and C-18 oxygen are critical to the biological profile of fusarisetins [64].

\subsection{3-Spirotetramic Acids}

Thirty-four members of 3-spirotetramic acids (3-STAs) (Figure 5) were isolated from marine fungi. The 3-STAs principally consisted of 3-spirofuranone-lactam TAs (FD-838, 11 pseurotins, 14 cephalimysins, and 2 azaspirofurans) and 3-STAs with hexatomic rings (three spirostaphylotrichins, two triticones, and cladosporicin A). The 3-spirofuranone-lactam TAs, possessing a 1-oxa-7-azaspiro[4.4]nonane core with a phenyl ketone and C-6-aliphatic appendages, rarely occur in natural sources.<smiles>CC/C=C\[C@H](O)[C@@H](O)C1=C(C)C(=O)[C@]2(O1)C(=O)N[C@](OC)(C(=O)c1ccccc1)[C@H]2O</smiles>

75 pseurotin A<smiles>CC/C=C\[C@H](O)[C@H](O)C1=C(C)C(=O)[C@]2(O1)C(=O)N[C@](OC)(C(=O)c1ccccc1)[C@H]2O</smiles>

78 pseurotin $A_{1}$<smiles>CC/C(O)=C/C=C(\O)C1=C(C)C(=O)[C@]2(O1)C(=O)N[C@](OC)(C(=O)c1ccccc1)[C@H]2O</smiles>

81 pseurotin $\mathrm{G}$<smiles>CCc1ccc(C2=C(C)C(=O)[C@]3(OC2=O)C(=O)N[C@@](OC)(C(=O)c2ccccc2)[C@H]3O)o1</smiles>

84 azaspirofuran $A$<smiles>CC/C=C\[C@H](OC)[C@@H](O)C1=C(C)C(=O)[C@@]2(OC1=O)C(=O)N[C@](OC)(C(=O)c1ccccc1)[C@H]2O</smiles>

76 11-O-methylpseurotin A<smiles>CC/C=C\[C@H](O)C(O)C1=C(C)C(=O)[C@@]2(O1)C(=O)N[C@](OC)(C(=O)c1ccccc1)[C@H]2O</smiles>

79 pseurotin $A_{2}$<smiles>CO[C@]1(C(=O)c2ccccc2)NC(=O)[C@]2(OC([C@H](O)[C@@H](O)/C=C\C(C)C)=C(C)C2=O)[C@H]1O</smiles>

82 pseurotin D<smiles>CCc1ccc(C2=C(C)C(=O)[C@@]3(O2)C(=O)N[C@](O)(C(=O)c2ccccc2)[C@H]3O)o1</smiles>

85 azaspirofuran B<smiles>C/C=C\[C@H](O)[C@@H](O)C1=C(C)C(=O)[C@@]2(OC1=O)C(=O)N[C@](OC)(C(=O)c1ccccc1)[C@H]2O</smiles>

77 14-norpseurotin A<smiles>CC/C=C\[C@H](O)[C@H](O)C1=C(C)C(=O)[C@@]2(OC1=O)C(=O)N[C@](OC)(C(=O)c1ccccc1)[C@H]2O</smiles>

80 pseurotin $A_{3}$<smiles>CC/C=C\[C@H](O)[C@@H](O)C1=C(C)C(=O)[C@@]2(OC1=O)C(=O)N[C@](O)(C(=O)c1ccccc1)[C@H]2O</smiles>

83 pseurotin $F_{2}$<smiles>CC/C=C\[C@H](O)[C@@H](O)C1=C(C)C(=O)[C@@]2(O1)C(=O)N[C@](O)(C(=O)c1ccccc1)[C@H]2O</smiles>

86 pseurotin $F_{1}$

Figure 5. Cont. 
<smiles>CC/C=C\[C@H](Nc1ccccc1C(N)=O)[C@H](O)C1=C(C)C(=O)[C@@]2(OC1=O)C(=O)N[C@](OC)(C(=O)c1ccccc1)[C@@H]2O</smiles><smiles>CC/C=C/CCC1=C(C)C(=O)[C@@]2(O1)C(=O)N[C@](OC)(C(=O)c1ccccc1)[C@H]2O</smiles>

89 cephalimysin A

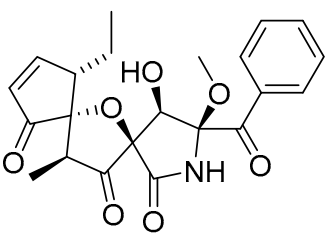

93 cephalimysin E<smiles>CC[C@H]1C=CC(=O)C12O[C@]1(C(=O)N[C@@](OC)(C(=O)c3ccccc3)C(O)[C@H]1OC)C(=O)C2C</smiles>

97 cephalimysin I<smiles>CCc1ccc(C2=C(C)C(=O)[C@]3(O2)C(=O)N[C@](OC)(C(=O)c2ccccc2)[C@H]3O)o1</smiles>

90 cephalimysin B<smiles>CC[C@H]1C=CC(=O)[C@]12O[C@]1(C(=O)C(=O)[C@]3(O)C(=O)NC3(OC)C(=O)c3ccccc3)C(C)C(=O)[C@@H]21</smiles>

94 cephalimysin F

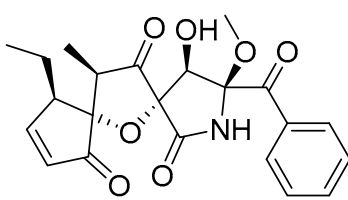

98 cephalimysin $\mathrm{J}$

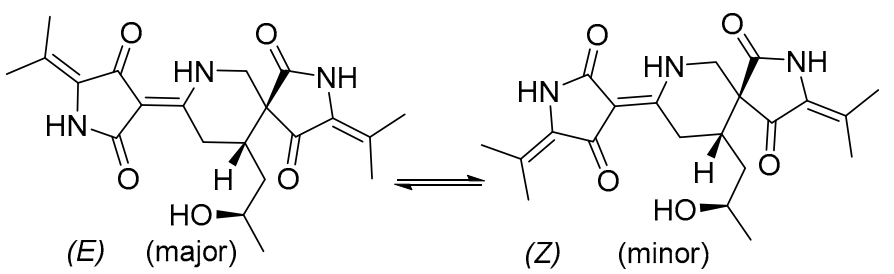

88 cladosporicin $\mathrm{A}$<smiles>COC(=O)c1ccccc1</smiles>

91 cephalimysin $\mathrm{C}$<smiles>CC[C@H]1C=CC(=O)C12O[C@]1(C(=O)N[C@@](OC)(C(=O)c3ccccc3)[C@H]1O)C(=O)C2C</smiles>

95 cephalimysin G<smiles>COC1C(OC)(C(=O)c2ccccc2)NC(=O)[C@@]12O[C@]1(C(=O)C=C[C@H]1C)[C@@H](C)C2=O</smiles>

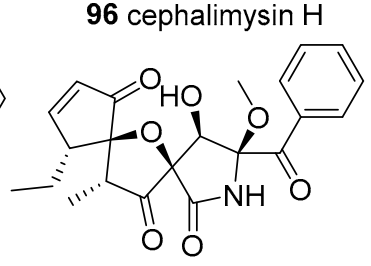

99 cephalimysin $\mathrm{K}$<smiles>CC[C@H]1C=CC(=O)C12OC1(C(=O)NC(C(=O)c3ccccc3)(C(=O)c3ccccc3)C1O)C(=O)C2C</smiles><smiles>CCc1ccc(C2=C(C)C(=O)[C@@]3(O2)C(=O)N[C@@](OC)(C(=O)c2ccccc2)[C@H]3O)o1</smiles>

92 cephalimysin D

100 cephalimysin $\mathrm{L}$<smiles>CCCCCC(O)C1=C(C)C(=O)[C@@]2(O1)C(=O)N[C@@](OC)(C(=O)c1ccccc1)[C@H]2O</smiles><smiles>CCc1ccc(C2=C(CO)C(=O)C3(NC(=O)[C@](OC)(C(=O)c4ccccc4)[C@@H]3O)OC2=O)o1</smiles><smiles>CCc1ccc(C2=C(C)C(=O)[C@]3(O2)C(=O)N[C@](OC)(C(=O)c2ccccc2)[C@H]3O)o1</smiles>

101 cephalimysin $M$<smiles>CC/C=C1/C=CC(=O)[C@H](O)[C@@]1(CC)C(=O)N(OC)C(C)(C)OC</smiles>

102 cephalimysin $N$<smiles>CC/C=C1/C=CC(=O)C(O)[C@@]12OC(=O)N(OC)C2=O</smiles><smiles>[R]C1C(=O)C=C/C(=C/CC)[C@@]12C[C@](C)(O)[C@@](C)(O)N(OC)C2=O</smiles>

106 spirostaphylotrichin $\mathrm{R} R=-\mathrm{OH}$ 107 triticone $\mathrm{E} \quad \mathrm{R}=\ldots, \mathrm{OH}$
103 FD-838<smiles>C=C1C[C@]2(C(=O)N1OC)/C(=C\CC)C=CC(=O)[C@H]2O</smiles>

108 triticone $D$

104 spirostaphylotrichin $X 105$ spirostaphylotrichin A

Figure 5. Chemical structures of 3-spirotetramic acids (75-108).

Pseurotin A (75) was initially isolated from the broth of a fungal strain Pseudeurotium ovalis Stolk in 1976 [66]. In recent years, pseurotin A and ten pseurotin-related analogues have been discovered from marine fungi Aspergillus fumigatus [67], Aspergillus sydowii [68], Aspergillus sp. [69], and Phoma sp. [70]. It is worth mentioning that the marine bacteria Bacillus sp. FS8D can also yield 75 [71]. Interestingly, 
pseurotin A showed extensive bioactivities, including monoamine oxidase inhibitory activity [72], apomorphine-antagonistic activity [73], chitin synthase inhibitory activity [74], the induction of cell differentiation [75], nematicidal activity [76], immunosuppressive activity [77], antiparasitic and cytotoxicity [78], antibacterial activity [79,80], antioxidant activity [81], and osteoporosis inhibition through suppressing reactive oxygen species levels [82].

Using a yeast halo assay as a bioassay-guided fractionation of marine-derived A. fumigatus resulted in the identification of 11-O-methyl pseurotin A (76), which selectively inhibited the Hof1 deletion strain [67]. The fermentation broth of the marine driftwood-derived fungus A. sydowii PFW1-13 yielded pseurotin A (75) and 14-norpseurotin A (77) [68]. Compound 77 displayed significant antimicrobial activities against Escherichia coli, Bacillus subtilis, and Micrococcus lysodeikticus, with MICs of 3.74, 14.97, and $7.49 \mu \mathrm{M}$ [68], moderate antiparasitic activity against Leishmania donovan and Plasmodium falciparum, and cytotoxicity against MCF-7 and U937; 77 also significantly induced the neurite outgrowth of rat pheochromocytoma cells (PC12) at $10.0 \mu \mathrm{M}[78,83]$. Using the bioassay-guided method to investigate another fungus, A. fumigatus WFZ-25, which is associated with marine holothurian, this group obtained two new pseurotins, pseurotin A1 and A2 (78 and 79), as well as 75 [84], which were also re-isolated from the marine fish-derived A. fumigatus OUPS-T106B-5 and resulted in a structural revision of pseurotin A2, as shown in 79 [85]. When screening for compounds with cytotoxicity and anti-inflammatory activities, two new 3-STAs, pseurotins A3 and G (80 and 81), as well as their analogues pseurotins D (82), F2 (83), A(75), A1 (78), and A2 (79), were identified from the marine fungus Phoma sp. NTOU4195, separated from the edible red alga Pterocladiella capillacea [70]. According to the bioassays, compound $\mathbf{8 1}$ revealed moderate antiangiogenic activity by inhibiting tube formation in human endothelial progenitor cells, with an $\mathrm{IC}_{50}$ value of $16.7 \mu \mathrm{M}$; compounds 78-81 displayed moderate anti-inflammatory inhibitory activity against NO production using LPS-induced RAW 264.7cCells $\left(\mathrm{IC}_{50}=34.5-62.5 \mu \mathrm{M}\right.$, aminoguanidine $\left.24.7 \mu \mathrm{M}\right)$ [70]. In addition, pseurotins $\mathrm{D}(82)$ displayed an apomorphine-antagonistic effect [73], as well as antiparasitic and cytotoxicity affects [78], and pseurotins F2 (83) demonstrated apomorphine-antagonistic activity [86] and chitin synthase inhibition [74].

Screening for antitumor agents, the marine-sediment-derived fungus Aspergillus sydowii D2-6 was found to produce two new 3-STAs, named azaspirofurans A and B (84 and 85), which feature a new furan ring instead of the long linear side chain of pseurotin [87]. In vitro cytotoxicity experiments have demonstrated that 85 has moderate cytotoxicity toward A549 HTCL $\left(\mathrm{IC}_{50}=10 \mu \mathrm{M}\right)$ [87]. Six years later, azaspirofuran B (85) and pseurotin F1 (86) were re-obtained from a marine jellyfish-derived fungus A. fumigates [88]. In recent years, seven known 3-STAs, 75, 76, 79, 83-86, were isolated from the marine Aspergillus fumigatus MR2012, associated with Red Sea sediment, using zebrafish embryos and larvae in an attempt to discover promising compounds from marine microorganisms that may have in vivo antiseizure activity [89]. Based on a series of experiments (including the larval zebrafish pentylenetetrazole seizure experiment, electrophysiological analysis, and ADMET assessment) among them, $\mathbf{7 9}$ and $\mathbf{8 4}$ were demonstrated to be lead antiseizure compounds and possible new antiseizure therapeutics [89]. A new pseurotin derivative, pseurotin $G^{\prime}$ (87), together with 11-O-methyl pseurotin A (76), was discovered from the co-culture of the fungus A. fumigatus MR2012 and the bacterium Streptomyces leeuwenhoekii C34 [90].

The E/Z mixture, cladosporicin A (88), containing a rare 2,7-diazaspiro[4.5]decane-1,4-dione skeleton conjugated with a tetramate moiety, was identified from Cladosporium sphaerospermum SW67 in association with the marine fungus Hydractinia, and displayed weak cytotoxicity against four HTCLs [91].

Fifteen cephalimysins and their analogue FD-838, containing a spiroheterocyclic $\gamma$-lactam motif and six chiral centers, were found in the marine Aspergillus fumigatus. The fermentation broth of A. fumigatus OUPS-T106B-5 provided a class of 3-STAs consisting of cephalimysins A-L (89-100) and FD-838 (103) [92-95]. Among them, compounds 90-92 are diastereomers of 103 [93], which was first reported in a patent as being able to induce differentiation of leukemic cells, as well as to have 
antibacterial and antifungal activities [81,96]. Cytotoxicity experiments revealed that cephalimysins 89-100 (except for 90) and 103, have moderate cytotoxic activity against several HTCLs [92,93,95], particularly 89, which is cytotoxic against the murine P388 and human HL-60 cell lines $\left(\mathrm{IC}_{50}=15.0\right.$ and $9.5 \mu \mathrm{M})$ [92], with 96 and 97 displaying cytotoxicity against the L1210 leukemia cell line $\left(\mathrm{IC}_{50}=12.8\right.$ and $14.3 \mu \mathrm{M})$ [95] and 96 and 95 exhibiting potent cytotoxicity towards the KB epidermoid carcinoma cell line $\left(\mathrm{IC}_{50}=7,11.1 \mu \mathrm{M}\right.$, equal to that of 5-fluorouracil $\left.\mathrm{IC}_{50}=8.5 \mu \mathrm{M}\right)$ [95]. Recently, cephalimysins $\mathrm{M}$ and $\mathrm{N}$ (101 and 102), together with 89 and 103, were identified as co-metabolites of the marine fungus A. fumigatus CUGBMF17018, while neither of them displayed antimicrobial activities [97].

A subgroup of the fungal 3-STA derivatives with a 6-membered carbocyclic motif, spirostaphylotrichin $X(\mathbf{1 0 4})$, and three related analogues, spirostaphylotrichins A and R as well as triticone E $(\mathbf{1 0 5}, \mathbf{1 0 6}$, and 107), were identified as metabolites of the marine alga-derived fungus Cochliobolus lunatus SCSIO41401 [98]. Compounds 105-107 showed weak or inactive anti-influenza virus (IAV) activity, while 104 displayed a noticeable inhibitory effect against multiple IAVs $\left(\mathrm{IC}_{50}=1.2-5.5 \mu \mathrm{M}\right)$ by inhibiting polymerase PB2 protein activity and interfering with the production of its progeny's viral RNA, thus representing a new type of potential lead compound for anti-IAV therapeutics [98]. Another analogue, triticone D (108), was isolated from the marine sediment-derived Westerdykella dispersa, and found to lack antibacterial and cytotoxic properties [99].

\subsection{Macrocyclic Tetramic Acids}

Macrocyclic tetramic acids (MTAs) have become compounds of great importance and interest, due to their complex structures and unique bioactivities in the field of natural products. More than 57 members of MTAs collectively constitute the major source of TAs from marine microorganisms. MTAs can be categorized into two subgroups: polycyclic tetramate macrolactams (PTMs) (Figure 6) from marine actinobacteria and bacteria, and pyrrocidine tetramate alkaloids (PTAs) (Figure 7) from marine fungi. Structurally, PTMs are composed of a polycyclic carbocycle (5, 5/5, 5/5/6 or 5/6/5 ring system) and a 16-membered macrolactam core fused with a TA moiety at C-3 [9,100]. PTAs are very rare in nature, featuring a polycyclic carbocycle (6/5/6, 6/5/6/6, or 6/5/6/5 ring system), a 12- or 13-membered macrocyclic-integrated 1,4-disubstituted phenyl and tetramate or its analogue moieties at C-3. MTAs originated from a conserved PKS/NRPS pathway, while tetramate polyene is considered to be the initial precursor of PTMs and tyrosine-nonaketide is the precursor of PTAs [8]. Moreover, the PKS module was used for the macrocyclic TA backbone assembly [101], and the NRPS domain incorporated L-ornithine [102] and L-tyrosine [8]. 


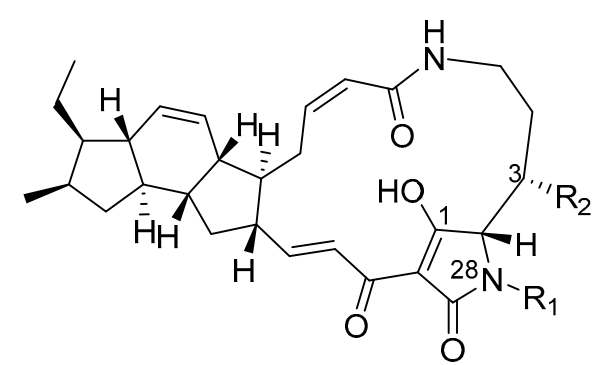

109 ikarugamycin

110 butremycin $\mathrm{R}_{1}=\mathrm{R}_{2}=\mathrm{H}$

111 28- $N$-methylikarugamycin $\mathrm{R}_{1}=\mathrm{CH}_{3} \mathrm{R}_{2}=\mathrm{H}$

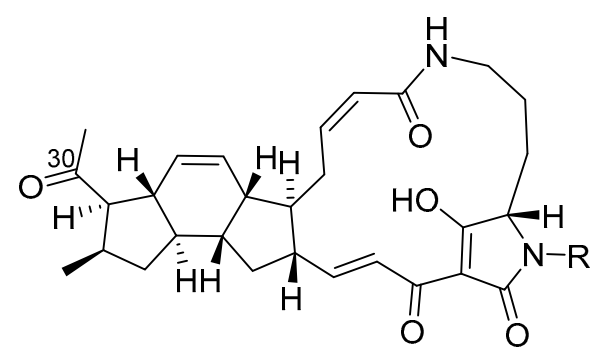

113 30-oxo-28- $N$-methylikarugamycin $\mathrm{R}=\mathrm{CH}_{3}$ 114 clifednamide $A \quad \mathrm{R}=\mathrm{H}$

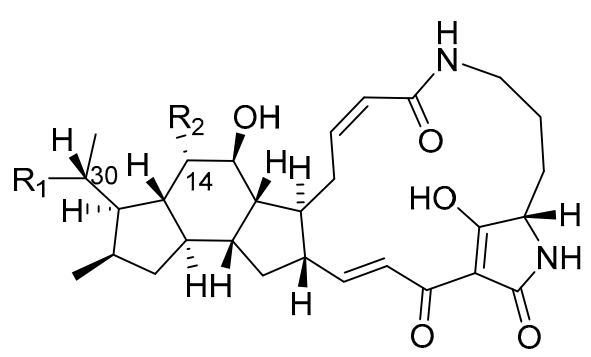

117 capsimycin C

118 capsimycin D

119 capsimycin $E$

120 capsimycin $F$

123 hydroxyikarugamycin $\mathrm{B} \mathrm{R}_{1}=\mathrm{OCH}_{3} \mathrm{R}_{2}=\mathrm{OH}$

124 hydroxyikarugamycin $\mathrm{C} \mathrm{R}_{1}=\mathrm{R}_{2}=\mathrm{OH}$

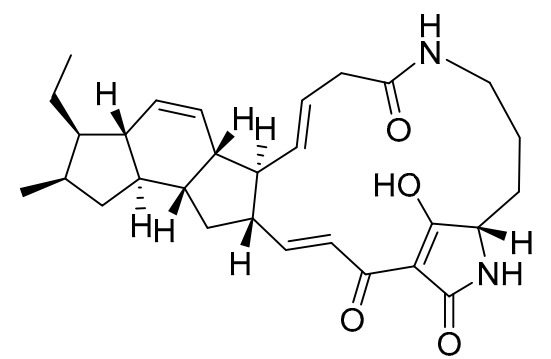

112 isolkarugamycin

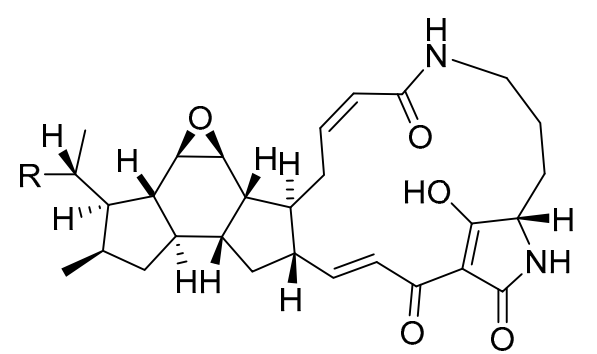

115 capsimycin $\quad \mathrm{R}=\mathrm{OCH}_{3}$

116 epoxyikarugamycin(capsimycin $\mathrm{B}$ ) $\mathrm{R}=\mathrm{H}$ 121 capsimycin $\mathrm{G} \quad \mathrm{R}=\mathrm{OH}$

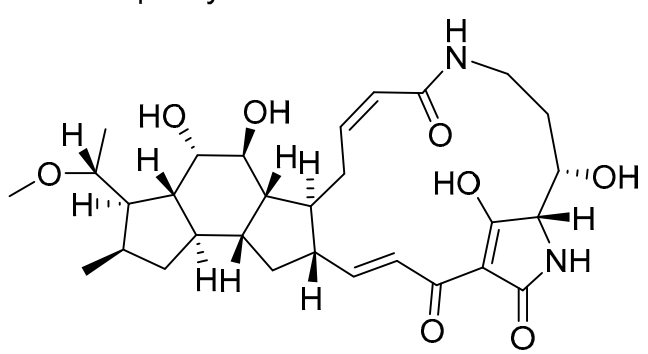

122 hydroxyikarugamycin $A$

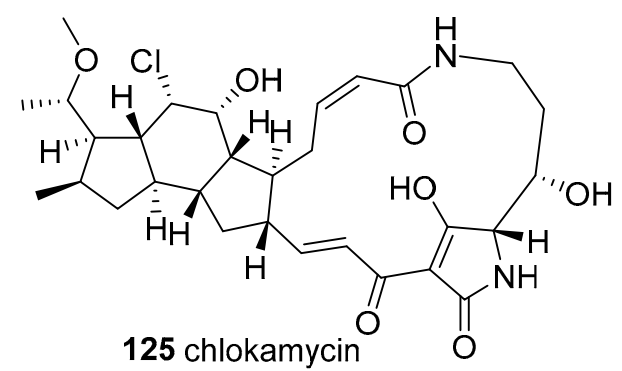

Figure 6. Cont. 


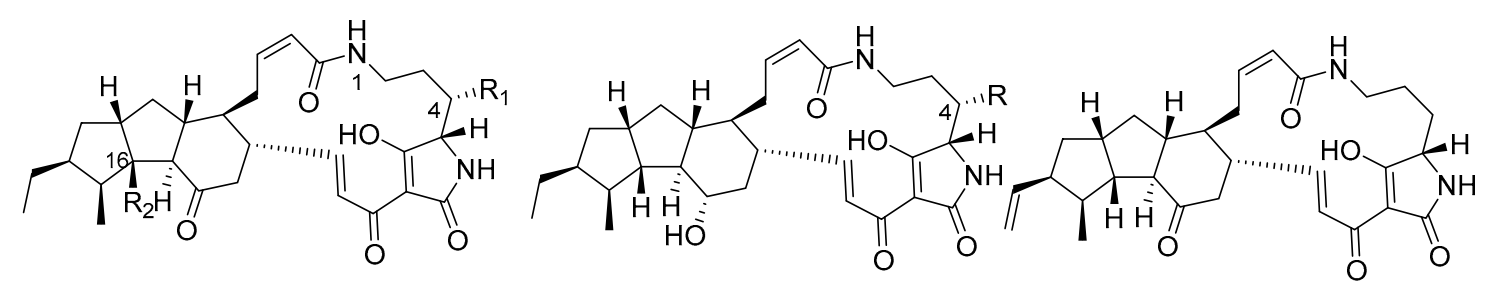

126 16-hydroxymaltophilin $\mathrm{R}_{1}=\mathrm{R}_{2}=\mathrm{OH} \quad 130$ dihydromaltophilin/HSAF $\mathrm{R}=\mathrm{OH}$ 127 maltophilin $\quad \mathrm{R}_{1}=\mathrm{OH} \mathrm{R}=\mathrm{H} \quad 1314$-deoxydihydromaltophilin $\mathrm{R}=\mathrm{H}$ 128 xanthobaccin $\mathrm{C} \quad \mathrm{R}_{1}=\mathrm{R}_{2}=\mathrm{H}$ $129 \mathrm{FI}-2$ $\mathrm{R}_{1}=\mathrm{H} \mathrm{R}_{2}=\mathrm{OH}$

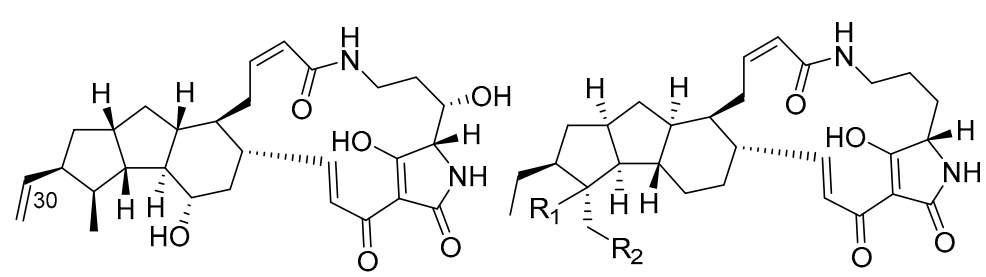

$133 \Delta^{30}$ - dihydromaltophilin/HSAF
134 pactamide $A R_{1}=R_{2}=H$ 139 pactamide $\mathrm{F} \mathrm{R}_{1}=\mathrm{OH} \mathrm{R} \mathrm{R}_{2}=\mathrm{Cl}$<smiles>CCC1C(O)=C(/C=C/C=C/C=C/C(=O)C2=C(O)[C@@H](CCCCNC(=O)/C=C/C=C/C=C/[C@H]3CC(CC)[C@@H]3C)NC2=O)C[C@@H]1C</smiles>

138 pactamide $E$

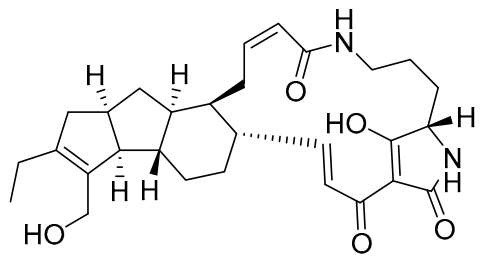

135 pactamide $B$

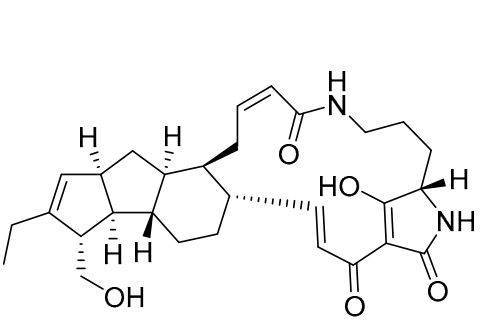

137 pactamide $D$

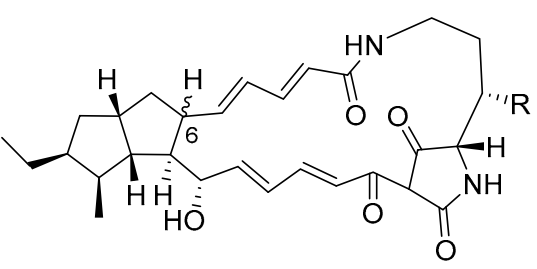

140 alteramide $A \quad \mathrm{R}=\mathrm{OH} \quad 6 \mathrm{~S}$ 141 alteramide $B \quad \mathrm{R}=\mathrm{H} \quad 6 S$ 1426 -epi-alteramide $\mathrm{A} \quad \mathrm{R}=\mathrm{OH} 6 R$ 1436 -epi-alteramide $\mathrm{B} \mathrm{R}=\mathrm{H} \quad 6 R$

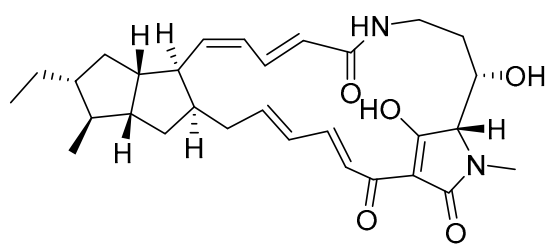

144 aburatubolactam $A$

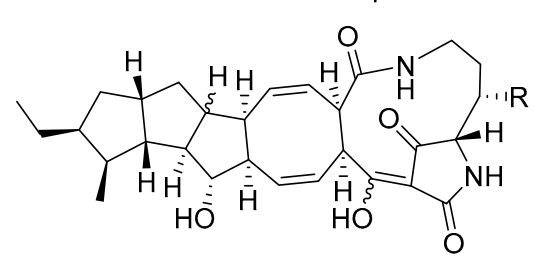

140a intramolecular cyclized alteramide $A \quad R=O H$ 141a intramolecular cyclized alteramide $B \quad R=H$

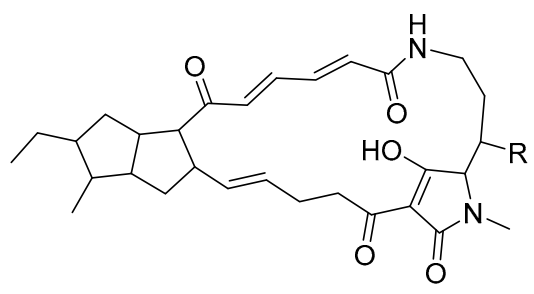

145 aburatubolactam $\mathrm{B} \mathrm{R}=\mathrm{OH}$ 146 aburatubolactam $\mathrm{C} \mathrm{R}=\mathrm{H}$

Figure 6. Chemical structures of macrocyclic tetramic acids-polycyclic tetramate macrolactams (109-146). 


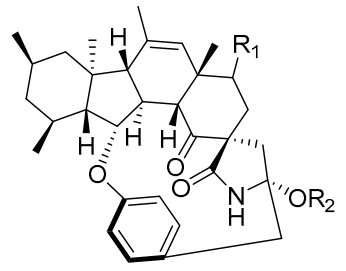

147 pyrrospirone $\mathrm{C} \quad \mathrm{R}_{1}=\alpha-\mathrm{OH} \quad \mathrm{R}_{2}=\mathrm{CH}_{3}$ 148 pyrrospirone $\mathrm{D} \quad \mathrm{R}_{1}=\beta-\mathrm{OH} \quad \mathrm{R}_{2}=\mathrm{CH}_{3}$ 149 pyrrospirone $E \quad R_{1}=\alpha-O H \quad R_{2}=H$ 150 pyrrospirone $F \quad R_{1}=\beta-O H \quad R_{2}=H$ 151 pyrrospirone $\mathrm{G} \mathrm{R}_{1}==\mathrm{O} \quad \mathrm{R}_{2}=\mathrm{H}$ 152 pyrrospirone $\mathrm{H} \mathrm{R} \mathrm{R}_{1}=\mathrm{H} \quad \mathrm{R}_{2}=\mathrm{H}$

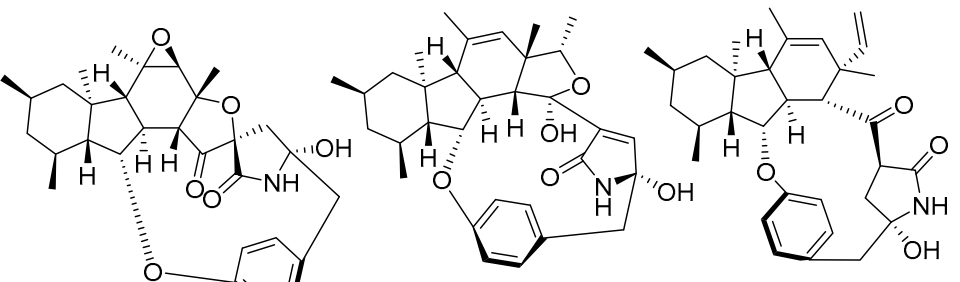

154 pyrrospirone $\mathrm{J}$

156 penicipyrroether $A$
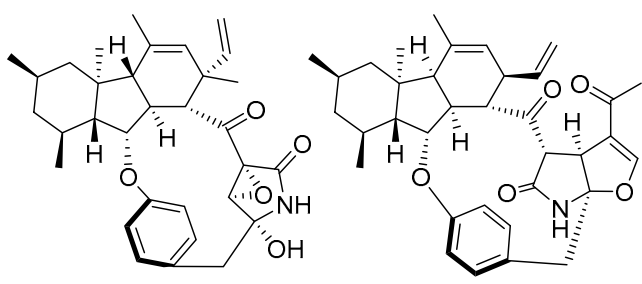

159 GKK1032C
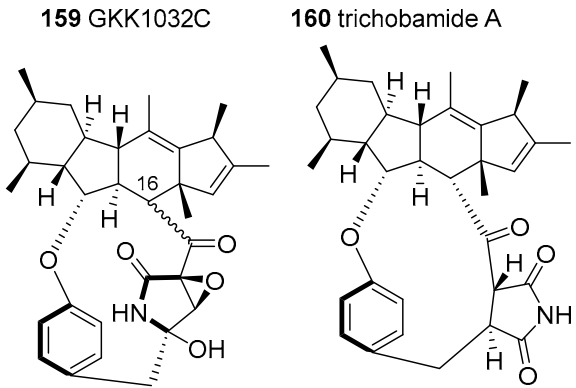

163 ascomylactam $C \quad 16 R$ 165 phomapyrrolidone C $16 S$

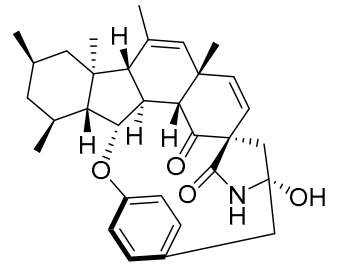

153 pyrrospirone I

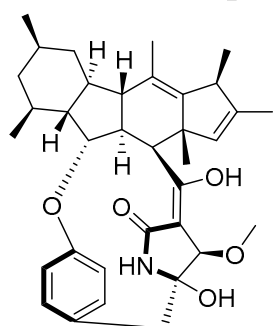

161 ascomylactam $A$

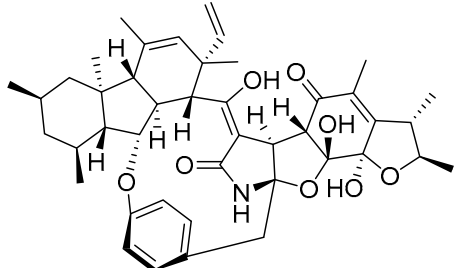

155 penicipyrrodiether $A$

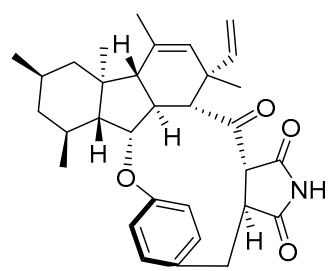

158 GKK1032B

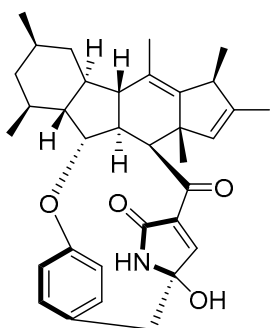

162 ascomylactam B 
In subsequent years, many ikarugamycin-related structures have been continually isolated from marine-derived actinomycetes. Butremycin (110), a 3-hydroxylated ikarugamycin, was reported in 2014 from the new Ghanaian mangrove river-sediment-derived actinomycete Micromonospora sp. K310, representing the first example of a microbial producer of ikarugamycins other than the Streptomyces species; however, it only displayed fragile antibacterial activity (MIC $\geq 50 \mu \mathrm{g} / \mathrm{mL}$ ) [114]. The following year, three new ikarugamycins, 28- $N$-methylikarugamycin (111), iso-ikarugamycin (112), and 30-oxo-28- $\mathrm{N}$-methylikarugamycin (113), as well as 109, were obtained from marine-sediment-derived Streptomyces zhaozhouensis CA-185989 [106]. Ikarugamycins 111, 112, and 109 showed significant anti-MRSA (MIC $1-4 \mu \mathrm{g} / \mathrm{mL}$ ) activity and antifungal properties against Candida albicans and Aspergillus fumigatus $(\mathrm{MIC}=2-8 \mu \mathrm{g} / \mathrm{mL}$ ), while 113 displayed weak or no antimicrobial activity (MIC $\geq 32-64 \mu \mathrm{g} / \mathrm{mL}$ ) [106]. Ikarugamycins 109, 111, 113, and clifednamide A (114), were re-discovered from a marine sponge-associated novel actinomycete Streptomyces zhaozhouensis (strain MCCB267) using a cytotoxicity-guided strategy [108]. All compounds $(\mathbf{1 0 9}, \mathbf{1 1 1}, \mathbf{1 1 3}$, and 114) displayed promising cytotoxic activity against NCI-H460 lung carcinoma cells $\left(\mathrm{IC}_{50}=1.43-16.26 \mu \mathrm{g} / \mathrm{mL}\right)$ by binding with DNA and disrupting the cell cycle to induce apoptotic stimuli leading to cell death in the G1 or S phase [108].

Capsimycin (115), bearing an O-methoxy group at the C-30 of ikarugamycin epoxide (116), was first reported as an antifungal agent from Streptomyces sp. C49-87 in 1979 [115]. In 2003, ikarugamycin epoxide (later termed capsimycin B) (116), along with 109, were discovered from Streptomyces sp. Tü 6239 [105] and showed moderate antibacterial activity and cytotoxicity $[105,110]$. Utilizing biosynthetic technology, capsimycins C-G (117-121) and three known PTMs (109, 115, and 116) were identified from the marine mangrove-derived Streptomyces xiamenensis 318 [109]. Among them, the known PTMs (109, 115, and 116) exhibited strong antiproliferation activities against pancreatic carcinoma $\left(\mathrm{IC}_{50}=1.30-3.37 \mu \mathrm{M}\right)$, with negligible cytotoxicity towards normal cells at the same concentrations [109]. In addition, compound 115 inhibited six pancreatic carcinoma cells $\left(\mathrm{IC}_{50}=2.2-7.59 \mu \mathrm{M}\right)$, with weak cytotoxicity against normal cells $\left(\mathrm{IC}_{50}=9.64 \mu \mathrm{M}\right)$ [109]. Capsimycins $\mathbf{1 1 7}-\mathbf{1 2 0}$ were significantly less actively cytotoxic than $\mathbf{1 0 9}, \mathbf{1 1 5}$, and 116, emphasizing the importance of the C-13/C-14 double bond and epoxide ring for cytotoxicity [109]. Under a genomics-guided approach, cultivation of the marine sediment-derived Streptomyces sp. SCSIO 40060 led to the isolation and characterization of three new PTM analogues, hydroxyikarugamycins A-C (122-124) and four known PTMs, 109, and 115-117 [110]. Unfortunately, compounds 122-124 were devoid of bioactivities [110].

A new chlorinated 565-PTM chlokamycin (125), together with 109, was isolated from the culture broth of the marine-derived Streptomyces sp. MA2-12 [116]. Compound 125 moderately inhibited the growth of Jurkat cells and HCT116 cells, with $\mathrm{IC}_{50}$ values of 24.7 and $33.5 \mu \mathrm{M}$, respectively [116].

Twelve members of PTMs bearing the 5/5/6 ring system (collectively known as 5/5/6-PTMs), including maltophilins, xanthobaccins, HSAFs, FIs, and pactamides $\mathrm{A}, \mathrm{B}, \mathrm{D}$, and $\mathrm{F}$, were isolated from marine actinomyces (126-135, 137, and $\mathbf{1 3 9}$ in Figure 6).

The fermentation broth of the marine-derived Actinoalloteichus cyanogriseus WH1-2216-6 yielded a new 5/5/6-PTM named 16-hydroxymaltophilin (126) and five known analogues, maltophilin (127), xanthobaccin C (128), frontalamide precursor FI-2 (129), dihydromaltophilin/HSAF (heat-stable antifungal factor) (130), and 4-deoxydihydromaltophilin (131) [117]. In cytotoxic assays, the 5/5/6-PTMs 126-128 and 130-131 showed significant cytotoxicity against six HTCLs, with $\mathrm{IC}_{50}$ values of $0.1-9.7 \mu \mathrm{M}$. Among them, compound 126 revealed the most selective cytotoxicity against seven HTCLs, with $\mathrm{IC}_{50}=4.5-9.7 \mu \mathrm{M}$ (selectivity index $=24.3-51.4$ ) [117]. Compounds 127, 128, 130, and 131 also displayed antifungal activity (Aspergillus fumigatus AF293), with MIC $=1.56-25.0 \mu \mathrm{g} / \mathrm{mL}$ [117]. However, compounds 130 and 127 were most effective in their antifungal activities, with MIC values of 1.56 and $3.125 \mu \mathrm{g} / \mathrm{mL}$. It was indicated that the 3-OH and 14-OH group of 5/,5/6-PTMs possibly contributed to antifungal activity, while the 16-OH group decreased bioactivity [117]. In the same year, chemical and genetic profile analyses of the marine cone-snail-associated Streptomyces CMB-CS038 yielded four 5/5/6 PTMs, 130, and three minor co-metabolites, 128, as well as the frontalamide precursor FI-3 (132) and a new HSAF derivate, 
$\triangle^{30}$-dihydromaltophilin (133) [100]. Notably, compound 130 is a potent broad-spectrum antifungal agent with a novel mechanism of action and observable cytotoxicity [100,118,119].

The activation of the silent PTM gene clusters of the Streptomyces pactum SCSIO 02999 by genome-mining led to the production of six new PTMs, 5/5/6-PTMs (pactamide A, B, D, and F) (134, 135, 137, and 139), 5/5-PTM (pactamide C 136), and 5-PTM (pactamide E 138), which (except for compounds 135 and 137) displayed potent or moderate cytotoxic activity against the four HTCLs of $\mathrm{IC}_{50}=0.24-8.7 \mu \mathrm{M}$ [120]. Among these compounds, $\mathbf{1 3 4}$ exhibited the most active cytotoxic activity, with $\mathrm{IC}_{50}$ values of $0.24-0.51 \mu \mathrm{M}$, whereas 135 and 137 showed weak cytotoxicity, with $\mathrm{IC}_{50}=14.50-26.15 \mu \mathrm{M}$, suggesting that the presence of a double bond in the A ring of the 5/5/6 ring system significantly decreased their cytotoxicity [120].

Alteramides are a family of PTMs containing a 5/5 ring system fused to the macrolactam. Alteramides A and B (140 and 141) were obtained from the marine-sponge-associated bacterium Alteromonas sp. by the Kobayashi group in 1992 [121]. Their corresponding isomers, 6-epi-alteramides A and B (142 and 143), were sourced from the coral-associated Pseudoalteromonas sp. OT59 [122] by microbial MALDI-imaging mass spectrometry coupled with a molecular network strategy and were used to revise the original stereochemistry of alteramides, which were originally isolated from the Streptomyces albus J1074 in 2014 [123]. Alteramides 142 and 143 were responsible for the observed antifungal activity of this strain when grown in the dark, although they were inactivated by light through photoinduced intramolecular [4+4] cycloaddition to generate the hexacyclic products 140a and 141a [121,122]. Further, 140 exhibited in vitro cytotoxicity against P388, L1210, and KB cells, with $\mathrm{IC}_{50}$ values of $0.1,1.7$, and $5.0 \mu \mathrm{g} / \mathrm{mL}$, respectively [121], while 141 showed no cytotoxicity, indicating that the presence of the C-25-hydroxyl group led to the abolishment of antiproliferative activity [121].

Aburatubolactams A-C (144-146) were isolated as the metabolites of a mollusk-associated Streptomyces sp. SCRC-A20 by the Uemura group in 1996 and 1998 [124,125]. Aburatubolactams (144-146) inhibited the TPA-induced superoxide anion generation by human neutrophils ( $\mathrm{IC}_{50} 26$, $6.3,2.7 \mu \mathrm{g} / \mathrm{mL}$, respectively), which is related to inflammation, cancer, and aging [125]. Additionally, 144 showed cytotoxicity, antimicrobial activity, and the inhibition of superoxide generation $[125,126]$. Compound $\mathbf{1 4 6}$ was cytotoxic to five leukemia and lymphoma HTCLs, inducing apoptosis, with $\mathrm{IC}_{50}$ values of $0.3-1.9 \mu \mathrm{g} / \mathrm{mL}$ [124].

\subsubsection{Pyrrocidine Tetramate Alkaloids (PTAs)}

Pyrrocidine tetramate alkaloids (PTAs) (147-165 in Figure 7) form a class of complicated and changeable MTAs, and were recently isolated from marine fungi. These PTAs, bearing a polycyclic unit $(6 / 5 / 6,6 / 5 / 6 / 6$, or 6/5/6/5 ring system), a 12- or 13-membered macrocyclic integrated 1,4-disubstituted phenyl, and a TA (or its analogue framework at C-3), are very unusual in the natural product field.

A cytotoxicity-guided chemical investigation of the marine-derived fungus Penicillium sp. ZZ380 resulted in the isolation of seven rare new pyrrospirones C-I (147-153) [127] featuring a 6/5/6/6 fused ring system, minor penicipyrrodiether A (155) [128], and GKK1032B (158). Compound 151 showed potent cytotoxicity against four glioma cells, with $\mathrm{IC}_{50}$ values of $1.06-8.52 \mu \mathrm{M}$, while being devoid of antibacterial activity [128]. PTAs 147-150, 152-153, and 155 showed moderate cytotoxicity, with $\mathrm{IC}_{50}$ values of 7.44-29.10 $\mu \mathrm{M}$, and antibacterial activity against both MRSA and E. coli, with MICs of $2.0-34.0 \mu \mathrm{g} / \mathrm{mL}(\mathbf{1 4 7}, \mathbf{1 5 0}$, and 153: MICs $=2.0-5.0 \mu \mathrm{g} / \mathrm{mL})[127,128]$. It is worth noting that 155 was the first example of a hybrid of phenol A fused to the GKK1032 skeleton via the addition of a five-membered ether ring and displayed anti-MRSA activity (MIC $=5.0 \mu \mathrm{g} / \mathrm{mL}$ ) [128]. Through further chemical investigation by the OSMAC method, this strain yielded two novel PTAs with a unique 6/5/6/5 polycyclic fusion, penicipyrroether A and pyrrospirone J (154 and 156) [129]. Compound 154 displayed potent selective antiproliferative activity against human glioma U87MG and U251 cells $\left(\mathrm{IC}_{50}=1.64-5.50 \mu \mathrm{M}\right)$, equivalent to doxorubicin, and potent antibacterial activity against MRSA and E. coli, with MIC $=1.7-3.0 \mu \mathrm{g} / \mathrm{mL}[129]$. 
A new member of the GKK1032 family, GKK1032C (159), and four known analogues, GKK1032A2 (157), GKK1032B (158), and pyrrospirones E and F (149 and 150), were identified from the culture of the mangrove endophytic fungus, Penicillium sp. CPCC 400817. Among them, compounds 159 and 157 exhibited potent antibacterial activity against MRSA, with MIC values of 1.6 and $3.2 \mu \mathrm{g} / \mathrm{mL}$ [130]. The GKK1032 family possesses unique structural features, with 12- or 13-membered macrocyclic ether-containing 1,4-disubstituted phenyl and TA components, such as $\gamma$-lactam or succinimide scaffolds, and a rare tricarbocyclic system in polyketides [130].

From the marine ascidian-derived fungus Trichobotrys effuse 4729, our research group recently obtained a novel pyrrocidine alkaloid, trichobamide A (160), with an unprecedented tetrahydro-5Hfuro[2,3-b]pyrrol-5-one moiety. This molecule (160) significantly inhibited the proliferation of U251 and SNB19 glioma cell lines by inducing apoptosis in human glioma cells through the P53/Bax/Bcl-2 pathway [131]. The fermentation of the mangrove endophytic fungus Didymella sp. CYSK-4 afforded three new natural products, ascomylactams A-C (161-163) and the known analogues phomapyrrolidones A and C (164 and 165) [132], whose configurations were revised as 164 and 165, bearing an unusual 6/5/6/5 tetracyclic skeleton fused with a 12- or 13-membered macrocyclic motif [133]. In the cytotoxic assay, 161 and 163 showed moderate cytotoxicity against six HTCLs (MDA-MB-435, MDA-MB-231, SNB19, HCT116, NCI-H460, and PC-3), with $\mathrm{IC}_{50}$ values in the range of 4.2-7.8 $\mu \mathrm{M}$ [133], while 162 and 165 displayed weak cytotoxicity against six HTCLs, with $\mathrm{IC}_{50}=4.5-29 \mu \mathrm{M}$ [133], and 165 exhibited weak antitubercular activity, with MIC 5.2-13.4 $\mu \mathrm{g} / \mathrm{mL}$ in vitro [132].

\subsection{N-acylated Tetramic Acids}

The class of $N$-acylated tetramic acids (44 compounds, 166-210 in Figure 8) contains the tetramate components, $\mathrm{N}$-acyl-3-pyrrolin-2-one (6 jamaicamides, 11 microcolins, 2 majusculamides, 3 ypaoamides, and malyngamide 4 ) or $N$-acyl-4-methoxy-3-pyrrolin-2-ones (6 malyngamides, 7 pukeleimides, belamide A, caldoramide, symplostatin 4, and palau'imide), or their related derivatives, commonly found as linear lipopeptides in the marine cyanobacterium Moorea producens (formerly Lyngbya majuscula). Although $N$-acylated TAs like dolastatin 15 were also discovered from marine animals (e.g., sea hares feeding on cyanobacterium), the actual producer has always been considered to be their symbiotic cyanobacterium [134].

Jamaicamides, a class of linear hybrid NRPS/PKS neurotoxic lipopeptides with two peptide bonds and halogen, were isolated from marine M. producens collected in Hector Bay, Jamaica by the Gerwick group [135,136]. Using a bioassay-guided strategy, jamaicamides A-C (166-168), were isolated and found to display sodium-channel-blocking activity at $5 \mu \mathrm{M}$ and cytotoxicity against the $\mathrm{H}-460$ and Neuro-2a cell lines $\left(\mathrm{LC}_{50}=15 \mu \mathrm{M}\right)$, two of which (167 and 168) showed neurotoxic activity (100\% lethality at $\leq 10 \mathrm{ppm}$ after $90 \mathrm{~min}$ ) in a goldfish toxicity assay [135]. Three other new analogues, jamaicamides D-F (169-171), were discovered from this strain using an orthogonal natural product workflow, containing LC-MS/MS molecular networking and OSMAC approaches [136]. Some of the jamaicamides (166, 167, and 171) showed concentration-dependent antagonism of an increase in neuronal $\left[\mathrm{Ca}^{2+}\right] \mathrm{i} /\left[\mathrm{Na}^{+}\right] \mathrm{i}$ induced by veratridine ( $\mathrm{IC}_{50}=1.82-6.88 \mu \mathrm{M}$, and 1.1-3.6 $\mu \mathrm{M}$, respectively) [136]. In comparison, compound 166, as a sodium/calcium channel blocker in neocortical neurons, was approximately two to three times more active than compounds 167 and 171 [136]. 


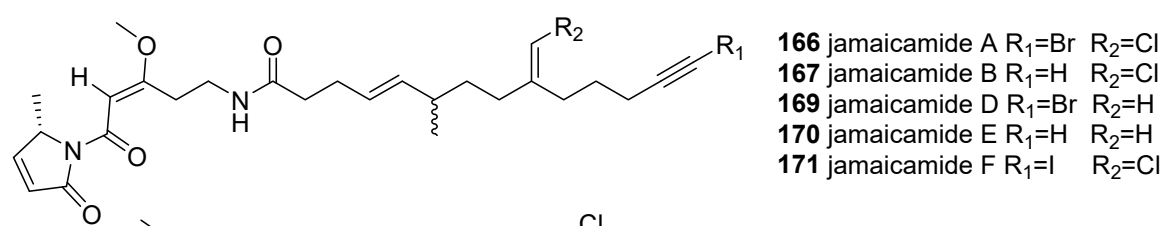<smiles>C=CCCCC(=CCl)CC[C@H](C)/C=C/CCC(=O)NCC/C(=C\C(=O)N1C(=O)C=C[C@H]1C)OC</smiles>

168 jamaicamide $C$

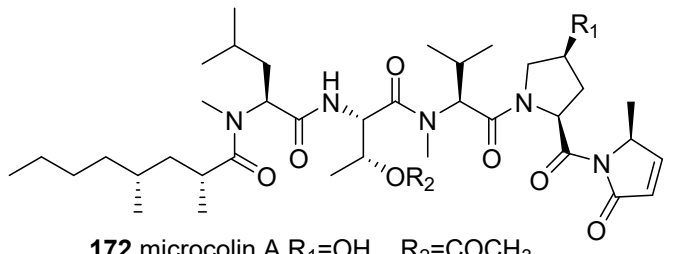

172 microcolin $A R_{1}=O H \quad R_{2}=\mathrm{COCH}_{3}$

173 microcolin $B R_{1}=H \quad R_{2}=\mathrm{COCH}_{3}$

174 microcolin $\mathrm{C} /$ desacetylmicrocolin $B \mathrm{R}_{1}=\mathrm{R}_{2}=\mathrm{H}$

175 microcolin $\mathrm{D} \mathrm{R}_{1}=\mathrm{OH} \quad \mathrm{R}_{2}=\mathrm{H}$

182 microcolin $\mathrm{K} \mathrm{R}_{1}=\mathrm{OH} \quad \mathrm{R}_{2}=\mathrm{COCH}_{2} \mathrm{CH}_{3}$<smiles>[R]C1C[C@H](C(=O)N2C[C@H](C)C=CC2=O)N(C(=O)[C@H](C(C)C)N(C)C(=O)[C@H](NC(=O)[C@H](CC(C)C)N(C)C(=O)[C@H](C)CCCCCC)[C@@H](C)OC(C)=O)C1</smiles>

179 microcolin $\mathrm{H} \mathrm{R}=\mathrm{OH}$

180 microcolin I $\mathrm{R}_{1}=\mathrm{H}$<smiles>CCCC[C@H](C)C[C@H](C)C(=O)N(C)[C@H](CC(C)CC)C(=O)N[C@H](C(=O)N(C)[C@H](C(=O)N1CC(O)C[C@H]1C(=O)N1C(=O)C=C[C@H]1C)C(C)C)[C@@H](C)OC(C)=O</smiles>

183 microcolin L<smiles>[R]C1C[C@H](C(=O)N2C(=O)C=C[C@@H]2C)N(C(=O)[C@H](C(C)C)N(C)C(=O)[C@H](NC(=O)[C@H](Cc2ccc(OC)cc2)N(C)C(=O)[C@H](C)C[C@@H](C)CCCC)[C@H](C)OC(C)=O)C1</smiles>

184 majusculamide $D$

$\mathrm{R}=\mathrm{OH}$

185 deoxymajusculamide $D \quad R=H$<smiles>CO/C(=C/C(=O)N1C(=O)C=CC1CC(C)C)CCCNC(=O)CCCCC(C)(C)C</smiles>

187 ypaoamide B

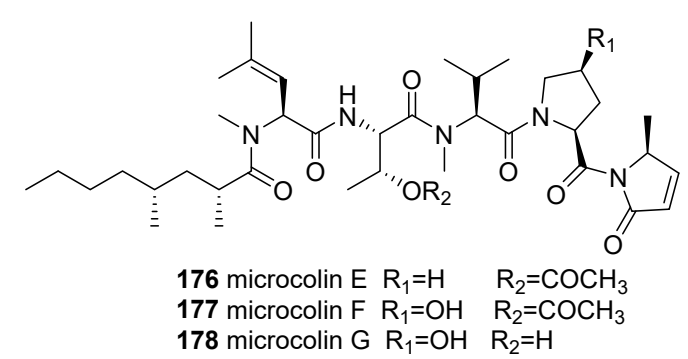

$\mathrm{R}_{2}=\mathrm{COCH}_{3}$<smiles>[R2]O[C@H](C)[C@H](NC(=O)[C@@H](CC(C)C)N(C)C(=O)[C@H](C)C[C@@H](C)CCCC)C(=O)N[C@H](C(=O)N1CC([R7])C[C@H]1C(=O)N1C(=O)C=C[C@H]1C)C(C)C</smiles>

181 microcolin $\mathrm{J} \mathrm{R}_{1}=\mathrm{H} \quad \mathrm{R}_{2}=\mathrm{COCH}_{3}$<smiles>CCCC[C@H](C)C[C@H](C)C(=O)N(C)[C@H](CC(C)C)C(=O)N[C@H](C(=O)N(C)C(C(=O)N1C[C@H](O)C[C@H]1C(=O)O)C(C)C)[C@@H](C)OC(C)=O</smiles>

microcolin M-- microcolin precursor<smiles>CO/C(=C/C(=O)N1C(=O)C=CC1Cc1ccc(O)cc1)CCCNC(=O)CCCCC(C)(C)C</smiles>

186 ypaoamide<smiles>CO/C(=C/C(=O)N1C(=O)C=C[C@H]1C)C/C(=C\Cl)CNC(=O)CCCCC(C)(C)C</smiles><smiles>COC(/C=C/CO)=C/C(=O)N1C(=O)C=CC1C</smiles>

188 ypaoamide $\mathrm{C}$

Figure 8. Cont. 

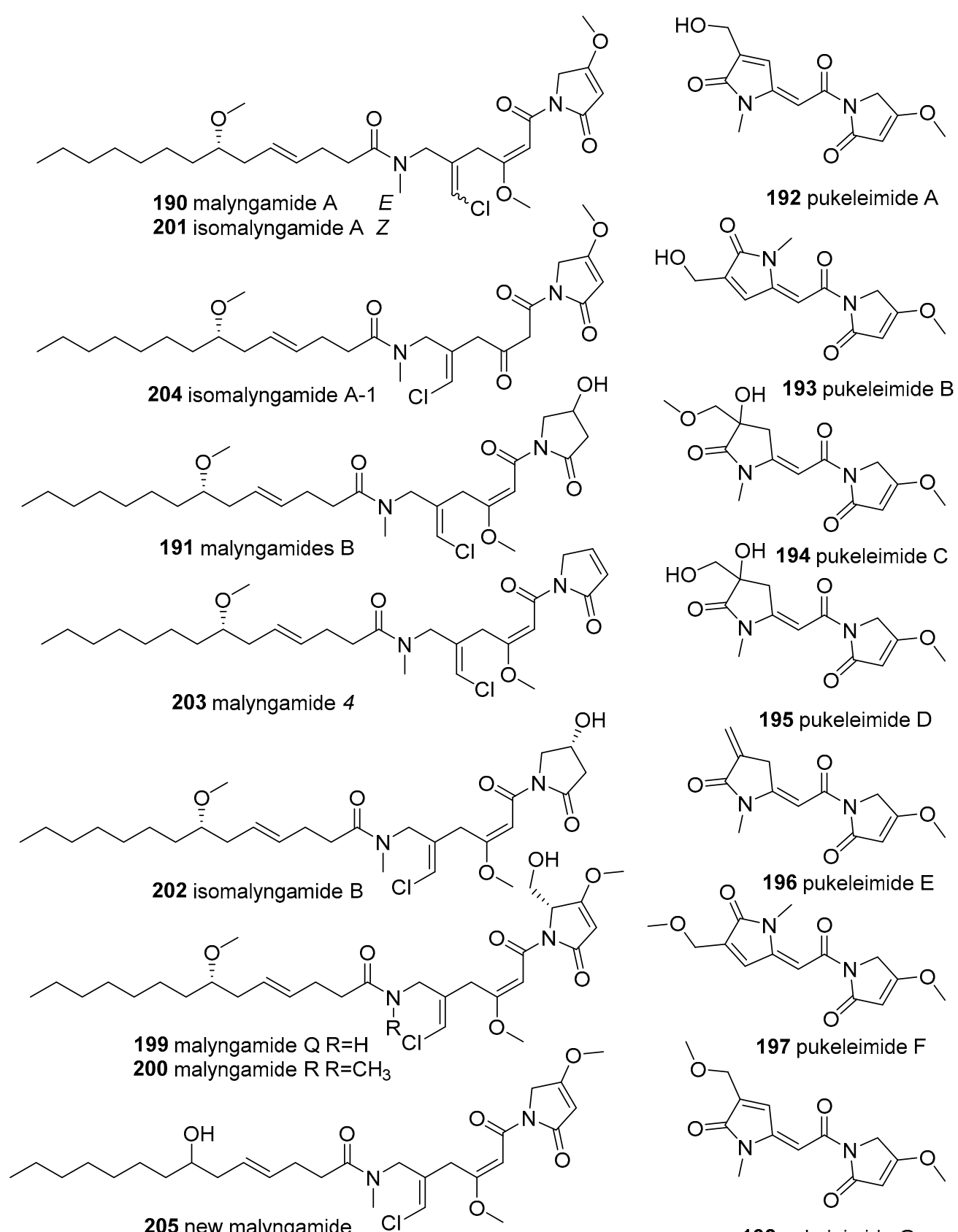<smiles>CCCCC(C)C(=O)NC(C(=O)N1C(=O)C(C)=C(OC)C1Cc1ccccc1)C(C)C</smiles>

206 palau'imide<smiles>COC1=CC(=O)N(C(=O)C(Cc2ccccc2)N(C)C(=O)C(C(C)C)N(C)C(=O)C(C(C)C)N(C)C)C1Cc1ccccc1</smiles><smiles>CC[C@H](C)[C@H](C(=O)O[C@H](CC(C)C)C(=O)N[C@@H](CC(C)C)C(=O)N[C@@H](C)/C=C/C(=O)N1C(=O)C=C(OC)[C@H]1C)N(C)C</smiles>

209 gallinamide $A$ / symplostatin 4

Figure 8. Chemical structures of $N$-acylated tetramic acids (166-209). 
Microcolins A and B (172 and 173), immunosuppressive lipopeptides, were first reported as metabolites of L. majuscula in Venezuela [137]. These two metabolites (172 and 173) and desacetylmicrocolin B (also termed microcolin C) (174) were also isolated from an active fractionation of L. polychroa in Florida [138]. Compounds $\mathbf{1 7 2}$ and $\mathbf{1 7 3}$ displayed potent immunosuppressive activity in a two-way murine mixed lymphocyte reaction $\left(\mathrm{EC}_{50}=1.5\right.$ and $42.7 \mathrm{nM}, \mathrm{TC}_{50}=22.6$ and $\left.191.0 \mathrm{nM}\right)$ [137]. Recently, nine new linear lipopeptides, microcolins E-L (176-183) and their precursor microcolin M, together with the four known microcolins A-D (172-175), were isolated from marine $M$. producens using bioassay-guided and LC-MS/MS molecular networking approaches [139]. Structurally, microcolins E-G bearing unusual 4-methyl-2-(methylamino) pent-3-enoic (Mpe) acid units and microcolin L featuring 2-amino-4-methylhexanoic acid (N-Me-homoisoleucine) motifs are peptides that rarely occur in nature [139]. Additionally, microcolin $\mathrm{M}$ is the precursor of microcolins without an N-acyl-3-pyrrolin-2-one moiety [139]. Microcolin B (173) and D (175) were shown to be potential inhibitors of LFA-1/ICAM-1-mediated cell adhesion, with $\mathrm{IC}_{50}$ values of 0.15 and $0.9 \mu \mathrm{M}$, respectively [140]. At the same time, microcolins 172-174 were found to have significant inhibition of the growth of HT-29 and IMR-32 HTCLs ( IC $_{50}=0.28-14 \mathrm{nM}$ ) [138]. The molecule 172 displayed antiproliferative and immunosuppressive effects on lymphocytes, with $\mathrm{IC}_{50}$ values in the nanomolar range in vitro, whose inhibitory activity was time-dependent and reversible without showing a reduction in cell viability [141]. These metabolites (176-182), along with three semisynthetic derivatives, 3,4-dihydromicrocolins, A, B and D, showed significant cytotoxicity against H-460 lung HTCL, with $\mathrm{IC}_{50}$ values ranging from $6 \mathrm{nM}$ to $5.0 \mu \mathrm{M}\left(\mathbf{1 7 2}, \mathbf{1 7 5}, \mathbf{1 7 7}, \mathbf{1 7 9}\right.$, and $\mathbf{1 8 1}$, with $\mathrm{IC}_{50}$ values of $6,75,37,47$, and $69 \mathrm{nM}$, respectively) [139]. SAR revealed that a hydroxyl group at the C-4 of proline and a double bond in the Mdp (5-methyl-1,5-dihydro-2H-pyrrol-2-one) moiety are critical for cytotoxicity [139].

Investigation of the active fraction of marine L. majuscula yielded two cytotoxic lipopentapeptides, majusculamide D (184) and deoxymajusculamide D (185), in 1988 [142]. Recently, 184 was re-discovered from a marine Moorea sp., and its absolute configuration was determined by total synthesis [143]. Compound 184 exhibited selective and potent in vitro cytotoxicity toward pancreatic (PANC-1), glioblastoma $(\mathrm{U} 251 \mathrm{~N})\left(\mathrm{IC}_{50}=0.32\right.$ and $36.8 \mathrm{nM}$, respectively) and HepG2 HTCLs $\left(\mathrm{IC}_{50}=1.40 \mu \mathrm{M}\right)$ [143].

Ypaoamide (186), a lipopeptide with a feeding deterrent, was isolated from a marine cyanobacterial assemblage composed of Schizothrix calcicola and L. majuscula in 1996 [144]. Recently, biochemical studies on marine Okeania sp. collected in Okinawa produced two new analogues, ypaoamides B and C (187 and 188), which stimulated glucose uptake in a dose-dependent and insulin-independent manner in cultured L6 myotubes [145]. Furthermore, the effect of $\mathbf{1 8 8}$ on glucose uptake was found to occur by activation of the AMP-activated protein kinase (AMPK) pathway regulating cellular metabolism, suggested to be a potential therapeutic candidate for the treatment of Type 2 diabetes mellitus (T2DM) [145].

Palmyrrolinone (189), the only non-peptide $N$-acylated TA, was reported from a marine cyanobacterial assemblage consisting of cf. Oscillatoria and Hormoscilla spp. obtained from Palmyra Atoll and displayed potent molluscicidal activity against Biomphalaria glabrata $\left(\mathrm{LC}_{50}=6.0 \mu \mathrm{M}\right)$ [146].

Two chlorine-containing lipopeptides, malyngamides A and B (190 and 191), were described as the constituents of shallow water varieties of marine M. producens collected at Kahala Beach, Hawaii by Moore et al. in 1978 [147,148]. The same workers subsequently isolated seven closely related nontoxic compounds, pukeleimides A-G (192-198), lacking the fatty acid side chain and chlorine atoms of the 190 analogues from the same strain [149,150]. Malyngamide $Q$ and $R$ (201 and 202) [151] and isomalyngamides A and B (199 and 200) [152], a new subtype of malyngamide with different geometrical stereochemistry at C-6 (Z-chloromethylene), were purified from marine L. majuscula from Madagascan and Hawaiian waters, respectively. A bioassay-directed fractionation of the active fractions of a strain of $M$. producens derived from the Red Sea resulted in the isolation of a new malyngamide 4 (203), along with malyngamides A and B. Compounds 203 and 191 revealed moderate cytotoxicity against three HTCLs (A549, HT29, and MDA-MB-231, $\left(\mathrm{IC}_{50}=40-60 \mu \mathrm{M}\right)$ [153]. (Z)-malyngamides 199 and 200 showed lethal toxicity to crayfish at less than $0.5 \mathrm{mg} / \mathrm{kg}$ [152]. Subsequently, a new (Z)-malyngamide, named isomalyngamide A-1 (204), along with 199, was obtained from a Taiwanese L. majuscula [154]. Compounds 204 and 199 displayed 
potential in suppressing breast cancer cell (MDA-MB-231) migration, with nanomolar $\mathrm{IC}_{50}$ values of 337 and $60 \mathrm{nM}$, and blocked cell proliferation, with micromolar $\mathrm{IC}_{50}$ values of 12.7 , and $2.8 \mu \mathrm{M}$, by inactivating the expression of focal adhesion kinase (FAK), $p$-FAK, Akt, and $p$-Akt through the $\beta$ - 1 integrin-mediated antimetastatic pathway [154]. It was indicated that the C-12' enol methyl ether group of 204 was essential for its cytotoxicity against breast HTCLs [154]. A new malyngamide (205) - the first report of a malyngamide with a hydroxy group at C-7 of the fatty acid portion-as well as 199 and 200, were discovered in Hawaiian M. producens [155]. The bioactivity of 205, showing very weak cytotoxicity against L1210 and lethal toxicity to shrimp, was approximately 10-100 times weaker than that of 199 and 200, suggesting that the methoxy group at C-7 of the fatty acid section was the important pharmacophore of the malyngamide [155].

Palau'imide (206), with an $N$-acyl-4-methoxy-3-methyl-pyrrolin-2-one unit, was isolated from a marine Lyngbya sp. NIH309 collected in the Palau region and was cytotoxic to KB and LoVo cells $\left(\mathrm{IC}_{50}=1.4\right.$, and $\left.0.36 \mu \mathrm{M}\right)$ [156]. Belamide A (207), a highly methylated linear tetrapeptide analogue of dolastatins 10 and 15, was discovered in the Panamanian marine cyanobacterium Symploca sp. [157]. Compound 207 was found to be cytotoxic to MCF-7 and HCT-116 HTCLs, with IC 50 values of 1.6 and $0.74 \mu \mathrm{M}$, respectively [157]. Further, 207 also displayed classic tubulin-destabilizing antimitotic characteristics by depolymerizing the microtubule network in the A-10 cell lines at $20 \mu \mathrm{M}$ [157]. A new linear pentapeptide, caldoramide (208), sharing a structural similarity to 207 and dolastatins 10 and 15 , was isolated from the marine cyanobacterium Caldora penicillata (syn. Phormidium penicillatum) collected at Florida [158]. Compound 208 was cytotoxic to HCT116 colorectal cancer cells $\left(\mathrm{IC}_{50}=3.9-8.6 \mu \mathrm{M}\right)$ modified in oncogenic KRAS and hypoxia-inducible factor (HIF) pathways, which are related to angiogenesis, cell growth, apoptosis, and metastasis, suggesting that this compound can act as an indirect HIF inhibitor [158].

In 2009, the cyanobacterial linear lipodepsipeptide symplostatin 4 (Sym4) (209) [159] and gallinamide A (209) [160], containing a methylmethoxypyrrolinone (MMP) moiety, were independently isolated from Symploca sp. and Schizothrix sp., respectively. Subsequently, the total syntheses of both compounds revealed that they are indeed identical $[160,161]$. Subsequent biological evaluations of 209 and three synthetically generated N-terminal diastereoisomers demonstrated their potent antimalarial properties: potent antimalarial activities against the Plasmodium falciparum $3 \mathrm{D} 7$ strain $\left(\mathrm{IC}_{50}=37-104 \mathrm{nM}\right.$ ), similar to that of the positive control, chloroquine $\left(\mathrm{IC}_{50}=17.8 \mathrm{nM}\right)$ [160]. Compound 209 was also moderately activated in inhibiting the chloroquine-resistant strain of $P$. falciparum $\mathrm{W} 2\left(\mathrm{IC}_{50}=8.4 \mu \mathrm{M}\right)[162]$. Compound 209 also displayed moderate cytotoxicity against mammalian Vero cells $\left(\mathrm{IC}_{50}=10.4 \mu \mathrm{M}\right)$, HeLa cervical carcinoma cells $\left(\mathrm{IC}_{50}=12 \mu \mathrm{M}\right)$, and HT-29 colon adenocarcinoma cells $\left(\mathrm{IC}_{50}=53 \mu \mathrm{M}\right)$; surprisingly, the lack of cytotoxicity toward NCIH460 lung tumors or neuro- $2 \alpha$ mouse neuroblastoma cell lines at $16.9 \mu \mathrm{M}$ indicated that 209 could be considered as a promising lead antimalarial hit [159,162]. Furthermore, compound 209 was demonstrated to induce the G2 cell cycle arrest at a high micromolar concentration, which is related to microtubule-disrupting effects [162]. Notably, compound 209 did not cause the lysis of red blood cells (RBCs), even at high concentrations ( $>25 \mathrm{mM})$ [161], indicating that its antiparasitic effect was not due to the permeabilization of the RBC membrane. Compound 209 also potently and selectively inhibited the human cysteine protease cathepsin $\mathrm{L}\left(\mathrm{IC}_{50}=5.0 \mathrm{nM}\right)$ through a covalent and irreversible mechanism [163]. The sym4-treatment of $P$. falciparum-infected RBCs led to the generation of a swollen food vacuole phenotype and a reduction in parasitemia at an $\mathrm{EC}_{50}$ of $0.7 \mu \mathrm{M}$ [164]. Further studies of 209 and its derivatives revealed that 209 acts as a nanomolar inhibitor of the P. falciparum falcipains (FPs) in infected RBCs by inhibiting the hemoglobin degradation pathway and indicating its unusual MMP unit as the critical pharmacophores [164].

\section{7. $\alpha$-Cyclopiazonic acid (CPA)-type Tetramic Acids}

Cyclopiazonic acid ( $\alpha$-cyclopiazonic acid, $\alpha$-CPA) (210) is a potentially severe mycotoxin that possesses an indole-hydrindane-tetramate unit and is produced by many fungal species in the Ascomycta genera Penicillium and Aspergillus [165]. Compound 210 was biosynthesized from three precursors, including a tryptophan residue, two units of acetic acid, and an isoprenoid moiety with 
two intermediates (cyclo-acetoacetyl-L- tryptophan (cAATrp) (211) and $\beta$-cyclopiazonic acid ( $\beta$-CPA) (212)) in the PKS-NRPS hybrid pathway [165]. Additionally, $\alpha$-CPA was demonstrated to be a potent, selective, and reversible SERCA (sarco/endoplasmic reticulum $\mathrm{Ca}^{2+}$-ATPase) inhibitor in different tissues and cell types [166], and was observed to have an immunosuppressive effect [167] and antiviral activities against the Sendai virus, hepatitis B virus, rotavirus, and human respiratory syncytial virus via different mechanisms [168]. Since $\alpha$-CPA was first isolated in 1968, 26 CPA-type tetramate alkaloids (210-235 in Figure 9) have been reported from marine fungi Aspergilli, Penicillium, Pseudallescheria, and actinomycete Amycolatopsis. These marine CPA-type tetramic acids, containing the tetramic acid moiety as a critical structural motif, were characterized to have some structural variations, and all belong to the indole or oxindole (indolinone) subclasses of CPA-type tetramate alkaloids $[165,166]$.

In 2009, iso- $\alpha$-cyclopiazonic acid (213), along with its isomer 210, was structurally characterized in the marine algae-derived A. flavus C-F-3 [169], the marine prawn-derived A. flavus OUCMDZ-2205 [170], and marine-derived P. camemberti [171]. Two new CPA derivatives, amycocyclopiazonic acid (214) and amycolactam (215), were isolated from a sponge-associated rare actinomycete Amycolatopsis sp. [172]. Very recently, a new CPA derivative, pseuboydone E (216), was isolated from the marine soft coral-derived Pseudallescheria boydii F19-1 [173]. Compounds 211 and 212 were confirmed to be the biosynthesized intermediates of CPA in the marine fungus Aspergillus oryzae HMP-F28 using biosynthetic machinery [174].

Metabolites 210-216 are the CPA derivatives belonging to the indole subclass of CPA-type tetramate alkaloids. All the remaining analogues, cyclopiamides (217-226), speradines (227-235), and aspergillines (225), were categorized in the oxindole subclass of CPA-type tetramate alkaloids [166]. The first $N$-methylated pentacyclic oxindole analogues of $\alpha-\mathrm{CPA}$, speradine A and 3-OH-speradine A (227 and 228), were isolated in cultures of the marine-derived fungi A. tamarii M143 and A. oryzae HMP-F28 [174-176]. Four other tetracyclic oxindole alkaloids, named speradine B, C, D, and E (224, 229, 230, and 231), were identified from marine-sediment-derived A. oryzae [177]. A rare hexacyclic oxindole alkaloid, speradine F (also termed penicamedine A [171]) (232), together with two novel tetracyclic oxindoles, speradine G and H (224 and 234), were isolated from marine-sediment-derived Aspergillus oryzae [178]. The terminology for oxindoles has been incorrectly used in the literature. For example, Ma et al. [179] reported the identification of speradine B, C, and D from a sponge-derived strain of A. flavus MXH-X104, and Wang et al. [180] reported the identification of speradine B from a mangrove-derived strain of $P$. dipodomyicola Y26-02. However, these molecules do not correspond with the metabolites previously described in $\mathrm{Hu}^{\prime}$ s report [177]. Another group of CPA-related oxindoles, cyclopiamides B-J (218-226), along with cyclopiamides 210, 232, and 234, were isolated from a deep-sea-derived strain of P. commune DFFSCS026 [181]. Cyclopiamides H and I, separated in $P$. commune, were proven to be the same chemical entities as speradine B (224) and aspergilline D (isolated from the A. versicolor in 2014 [182]) (225), respectively. To avoid future confusion, we suggest renaming these compounds according to the chronology of their discovery, as follows: speradine $B, C$, and D [179], should be re-designated as speradine F, $C^{\prime}$, and $C(\mathbf{2 3 2}, \mathbf{2 3 5}$, and 229), speradine B in [180] should be renamed as 2-demethylsperadine F (233) [183], and speradine G in [178] as speradine B (225). Notably, 234 [179] possesses an unusual 6/5/6/5/5/6 hexacyclic system with a unique 4-oxo-1,3-oxazinane ring, and 225 [182], 226 [181], 232 [171], and 233 [180] bear an unusual rigid and sterically congested hexacyclic 6/5/6/5/5/5 indole-tetrahydrofuran-tetramate scaffold.

The bioassay results showed that $\mathbf{2 1 0}$ has potent toxicity toward brine shrimp $\left(\mathrm{IC}_{50}<1.0 \mu \mathrm{g} / \mathrm{mL}\right)$ [181] and cytotoxicity against four HTCLs $\left(\mathrm{IC}_{50}=2.4-21.5 \mu \mathrm{M}\right)$ [169] as well as antibacterial activity against E. coli [184]. However, its isomer (213) only displayed weak cytotoxicity against A549 $\left(\mathrm{IC}_{50}=42.2 \mu \mathrm{M}\right)[169]$. Compound 215 displayed significant cytotoxicity towards the SNU638 and HCT116 cell lines $\left(\mathrm{IC}_{50}=0.8\right.$, $2.0 \mu \mathrm{M})$, and moderate cytotoxicity against the A546, K562, and SK-HEP1 cell lines $\left(\mathrm{IC}_{50}=13.7,9.6\right.$, $8.3 \mu \mathrm{M})$ [172]. Compound 227 revealed inhibitory activity against SERCA $\left(\mathrm{IC}_{50}=8 \mu \mathrm{M}\right)$ and inhibitory activity towards histone deacetylase $\left(\mathrm{IC}_{50}=100 \mu \mathrm{g} / \mathrm{mL}\right)$, as well as antibacterial activity against Micrococcus luteus (MIC $=16.7 \mu \mathrm{g} / \mathrm{mL}$ ) [175]. Compound 235 [179] displayed potent inhibition activity against Sf9 insect 
cells with $\mathrm{IC}_{50}=0.9 \mu \mathrm{M}$. Speradine B (225) [182] displayed potent anti-TMV (tobacco mosaic virus) activity on nicotine tobacco leaf $\left(\mathrm{IC}_{50}=38.9 \mu \mathrm{M}\right.$, with the positive control of ningnamycin $\left.30.5 \mu \mathrm{M}\right)$, protecting the host plant against TMV infection and presenting moderate cytotoxicity against five HTCLs ( IC $\left._{50}=1.2-4.2 \mu \mathrm{M}\right)$. Cyclopiamides (217-226) showed weak toxicity to brine shrimp ( $\left.\mathrm{IC}_{50}=14.1-46.5 \mu \mathrm{g} / \mathrm{mL}\right)$ and displayed no cytotoxic (HepG-2 and HeLa) or antiviral (N1H1) activities [181].

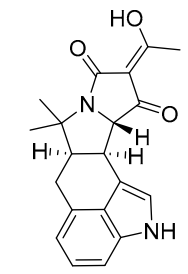

210 cyclopiazonic acid $(\alpha-\mathrm{CPA})$<smiles>CC(O)=C1C(=O)N[C@@H](Cc2c[nH]c3ccccc23)C1=O</smiles>

211 cAATrp<smiles></smiles>

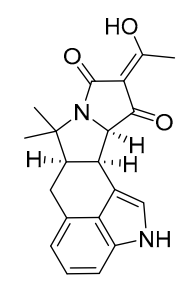

213 iso- $\alpha$-CPA

215 amycolactam

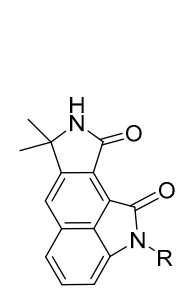

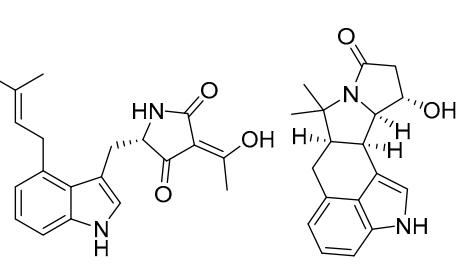

$212 \beta$-CPA

214 amycocyclopiazonic acid

217 cyclopiamide $\mathrm{R}=\mathrm{CH}_{3}$ 222 cyclopiamide $F \mathrm{R}=\mathrm{H}$

218 cyclopiamide $\mathrm{B} \mathrm{R}=\mathrm{CH}_{3}$ 219 cyclopiamide $\mathrm{C} \mathrm{R}=\mathrm{H}$

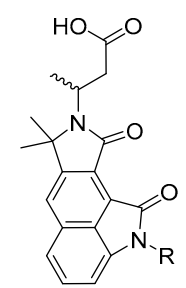

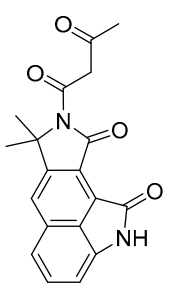
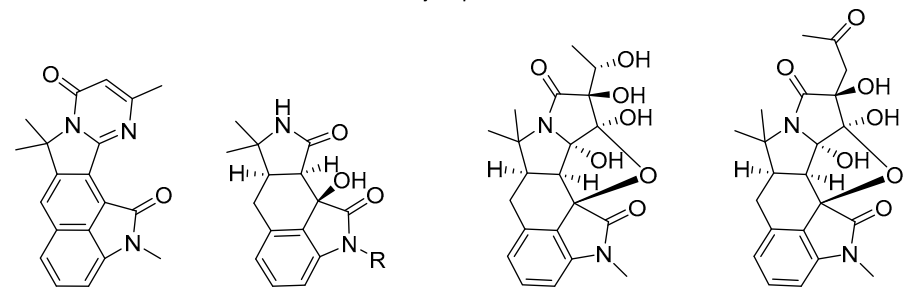

220 cyclopiamide D

221 cyclopiamide 223 cyclopiamide $\mathrm{G}$ R=H

224 cyclopiamide $\mathrm{H} /$

225 aspergilline D/ cyclopiamide I
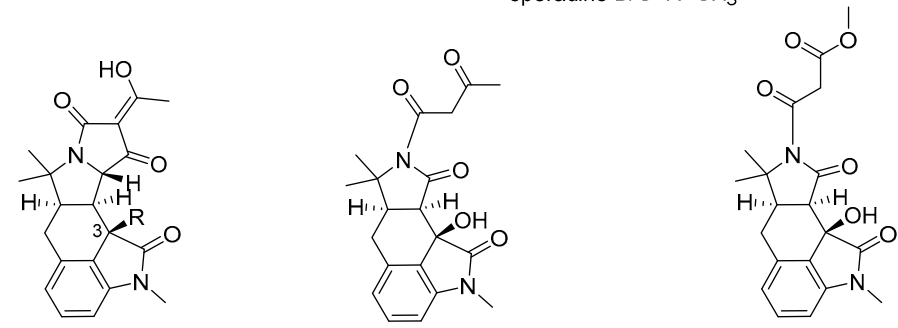

226 cyclopiamide J $\begin{array}{lr}227 \text { speradine } A & \mathrm{R}=\mathrm{H} \\ 2283-\mathrm{OH} \text {-speradine } \mathrm{A} \mathrm{R}=\mathrm{OH}\end{array}$

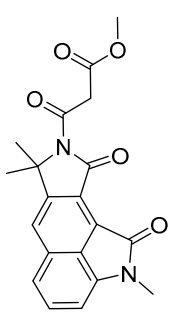

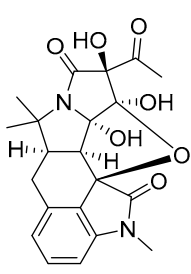

232 speradine $F$ penicamedine $A$
229 speradine C

230 speradine $D$

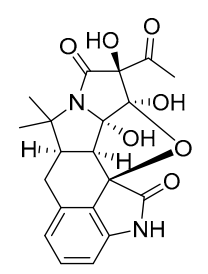

233 2-demethylsperadine $\mathrm{F}$
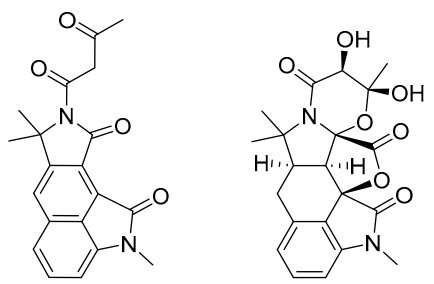

231 speradine $E$

Figure 9. Chemical structures of CPA-type tetramic acids (210-235). 


\subsection{Other Tetramic Acids}

All of the smaller subgroups of TAs, whose numbers were less than 13, were called "other tetramic acids", which include 42 compounds (236-277 in Figure 10).<smiles>C/C=C/c1oc2c(c(=O)c1O)C(=O)N[C@H]2O</smiles>

236 pyranonigrin $\mathrm{A}$<smiles>C/C=C/c1oc2c(OC)c(O)n(O)c2c(=O)c1O</smiles>

237 pyranonigrin $B$<smiles>CCC/C=C/c1oc2c(c(=O)c1O)C(=O)N[C@H]2O</smiles><smiles>C/C=C/c1oc2c(c(=O)c1O)C(=O)NC2</smiles>

241 pyranonigrin $S$<smiles>CC(C)=C1NC(=O)C2C(=O)CC(CC(C)O)OC12</smiles>

245 cladosporiumin $\mathrm{K}$<smiles>C/C=C/c1oc2c(O)c(OC)n(O)c2c(=O)c1O</smiles>

238 pyranonigrin C<smiles>CC[C@H](O)[C@H]1Oc2cc([C@@H](C)[C@H](C)O)c(C)c(O)c2[C@@]1(O)C(=O)N(C)C</smiles>

242 nigrospine<smiles>CC1CC=CC(=C2C(=O)NC(C(C)C)C2=O)O1</smiles>

246 cladosporiumin $E$ (major) /Z (minor)<smiles>C/C=C/c1oc2c3c([nH]c2c(=O)c1O)OCO3</smiles>

239 pyranonigrin $D$<smiles>C/C=C/C1=CC=CC(=C2C(=O)CNC2=O)O1</smiles>

243 vermelhotin $E / Z$<smiles>CC(C)=C1NC(=O)/C(=C2\C=CCC(C)O2)C1=O</smiles>

247 cladodionen $E$ (major) /Z (minor)<smiles>CC(C)=C1NC(=O)C(C2CC(=O)OC(C)C2)C1CC=CCC(C)O</smiles>

248 cladosporiumin A 249 cladosporiumin B<smiles>CC(C)=C1NC(=O)C(CC=CCC(C)O)(C2CC(=O)OC(C)C2)C1=O</smiles><smiles>CC(C)=C1NC(=O)C(C2CCC(C)OC2=O)C1CC=CCC(C)O</smiles><smiles>CC(C)=C1NC(=O)C(O)(C/C=C/CC(C)O)C1=O</smiles><smiles>CC(C)=C1NC(=O)C(C2CCC(=O)OC2)C1CC=CCC(C)O</smiles>

250 cladosporiumin C 251 cladosporiumin D 252 cladosporiumin I'<smiles>CC(C)=C1NC(=O)C(=O)C1(/C=C/CC(C)O)C1CC(=O)OC(C)C1</smiles><smiles>CC(C)=C1NC(=O)C(C(N)=CC(=O)O)C1=O</smiles><smiles>CC(C)=C1NC(=O)C(C(N)/C=C/CC(C)O)C1=O</smiles><smiles>CC(C)=C1NC(=O)C(C(N)/C=C\CC(C)O)C1=O</smiles><smiles>[R9]C(CC(N)=C1C(=O)NC(=C(C)C)C1=O)CC(C)O</smiles>

253 cladosporiumin J' 254 cladosin $\mathrm{A} \mathrm{R}=\mathrm{CH}_{3}$ (Z/E)

$$
\begin{aligned}
& 255 \text { cladosin } \mathrm{A} \mathrm{R}=\mathrm{CH}_{3}(\mathrm{Z} / \mathrm{E}) \\
& 255 \text { cladosin } \mathrm{B} \mathrm{R}=\mathrm{H} \quad \text { (Z/E) } 256 \text { cladosin } \mathrm{C} \text { (Z/E) }
\end{aligned}
$$

257 cladosin $\mathrm{D}(\mathrm{Z} / \mathrm{E}) 258$ cladosin $\mathrm{F} \mathrm{R}=\mathrm{H} \quad$ (Z/E) 259 cladosin $\mathrm{G} \mathrm{R}=\mathrm{CH}_{3}(\mathrm{Z} / \mathrm{E})$<smiles>CO[C@@H](CC1=C(Nc2ccccc2)C(=O)NC1=C(C)C)C[C@@H](C)O</smiles>

260 cladosin H $8 S$ (Z/E) 261 cladosin I $8 R$ (Z/E)<smiles>CC(C)=C1NC(=O)C(=C(C[C@H](CC(C)O)Nc2ccccc2)Nc2ccccc2)C1=O</smiles>

262 cladosin J $8 S$ (Z/E) 263 cladosin $\mathrm{K}$ 8R (Z/E)<smiles>CC1=C(C)C(=O)C(C)(C2(C)C(=O)NC(C(O)c3ccccc3)C2=O)C1</smiles>

264 tersone F

Figure 10. Cont. 
<smiles>[Z20]c1ccccc1C1=CC(OC)NC1=O</smiles>

Figure 10. Chemical structures of other tetramic acids (236-277).

Pyranonigrins, featuring an unprecedented pyrano[3,2-b]pyrrole skeleton, were mainly isolated from the fungi Aspergillus and Penicillium. Pyranonigrin A (236) and pyranonigrins B-D (237-239) were initially obtained from the sponge-derived fungus Aspergillu niger Van Tieghem [185]. Subsequently, pyranonigrin A (236) and pyranonigrin S (240) were also purified from the extracts of the marine fungus Aspergillus niger LL-LV3020, and its original structure was revised as 236 [186]. Pyranonigrin F (241) together with 236 were identified from the mangrove-derived Penicillium brocae MA-231 [187]. Interestingly, $\mathbf{2 3 6}$ was found to have extensive bioactivities, such as inhibition of the growth of neonate larval of the plant-insect Spodoptera littoralis [185] and suppression of the expression of vascular cell adhesion molecules (VCAM)-1 in human umbilical vein endothelial cells (HUVECs) induced by tumor necrosis factor (TNF)- $\alpha$ without affecting the cell viability of HUVECs [188], as well as displaying Epstein-Barr virus early antigen inhibitory activity [189]. Further, compounds 236 and 241 showed significant antimicrobial activities against human pathogens (Staphyloccocus aureus), aquatic bacteria (Vibrio harveyi and V. parahaemolyticus), and plant pathogens (Alternaria brassicae and Colletotrichum gloeosprioides) with an MIC of $0.5 \mu \mathrm{g} / \mathrm{mL}$, which is more potent than the positive control chloromycetin and bleomycin (for plant pathogens) [187]. Furthermore, compound 240 exhibited a higher level of 1,1-diphenyl-2-picryhydrozyl (DPPH) radical scavenging activity than 
$236[188,190,191]$. Nigrospine (242) with a rare 2,3-dihydro-benzofuran[2,3-c]2-pyrrolidone skeleton was purified from the marine-derived fungus Nigrospora oryzae SCSGAF 0111 [192].

Vermelhotin (243) was the first example of a TA with a C-3-pyrane ring. It was initially isolated as the E-isomer from the terrestrial fungus IFM52672 [193] and then obtained as an E/Z mixture from a marine sponge-associated unidentified fungus CRI247-01 [194]. Compound 243 displayed a full range of biological activities, such as potent inhibition of calmodulin by binding to calmodulin at site I [195], significant cytotoxicity against eleven HTCLs ( $\left.\mathrm{IC}_{50}=0.31-13.5 \mu \mathrm{g} / \mathrm{mL}\right)$ [194], moderate antiplasmodial activity $\left(\mathrm{IC}_{50}=1-10 \mu \mathrm{M}\right)$ [194], anti-inflammatory activity through the inhibition of NO production $\left(\mathrm{IC}_{50}=5.35 \mu \mathrm{M}\right)$ in LPS-induced RAW 264.7 cells via inhibition of iNOS expression and p38 phosphorylation [196], and inhibition of the MDR-TB isolates Mycobacterium tuberculosis (MIC $1.5-12.5 \mu \mathrm{g} / \mathrm{mL}$ ) [197].

Recently, deep-sea-sediment-derived fungi have been demonstrated to be the source of the chemical diversity of TAs. The genera of Cladosporium from deep-sea sediments are sources of many subclasses of tetramic acid derivatives with different C-3 substituent groups, including C3-acyl-linear side chains (simple 3-ATAs, cladosporiumins E-H and their Na complexes, cladosporiumins N-O, and L [31])), C3-dienoyl (cladosporiumin M [32]), pyrano[3,2-b] pyrone (cladosporiumins J and K [32]) (244 and 245), C3-pyrane ring (cladosporiumin I, and cladodionen [32]) (246 and 247), C3- linear side chains and pyran rings (cladosporiumins A-C [31], I' and J' [91]) (248-250, 252, and 253) and its tetramate precursor (cladosporiumin D [31]) (251), and C-3-imine-TA (cladosins A-K) (254-263). Notably, some of these compounds have special structures. For example, 248-250, 252, and 253 have a quaternary (C-3) center carrying a trans-hexylenic alcohol side chain and a six-membered lactone ring [31,91]. The pharmacological results showed that only compound $\mathbf{2 4 7}$ had cytotoxic activities against four HTCLs (MCF-7, HeLa, HCT-116, and HL-60), with IC $_{50}$ values of 18.7, 19.1, 17.9, and 9.1 $\mu \mathrm{M}$ [198]. However, cladosporiumins I' - J' (252-253), and other cladosporiumins displayed weak or no cytotoxicity against the four breast HTCLs [31,91].

Ten cladosins (A-D, and F-K) (254-263), a series of C-3-imine-TA analogues, were found in deep-sea-derived C. sphaerospermum. Cladosins 254-257 were discovered from deep-sea-derived C. sphaerospermum 2005-01-E3 cultured with a rice-based medium [199]. Following the OSMAC method, cladosins F-G (258-259) were isolated from the soybean-based medium fermentation of this strain [200]. Using a SAHA (suberanilohydroxamic acid)-based epigenetic modification strategy, cladosins $\mathrm{H}-\mathrm{K}$ (260-263), bearing an aniline-tetramic acid moiety, and a related compound, cladodionen, were obtained from the deep-sea-derived fungus, C. sphaerospermum L3P3, by the same group [201]. All of the cladosins existed as one pair of tautomeric mixtures, differing in their enamine configurations. Among them, 254-256 and 258-262 were isolated as an inseparable equilibrium mixture of two geometric isomers, exo-form $\mathrm{A}\left(\Delta^{3(6)}: E\right)$ and exo-form $\mathrm{B}\left(\Delta^{3(6)}: Z\right)$, with a ratio of $5: 3$, but 257 was opposite to the ratio of the tautomers [199-201]. Among the bioactivities of the cladosins, only 256 displayed mild anti-influenza A H1N1 virus activity with 254-259 [199,200], but the cladosins with an aniline moiety (260-263) showed enhanced cytotoxicity, especially $\mathbf{2 6 1}$, which presented promising cytotoxicity against the HL-60 cell line $\left(\mathrm{IC}_{50}=2.8 \mu \mathrm{M}\right)$ [201]. The deep-sea fungus Phomopsis tersa produced tersone $F$ (264), which was devoid of cytotoxic activities [202].

Lajollamycins, featuring a unique scaffold consisting of a 5 -spiro- $\beta$-lactone- $\gamma$-lactam ring and a nitro-tetraene group, were mainly isolated from a Streptomyces strain. The culture fermentation of Streptomyces nodosus (NPS007994) from marine sediment yielded lajollamycin (265), which showed antimicrobial activity against E.coli and three pairs of drug-sensitive and -resistant Gram-positive bacteria $(\mathrm{MIC}=1.5-20 \mu \mathrm{g} / \mathrm{mL})$ and inhibited the growth of B16-F10 tumor cells $\left(\mathrm{EC}_{50}=9.6 \mu \mathrm{M}\right)$ [203]. Another marine-derived Streptomyces sp., SMC72, isolated from a seashore sediment sample, produced a series of lajollamycin derivatives, including lajollamycins B-D (266-268) and lajollamycin (265), which displayed moderate inhibitory activities against Candida albicans isocitrate lyase (ICL) [204].

Streptopyrrolidine (270) was sourced as a metabolite of the marine-derived Streptomyces sp. KORDI-3973 and displayed significant anti-angiogenesis activity [205]. Spinoxazine A (270), with 
a $\gamma$-lactam moiety and a 1,3-oxazin-6-one system, was obtained from marine-derived Streptomyces spinoverrucosus collected in the Bahamas and lacked bioactivity against four HTCLs and two bacterial strains [206].

Epolactaene (271), with a long-chain-substituted $\gamma$-lactam group, was discovered from the marine fungus Penicillium sp. BM 1689-P and displayed neuritogenic properties by arresting the cell cycle at the G0/G1 phase and inducing the outgrowth of neurites in human neuroblastoma SH-SY5Y cells [207], selectively inhibiting the activities of mammalian DNA polymerases $\alpha$ and $\beta$ as well as human DNA topoisomerase II [208], and could combine with Hsp60 as a Michael acceptor to inhibit Hsp60 chaperone activity [209,210]. Pulchellalactam (272) was reported from the marine-derived-fungus Corollospora pulchella and was used as a selective inhibitor of the CD45 protein, tyrosine phosphatase [211].

When screened for antiprotozoal activity from a marine cyanobacterium, Oscillatoria sp. yielded hoshinolactam (273), which showed potent antitrypanosomal activity against Trypanosoma brucei brucei GUT, with an $\mathrm{IC}_{50}$ value of $3.9 \mathrm{nM}$ (equivalent to the positive control pentamidine: $\mathrm{IC}_{50}=4.7 \mathrm{nM}$ ) and no cytotoxicity against MRC-5 cells $\left(\mathrm{IC}_{50}>25 \mu \mathrm{M}\right)$ [212].

The 3-(2-amino-phenyl)-5-methoxy-1,5-dihydro-pyrrol-2-one (274) was identified as a metabolite of a novel marine bacterium Rapidithrix thailandica and displayed moderate but selective antibacterial activity against VRE [213].

Andrimid (275), moiramides B-C (276-277), and their precursor, moiramide A, were produced by the bacterium Pseudomonas fluorescens, isolated from marine tunicates [214]. In contrast to moiramide A and 277, both 275 and 276 showed antibacterial activity, highlighting that the intact succinimide moiety is the critical pharmacophore [214]. Compound 275 was active in inhibiting MRSA (MIC: $2 \mu \mathrm{g} / \mathrm{mL}$ ) and $V R E(32 \mu \mathrm{g} / \mathrm{mL})$, while $\mathbf{2 7 6}$, the congener with the shortest polyene chain, was more potent in its inhibition against both MRSA $(0.5 \mu \mathrm{g} / \mathrm{mL})$ and $V R E(4 \mu \mathrm{g} / \mathrm{mL})$ [214]. Further studies revealed that 275 and $\mathbf{2 7 6}$ had broad-spectrum antibacterial activity as a class of a new potent bacterial acetyl-CoA carboxylase inhibitor, targeting its fatty acid biosynthesis [215] and highlighting the fatty acid side chain and the pyrrolidinedione moiety as the most important pharmacophores [216].

\section{Summary of Tetramic Acid Products from Marine Microbes}

TAs were sourced from a diverse range of marine microorganisms. Culturable marine fungi provided the majority of natural TAs and belonged to 25 genera (Aspergillus, Penicillium, Cladosporium, Fusarium, Trichobotrys, Alternaria, Didymella, Phoma, Chaunopycnis, Cochliobolus, Tolypocladium, Ascochyta, Xylariaceae, Lindgomycetaceae, Zopfiella, Beauveria, Corollospora, Epicoccum, Nigrospora, Phomopsis, Pleosporale, Pseudallescheria, Trichoderma, Westerdykella, Microdiplodia, and unknown fungi). Other sources were from Actinobacteria (four genera, Streptomyces, Actinoalloteichus, Amycolatopsis, Micromonospora,), Cyanobacteria (seven families, Moorea producens, Oscillatoria, Symploca, Caldora, Schizothrix, Symploca, Okeania, and unidentified assemblages), and Bacteria (six genera, Rapidithrix, Pseudomonas, Vibrio, Bacillus, Alteromonas, and Pseudoalteromonas). Fungi were the dominant producers of the 277 TAs, with $61 \%$ of marine microbe-derived TAs from fungi (25 fungal genera), 19\% from Actinobacteria $(86.5 \%$ from the genus of Streptomyces), 16\% from Cyanobacteria (mainly from Moorea producens, formerly named as Lyngbya majuscula), and only 4\% from Bacteria (Figure 11a), with marine fungi consistently observed to be the dominant source of MNPs in the last ten years [10,11]. Within the individual fungi groups, the Aspergillus (29\%), Penicillium (22\%), and Cladosporium (17\%) species were the predominant fungal sources of TAs (Figure 11b). Based on an analysis of the relationship between the different chemical groups of TAs and their producers (Figure 11), it can be concluded that the positive correlation between the structures of metabolites and their producer microbes is related to their special BGCs. As seen in Figure 12, fungi can produce significant classes of compounds, including simple 3-ATA (96\% of this class of compounds, mainly from Penicillium, Cladosporium, and Aspergillus), 3-STA (97\%, mostly from Aspergillus), CPA-type TAs (92\%, mostly from Aspergillus and Penicillium), 3-DTA (86\%, from 12 species), others (74\%, mainly from Cladosporium and Aspergillus), MTAs (40\%, all PTAs, mainly from Penicillium, and Didymella), and 3-OTA (23\%, from Aspergillus and Cladosporium). All of the N-acylated 
TAs were produced by cyanobacteria (mostly from Moorea producens) as their marker compounds. Actinobacteria (mostly Streptomyces) can provide five groups of TAs: 3-OTA (77\%, from Streptomyces), MTAs (51\%, mainly PTMs, mainly from Streptomyces), 3-DTA (14\%, mainly from Streptomyces), others (14\%, all from Streptomyces), and 3-STA (3\%, from Amycolatopsis).

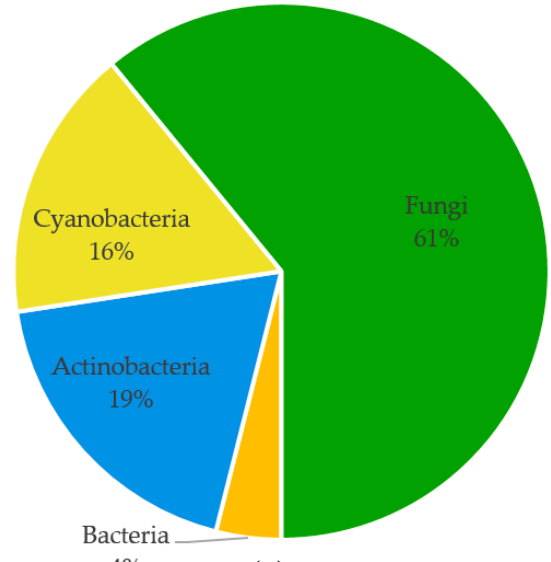

(a)

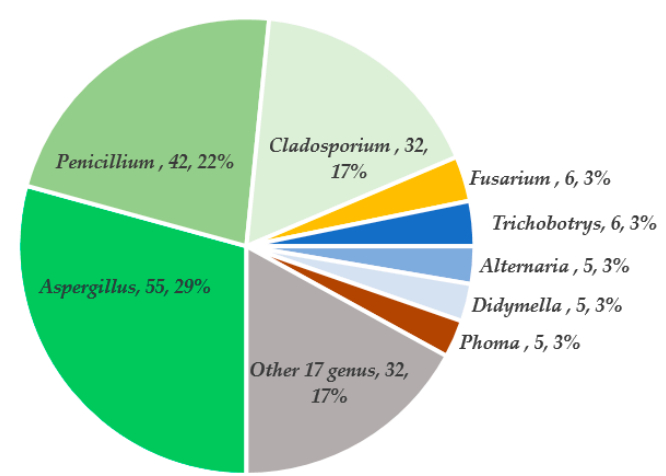

(b)

Figure 11. (a) The tetramic acids (TAs) from marine microorganisms in this review divided by the origin of microorganisms, indicating that fungi are the dominant source. (b) The pie chart provides more in-depth insight into the fungi.

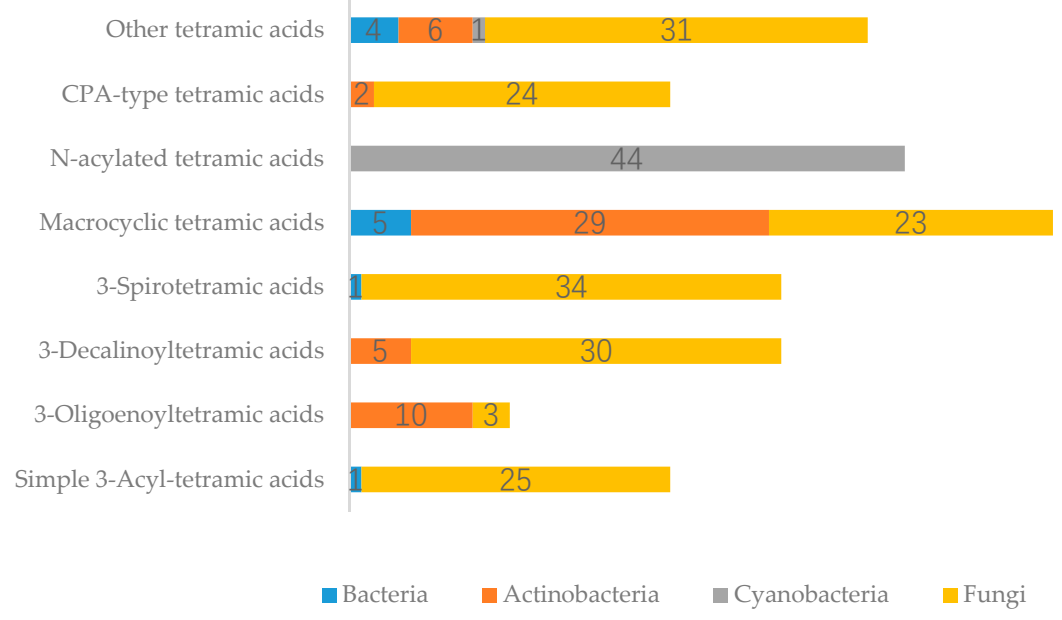

Figure 12. The relationship between different chemical groups of TAs and their producer (marine microorganisms). This number corresponds to the number of TA compounds in different chemical classes.

When looking at the habitats/sources of these marine microorganisms for TAs in Figure 13, 56\% of the compounds were isolated from marine environments (i.e., marine sediments $(41 \%)$, and seawater $(15 \%)$ (mainly cyanobacteria)), while the remaining compounds were obtained from living matter, i.e., marine animals $(30 \%)$ and aquatic plants $(12 \%)$. Within the individual groups, other marine sediments ( $25 \%)$, seawater $(15 \%)$, deep-sea sediments $(13 \%)$, mangrove habitats $(11 \%)$, sponges $(9 \%)$, and crustaceans $(6 \%)$ were the most predominant sources of microorganisms. A newly emerging source is the extreme environment, i.e., deep-sea sediments (13\%), which can produce structurally unique metabolites. 


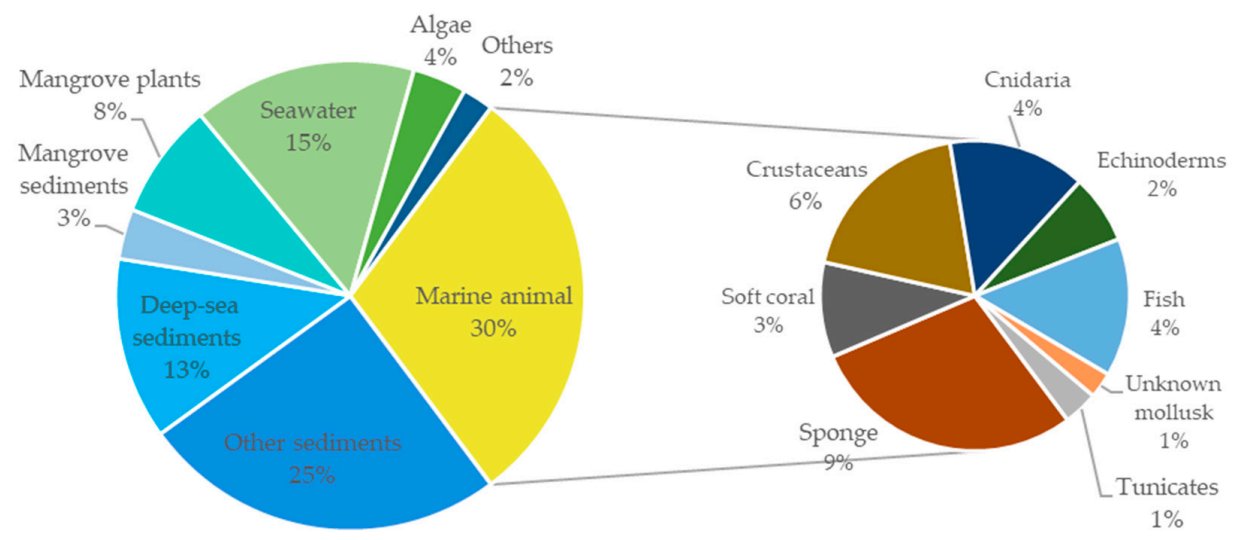

Figure 13. The TAs from marine microorganisms were divided by their sources (habitats); 277 TAs were isolated from 120 species of microorganisms in 120 habitats.

In the bioassay of the 261 tetramic acids (94.2\% compounds) from marine microorganisms, $77.4 \%$ of compounds (202) displayed various activities $(n=327)$ and, on average, exhibited 1.62 activities per bioactive-TA. This result is because some compounds presented various activities and were counted in more than one category. The ten major bioactivities are listed in Figure 14 (cytotoxicity, antibacterial, antifungal, antiviral, antiprotozoal, lethality-toxicity, phytotoxicity, anti-inflammatory, and antioxidant activities, as well as special protease enzyme inhibition activities). Cytotoxicity (40\%) was the most significant pharmacological activity, with up to 132 compounds among the 327 listed compounds, which inhibited the proliferation of different tumor cell lines in vitro, followed by anti-infective/antimicrobial activities (30\%), including antibacterial activities for 57 compounds (17\%), antifungal activities for 30 compounds (9\%), and antiviral activities for 14 compounds (4\%). This result is consistent with the focus of medical research, as tumors and infectious diseases remain the primary threat to human health in modern society. Other selected major activities included lethality-toxicity for 18 compounds (5\%), special protease inhibition for 15 compounds (5\%), and antiprotozoal activity for 10 compounds (3\%).

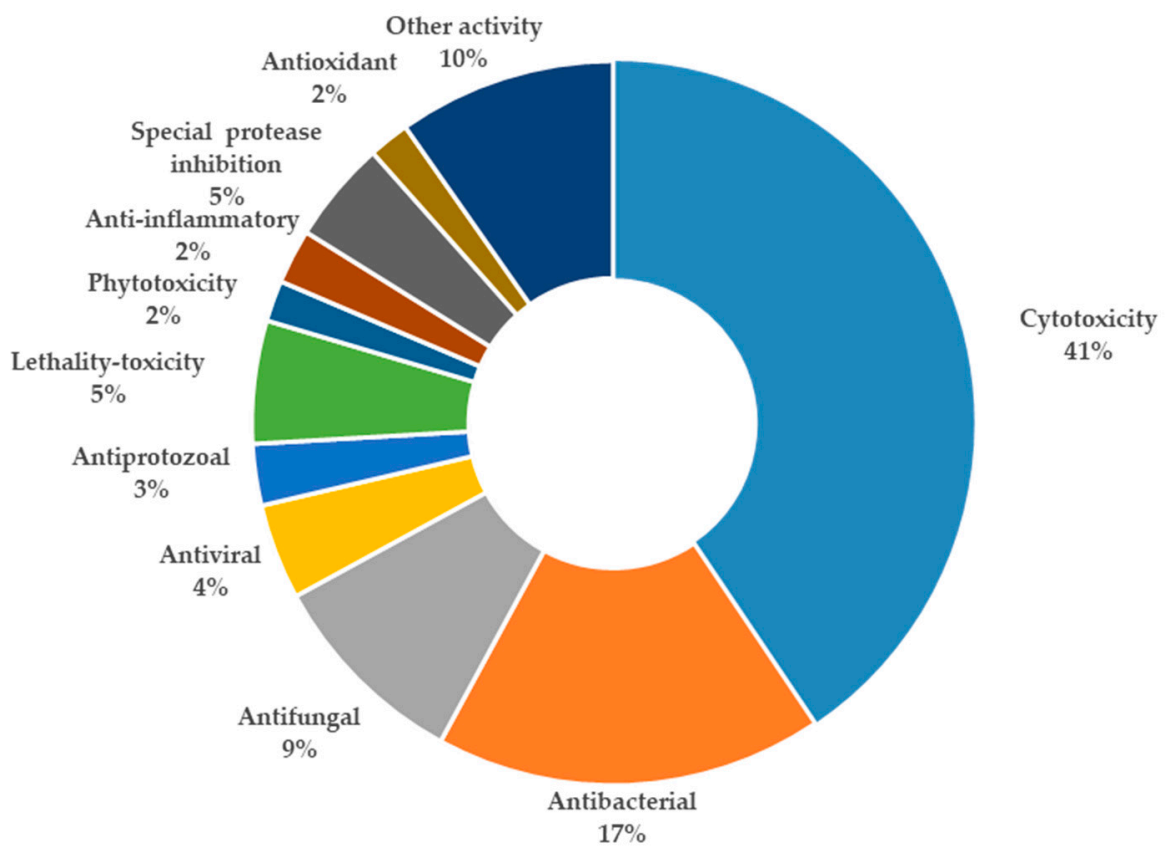

Figure 14. The percentage represents the proportion of one activity compared to the whole occurrence of activities of 202 bioactive TAs from marine microorganisms $(n=327)$. Some compounds present various activities and are counted in more than one category. 
The number of different chemical classes of TAs displaying each bioactivity is shown in Figure 15. The bioactivities of the compounds were evaluated for different targets, ranging from a specific cellular mechanism to the entire organism. For example, the inhibitory activity of special protease was shown to target enzymatic processes when antiprotozoal, lethality-toxicity, phytotoxicity, and antimicrobial activity were tested against whole organisms. Further, cytotoxicity was based on the cell line level, and some research is related to their specific cellular and molecular mechanisms; anti-inflammatory and antioxidant activities are mainly assessed on the basis of specific cellular mechanisms, which may also be included in cytotoxicity and other activities. The present analysis confirms the preceding observations (i.e., that cytotoxicity is the most common bioactivity, followed by antibacterial and antifungal activity). Some activities were displayed only for certain compounds: phytotoxicity involved only 3-D TAs; lethality-toxicity involved only $N$-acylated TAs and CPA-type TAs; anti-inflammatory activity was observed for 3-STAs, $N$-acylated TAs, and other TAs; and antioxidant activity was observed for 3-STAs, MTAs, and other TAs. For the chemical classes, no specific activities were observed for one chemical class concerning different types. Four chemical classes (3-STAs, 3-DTAs, N-acylated TAs, and MTAs) seem to present a relatively more extensive set of activities.

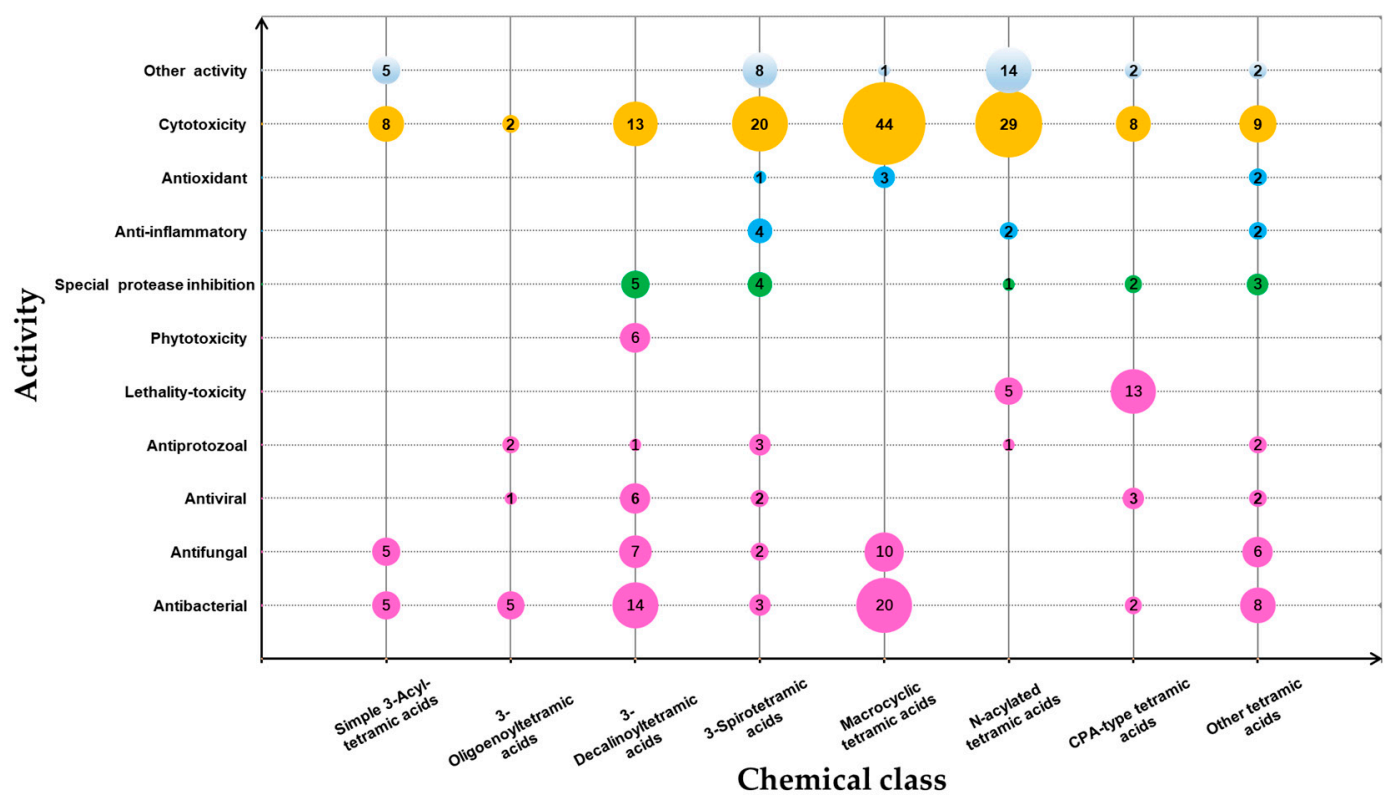

Figure 15. Classification of the 202 bioactive TAs according to their activities and chemical classes. The number of compounds is symbolized by the disc diameters for each bioactivity and each chemical class. The colors correspond to the different categories of the activity targets. Gray represents a mixed target; yellow mainly represents a cell line target, blue primarily represents the specific cellular mechanism, green represents the enzyme target, and purple represents the entire organism target.

\section{Conclusions and Outlooks}

This review has provided a comprehensive overview of 277 tetramic acid products from 120 marine-derived microbes (containing fungi, actinobacteria, bacteria, and cyanobacteria), presented by their structural characteristics and covering up to September 2019, with 195 research publications related to tetramic acids and their bioactivities. Marine fungi are the dominant source of the rapidly increasing numbers of TAs, of which the Aspergillus, Penicillium, Cladosporium species are the predominant marine microbe sources of TAs. Most TAs (77.4\%) displayed various pharmacological activities, especially cytotoxicity (40\%). Interestingly, deep-sea sediment-derived fungi have become an essential source of the unique structure of bioactive tetramic acids.

As microbial-derived compounds will almost certainly dominate the MNP field in the coming sesquidecade [11], the tetramic acid compounds from marine-derived microorganisms will reveal 
increasingly greater biological and chemical diversity. Because of the relative ease of collecting marine microbes, a wide variety of approaches for natural product discovery (including metagenomics and genome mining approaches, the heterologous expression method, the OSMAC approach, and chemical epigenetic modification) can be used, as well as advanced and combinational methods for metabolite identification, and several public, private, and commercial databases for rapid dereplication. The various pharmacological properties displayed by TAs with intriguing structures provide medicinal chemists with a variety of potential lead compounds for the development of marine drugs.

Supplementary Materials: The following are available online at http://www.mdpi.com/1660-3397/18/2/114/s1, Table S1: The tetramic acid compounds from marine-derived microorganisms.

Author Contributions: S.C. and M.J. conceived and designed the format of the manuscript. S.C. and M.J. analyzed the data, and drafted and edited the manuscript. S.C. and M.J. drew the chemical structure of compounds. S.C., L.L., and J.L. reviewed the manuscript. All the authors contributed to the critical reading and discussion of the manuscript. All authors have read and agreed to the published version of the manuscript.

Funding: This work was financially supported by the National Natural Science Foundation of China (Grant No. 41806155), Guangdong MEPP Fund [NO.GDOE (2019) A21]; Special Fund for Economic Development of Guangdong Province (Uses for Marine Economic Development) (GDME-2018C004); Natural Science Foundation of Guangdong Province (Grant No. 2018A030310304).

Conflicts of Interest: The authors declare no conflicts of interest.

\section{References}

1. Royles, B.J. Naturally occurring tetramic acids: Structure, isolation, and synthesis. Chem. Rev. 1995, 95, 1981-2001. [CrossRef]

2. Ghisalberti, E.L. Bioactive Tetramic Acid Metabolites. In Studies in Natural Products Chemistry; Elsevier: Amsterdam, The Netherlands, 2003; Volume 28, pp. 109-163.

3. Gossauer, A. Monopyrrolic natural compounds including tetramic acid derivatives. Chem. Org. Nat. 2003, 86, 1-188.

4. Schobert, R.; Schlenk, A. Tetramic and tetronic acids: An update on new derivatives and biological aspects. Bioorg. Med. Chem. 2008, 16, 4203-4221. [CrossRef]

5. Mo, X.; Li, Q.; Ju, J. Naturally occurring tetramic acid products: Isolation, structure elucidation and biological activity. RSC Adv. 2014, 4, 50566-50593. [CrossRef]

6. Boettger, D.; Hertweck, C. Molecular diversity sculpted by fungal PKS-NRPS hybrids. Chembiochem. 2013, 14, 28-42. [CrossRef]

7. Fisch, K.M. Biosynthesis of natural products by microbial iterative hybrid PKS-NRPS. RSC Adv. 2013, 3, 18228-18247. [CrossRef]

8. Li, X.W.; Ear, A.; Nay, B. Hirsutellones and beyond: Figuring out the biological and synthetic logics toward chemical complexity in fungal PKS-NRPS compounds. Nat. Prod. Rep. 2013, 30, 765-782. [CrossRef] [PubMed]

9. Zhang, G.; Zhang, W.; Saha, S.; Zhang, C. Recent advances in discovery, biosynthesis and genome mining of medicinally relevant polycyclic tetramate macrolactams. Curr. Top. Med. Chem. 2016, 16, 1727-1739. [CrossRef] [PubMed]

10. Carroll, A.R.; Copp, B.R.; Davis, R.A.; Keyzers, R.A.; Prinsep, M.R. Marine natural products. Nat. Prod. Rep. 2019, 36, 122-173. [CrossRef] [PubMed]

11. Raimundo, I.; Silva, S.G.; Costa, R.; Keller-Costa, T. Bioactive Secondary Metabolites from Octocoral-Associated Microbes-New Chances for Blue Growth. Mar. Drugs 2018, 16, 485. [CrossRef] [PubMed]

12. Jessen, H.J.; Gademann, K. 4-Hydroxy-2-pyridone alkaloids: Structures and synthetic approaches. Nat. Prod. Rep. 2010, 27, 1168-1185. [CrossRef] [PubMed]

13. Scherlach, K.; Boettger, D.; Remme, N.; Hertweck, C. The chemistry and biology of cytochalasans. Nat. Prod. Rep. 2010, 27, 869-886. [CrossRef] [PubMed]

14. Tao, W.; Zhu, M.; Deng, Z.; Sun, Y. Biosynthesis of tetronate antibiotics: A growing family of natural products with broad biological activities. Sci. China Chem. 2013, 56, 1364-1371. [CrossRef] 
15. Vieweg, L.; Reichau, S.; Schobert, R.; Leadlay, P.F.; Süssmuth, R.D. Recent advances in the field of bioactive tetronates. Nat. Prod. Rep. 2014, 31, 1554-1584. [CrossRef] [PubMed]

16. Skellam, E. The biosynthesis of cytochalasans. Nat. Prod. Rep. 2017, 34, 1252-1263. [CrossRef] [PubMed]

17. Imamura, N.; Adachi, K.; Sano, H. Magnesidin A, a component of marine antibiotic magnesidin, produced by Vibrio gazogenes ATCC29988. J. Antibiot. 1994, 47, 257-261. [CrossRef] [PubMed]

18. Gandhi, N.; Nazareth, J.; Divekar, P.; Kohl, H.; De Souza, N. Magnesidin, a novel magnesium-containing antibiotic. J. Antibiot. 1973, 26, 797-798. [CrossRef]

19. Wright, A.D.; Osterhage, C.; Konig, G.M. Epicoccamide, a novel secondary metabolite from a jellyfish-derived culture of Epicoccum purpurascens. Org. Biomol. Chem. 2003, 1, 507-510. [CrossRef]

20. Lin, Z.-J.; Lu, Z.-Y.; Zhu, T.-J.; Fang, Y.-C.; Gu, Q.-Q.; Zhu, W.-M. Penicillenols from Penicillium sp. GQ-7, an endophytic fungus associated with Aegiceras corniculatum. Chem. Pharm. Bull. 2008, 56, 217-221. [CrossRef]

21. Zhang, Q.-Q.; Chen, L.; Hu, X.; Gong, M.-W.; Zhang, W.-W.; Zheng, Q.-H.; Liu, Q.-Y. Novel Cytotoxic Metabolites from the Marine-derived Fungus Trichoderma citrinoviride. Heterocycles 2014, 89, 189-196.

22. Zhang, Q.-Q.; Chen, L.; Zhou, T.; Zhao, Y.-Y.; Gong, M.-W.; Xia, Q.-W.; Ying, M.-G.; Zheng, Q.-H.; Liu, Q.-Y. Four New Penicitrinols and Two New Penicillenols from the Marine-Derived Fungus Penicillium citrinum. Heterocycles 2015, 91, 1007-1016.

23. Kempf, K.; Schmitt, F.; Bilitewski, U.; Schobert, R. Synthesis, stereochemical assignment, and bioactivity of the Penicillium metabolites penicillenols B1 and B2. Tetrahedron 2015, 71, 5064-5068. [CrossRef]

24. Zhang, Q.-Q.; Chen, L.; Huang, K.; Zhong, P.; Hu, X.; Fang, Z.-X.; Wu, J.-L. Tumonoic Acids K and L, Novel Metabolites from the Marine-Derived Fungus Penicillium citrinum. Heterocycles 2012, 85, 413-419.

25. Wang, J.-F.; Qin, X.; Xu, F.-Q.; Zhang, T.; Liao, S.; Lin, X.; Yang, B.; Liu, J.; Wang, L.; Tu, Z.; et al. Tetramic acid derivatives and polyphenols from sponge-derived fungus and their biological evaluation. Nat. Prod. Res. 2015, 29, 1761-1765. [CrossRef] [PubMed]

26. Wang, J.; Yao, Q.F.; Amin, M.; Nong, X.H.; Zhang, X.Y.; Qi, S.H. Penicillenols from a deep-sea fungus Aspergillus restrictus inhibit Candida albicans biofilm formation and hyphal growth. J. Antibiot. 2017, 70, 763-770. [CrossRef] [PubMed]

27. Liu, Q.Y.; Zhou, T.; Zhao, Y.Y.; Chen, L.; Gong, M.W.; Xia, Q.W.; Ying, M.G.; Zheng, Q.H.; Zhang, Q.Q. Antitumor Effects and Related Mechanisms of Penicitrinine A, a Novel Alkaloid with a Unique Spiro Skeleton from the Marine Fungus Penicillium citrinum. Mar. Drugs 2015, 13, 4733. [CrossRef]

28. Shang, Z.; Li, L.; Esposito, B.P.; Salim, A.A.; Khalil, Z.G.; Quezada, M.; Bernhardt, P.V.; Capon, R.J. New PKS-NRPS tetramic acids and pyridinone from an Australian marine-derived fungus, Chaunopycnis sp. Org. Biomol. Chem. 2015, 13, 7795-7802. [CrossRef]

29. Nakada, T.; Nakajima, M.; Kobayashi, H.; Takahashi, M.; Tanaka, I. Novel compound F-14329, its manufacture, Chaunopycnis species producing the compound, and its use for pharmaceuticals. Japanese Kokai Tokkyo Koho JP2007-153840, 21 June 2007.

30. Kebede, B.; Wrigley, S.K.; Prashar, A.; Rahlff, J.; Wolf, M.; Reinshagen, J.; Gribbon, P.; Imhoff, J.F.; Silber, J.; Labes, A.; et al. Establishing the Secondary Metabolite Profile of the Marine Fungus: Tolypocladium geodes sp. MF458 and Subsequent Optimisation of Bioactive Secondary Metabolite Production. Mar. Drugs 2017, 15, 84. [CrossRef]

31. Huang, Z.-H.; Nong, X.-H.; Liang, X.; Qi, S.-H. New tetramic acid derivatives from the deep-sea-derived fungus Cladosporium sp. SCSIO z0025. Tetrahedron 2018, 74, 2620-2626. [CrossRef]

32. Liang, X.; Huang, Z.-H.; Ma, X.; Qi, S.-H. Unstable tetramic acid derivatives from the deep- sea-derived fungus Cladosporium sphaerospermum EIODSF 008. Mar. Drugs 2018, 16, 448. [CrossRef]

33. Lin, Y.; Wang, L.; Wang, Y.; Wang, W.; Hao, J.; Zhu, W. Bioactive Natural Products of Aspergillus sp. OUCMDZ-1914, an Aciduric Fungus from the Mangrove Soils. Chin. J. Org. Chem. 2015, 35, 1955-1960. [CrossRef]

34. Reusser, F. Tirandamycin, an inhibitor of bacterial ribonucleic acid polymerase. Antimicrob. Agents Chem. 1976, 10, 618-622. [CrossRef] [PubMed]

35. Reusser, F. Tirandamycin: Inhibition of oxidative phosphorylation in rat liver mitochondria. Infect. Immun. 1970, 2, 82-88. [CrossRef] [PubMed]

36. Ogasawara, Y.; Kondo, K.; Ikeda, A.; Harada, R.; Dairi, T. Identification of tirandamycins as specific inhibitors of the futalosine pathway. J. Antibiot. 2017, 70, 798-800. [CrossRef] 
37. Carlson, J.C.; Li, S.; Burr, D.A.; Sherman, D.H. Isolation and characterization of tirandamycins from a marine-derived Streptomyces sp. J. Nat. Prod. 2009, 72, 2076-2079. [CrossRef]

38. Duan, C.; Yao, Y.; Wang, Z.; Tian, X.; Zhang, S.; Zhang, C.; Ju, J. Fermentation optimization, isolation and identification of tirandamycins A and B from marine-derived Streptomyces sp. SCSIO 1666. Chin. J. Mar. Drugs 2010, 29, 12-20.

39. Huang, X.; Kong, F.; Zhou, S.; Huang, D.; Zheng, J.; Zhu, W. Streptomyces tirandamycinicus sp. nov., a novel marine sponge-derived actinobacterium with antibacterial potential against Streptococcus agalactiae. Front. Microbiol. 2019, 10, 482-492. [CrossRef]

40. Rateb, M.E.; Yu, Z.; Yan, Y.; Yang, D.; Huang, T.; Vodanovic-Jankovic, S.; Kron, M.A.; Shen, B. Medium optimization of Streptomyces sp. 17944 for tirandamycin B production and isolation and structural elucidation of tirandamycins H., I and J. J. Antibiot. 2014, 67, 127-132. [CrossRef]

41. Espinosa, A.; Socha, A.M.; Ryke, E.; Rowley, D.C. Antiamoebic properties of the actinomycete metabolites echinomycin A and tirandamycin A. Parasitol. Res. 2012, 111, 2473-2477. [CrossRef]

42. Cong, Z.; Huang, X.; Liu, Y.; Liu, Y.; Wang, P.; Liao, S.; Yang, B.; Zhou, X.; Huang, D.; Wang, J. Cytotoxic anthracycline and antibacterial tirandamycin analogues from a marine-derived Streptomyces sp. SCSIO 41399. J. Antibiot. 2019, 72, 45-49. [CrossRef]

43. Mo, X.; Wang, Z.; Wang, B.; Ma, J.; Huang, H.; Tian, X.; Zhang, S.; Zhang, C.; Ju, J. Cloning and characterization of the biosynthetic gene cluster of the bacterial RNA polymerase inhibitor tirandamycin from marine-derived Streptomyces sp. SCSIO1666. Biochem. Biophys. Res. Commun. 2011, 406, 341-347. [CrossRef] [PubMed]

44. Mo, X.; Ma, J.; Huang, H.; Wang, B.; Song, Y.; Zhang, S.; Zhang, C.; Ju, J. Delta(11,12) double bond formation in tirandamycin biosynthesis is atypically catalyzed by TrdE, a glycoside hydrolase family enzyme. J. Am. Chem. Soc. 2012, 134, 2844-2847. [CrossRef] [PubMed]

45. Mo, X.; Huang, H.; Ma, J.; Wang, Z.; Wang, B.; Zhang, S.; Zhang, C.; Ju, J. Characterization of TrdL as a 10-hydroxy dehydrogenase and generation of new analogues from a tirandamycin biosynthetic pathway. Org. Lett. 2011, 13, 2212-2215. [CrossRef] [PubMed]

46. Zhang, X.; Li, Z.; Du, L.; Chlipala, G.E.; Lopez, P.C.; Zhang, W.; Sherman, D.H.; Li, S. Identification of an unexpected shunt pathway product provides new insights into tirandamycin biosynthesis. Tetrahedron Lett. 2016, 57, 5919-5923. [CrossRef] [PubMed]

47. Zhao, D.; Han, X.; Wang, D.; Liu, M.; Gou, J.; Peng, Y.; Liu, J.; Li, Y.; Cao, F.; Zhang, C. Bioactive 3-decalinoyltetramic acids derivatives from a marine-derived strain of the fungus Fusarium equiseti D39. Front. Microbiol. 2019, 10, 1285-1294. [CrossRef] [PubMed]

48. Luo, M.; Ming, Y.; Wang, L.; Li, Y.; Li, B.; Chen, J.; Shi, S. Local delivery of deep marine fungus-derived equisetin from polyvinylpyrrolidone (PVP) nanofibers for anti-MRSA activity. Chem. Eng. J. 2018, 350, 157-163. [CrossRef]

49. Osterhage, C.; Kaminsky, R.; König, G.M.; Wright, A.D. Ascosalipyrrolidinone a, an antimicrobial alkaloid, from the obligate marine fungus Ascochyta s alicorniae. J. Org. Chem. 2000, 65, 6412-6417. [CrossRef]

50. Daferner, M.; Anke, T.; Sterner, O. Zopfiellamides A and B, antimicrobial pyrrolidinone derivatives from the marine fungus Zopfiella latipes. Tetrahedron 2002, 58, 7781-7784. [CrossRef]

51. Neumann, K.; Kehraus, S.; Guetschow, M.; Koenig, G.M. Cytotoxic and HLE-inhibitory tetramic acid derivatives from marine-derived fungi. Nat. Prod. Commun. 2009, 4, 347-354. [CrossRef]

52. Yang, S.W.; Mierzwa, R.; Terracciano, J.; Patel, M.; Gullo, V.; Wagner, N.; Baroudy, B.; Puar, M.; Chan, T.M.; McPhail, A.T.; et al. Chemokine receptor CCR-5 inhibitors produced by Chaetomium globosum. J. Nat. Prod. 2006, 69, 1025-1028. [CrossRef]

53. Sun, Y.-L.; Wang, J.; Wang, Y.-F.; Zhang, X.-Y.; Nong, X.-H.; Chen, M.-Y.; Xu, X.-Y.; Qi, S.-H. Cytotoxic and antiviral tetramic acid derivatives from the deep-sea-derived fungus Trichobotrys effusa DFFSCS021. Tetrahedron 2015, 71, 9328-9332. [CrossRef]

54. Wu, B.; Wiese, J.; Labes, A.; Kramer, A.; Schmaljohann, R.; Imhoff, J.F. Lindgomycin, an unusual antibiotic polyketide from a marine fungus of the Lindgomycetaceae. Mar Drugs 2015, 13, 4617-4632. [CrossRef]

55. Ondeyka, J.G.; Smith, S.K.; Zink, D.L.; Vicente, F.; Basilio, A.; Bills, G.F.; Polishook, J.D.; Garlisi, C.; McGuinness, D.; Smith, E.; et al. Isolation, structure elucidation and antibacterial activity of a new tetramic acid, ascosetin. J. Antibiot. 2014, 67, 527-531. [CrossRef] [PubMed] 
56. Grunwald, A.L.; Berrué, F.; Overy, D.P.; Kerr, R.G. Isolation of iqalisetins A and B from a Tolypocladium sp. isolated from marine sediment from Frobisher Bay in Canada's arctic. Can. J. Chem. 2016, 94, 444-448. [CrossRef]

57. Furumai, T.; Eto, K.; Sasaki, T.; Higuchi, H.; Onaka, H.; Saito, N.; Fujita, T.; Naoki, H.; Igarashi, Y. TPU-0037-A, B, C and D, novel lydicamycin congeners with anti-MRSA activity from Streptomyces platensis TP-A0598. J. Antibiot. 2002, 55, 873-880. [CrossRef]

58. Hayakawa, Y.; Kanamaru, N.; Shimazu, A.; Seto, H. Lydicamycin, a new antibiotic of a novel skeletal type. I. Taxonomy, fermentation, isolation and biological activity. J. Antibiot. 1991, 44, 282-287. [CrossRef]

59. Amagata, T.; Xiao, J.; Chen, Y.P.; Holsopple, N.; Oliver, A.G.; Gokey, T.; Guliaev, A.B.; Minoura, K. Creation of an HDAC-based yeast screening method for evaluation of marine-derived actinomycetes: Discovery of streptosetin A. J. Nat. Prod. 2012, 75, 2193-2199. [CrossRef]

60. Wang, P.; Cui, Y.; Cai, C.; Chen, H.; Dai, Y.; Chen, P.; Kong, F.; Yuan, J.; Song, X.; Mei, W.; et al. Two New Succinimide Derivatives Cladosporitins A and B from the Mangrove-derived Fungus Cladosporium sp. HNWSW-1. Mar. Drugs 2018, 17, 4. [CrossRef]

61. Yamada, T.; Kikuchi, T.; Tanaka, R. Altercrasin A, a novel decalin derivative with spirotetramic acid, produced by a sea urchin-derived Alternaria sp. Tetrahedron Lett. 2015, 56, 1229-1232. [CrossRef]

62. Yamada, T.; Tanaka, A.; Nehira, T.; Nishii, T.; Kikuchi, T. Altercrasins A-E, Decalin Derivatives, from a Sea-Urchin-Derived Alternaria sp.: Isolation and Structural Analysis Including Stereochemistry. Mar. Drugs 2019, 17, 218. [CrossRef]

63. Jang, J.H.; Asami, Y.; Jang, J.P.; Kim, S.O.; Moon, D.O.; Shin, K.S.; Hashizume, D.; Muroi, M.; Saito, T.; Oh, H.; et al. Fusarisetin A, an acinar morphogenesis inhibitor from a soil fungus, Fusarium sp. FN080326. J. Am. Chem. Soc. 2011, 133, 6865-6867. [CrossRef]

64. Caro-Diaz, E.J.; Aung, A.; Xu, J.; Varghese, S.; Theodorakis, E.A. Fusarisetins: Structure-function studies on a novel class of cell migration inhibitors. Org. Chem. Front. 2014, 1, 135-139. [CrossRef] [PubMed]

65. Xu, J.; Caro-Diaz, E.J.; Lacoske, M.H.; Hung, C.I.; Jamora, C.; Theodorakis, E.A. Fusarisetin A: Scalable Total Synthesis and Related Studies. Chem. Sci. 2012, 3, 3378-3386. [CrossRef]

66. Bloch, P.; Tamm, C.; Bollinger, P.; Petcher, T.J.; Weber, H.P. Pseurotin, a New Metabolite of Pseudeurotium ovalis STOLK Having an Unusual Hetero-Spirocyclic System. Helv. Chim. Acta. 1976, 59, 133-137. [CrossRef]

67. Boot, C.M.; Gassner, N.C.; Compton, J.E.; Tenney, K.; Tamble, C.M.; Lokey, R.S.; Holman, T.R.; Crews, P. Pinpointing pseurotins from a marine-derived Aspergillus as tools for chemical genetics using a synthetic lethality yeast screen. J. Nat. Prod. 2007, 70, 1672-1675. [CrossRef]

68. Zhang, M.; Wang, W.-L.; Fang, Y.-C.; Zhu, T.-J.; Gu, Q.-Q.; Zhu, W.-M. Cytotoxic alkaloids and antibiotic nordammarane triterpenoids from the marine-derived fungus Aspergillus sydowi. J. Nat. Prod. 2008, 71, 985-989. [CrossRef]

69. Saraiva, N.N.; Rodrigues, B.S.; Jimenez, P.C.; Guimaraes, L.A.; Torres, M.C.; Rodrigues-Filho, E.; Pfenning, L.H.; Abreu, L.M.; Mafezoli, J.; de Mattos, M.C.; et al. Cytotoxic compounds from the marine-derived fungus Aspergillus sp. recovered from the sediments of the Brazilian coast. Nat. Prod. Res. 2015, 29, 1545-1550. [CrossRef]

70. Lee, M.S.; Wang, S.W.; Wang, G.J.; Pang, K.L.; Lee, C.K.; Kuo, Y.H.; Cha, H.J.; Lin, R.K.; Lee, T.H. Angiogenesis Inhibitors and Anti-Inflammatory Agents from Phoma sp. NTOU4195. J. Nat. Prod. 2016, 79, 2983-2990. [CrossRef]

71. Anjum, K.; Bi, H.; Chai, W.; Lian, X.Y.; Zhang, Z. Antiglioma pseurotin A from marine Bacillus sp. FS8D regulating tumour metabolic enzymes. Nat. Prod. Res. 2018, 32, 1353-1356. [CrossRef]

72. Maebayashi, Y.; Horie, Y.; Satoh, Y.; Yamazaki, M. Isolation of pseurotin A and a new pyrazine from Pseudallescheria boydii. JSM Mycotoxins 1985, 1985, 33-34. [CrossRef]

73. Wink, J. Biologically active pseurotin A and D, new metabolites from Aspergillus fumigatus, process for their preparation and their use as apomorphine antagonists. European Patent EP0546475, 16 June 2003.

74. Wenke, J.; Anke, H.; Sterner, O. Pseurotin A and 8-O-demethylpseurotin A from Aspergillus fumigatus and their inhibitory activities on chitin synthase. Biosci. Biotechnol. Biochem. 1993, 57, 961-964. [CrossRef]

75. Komagata, D.; Fujita, S.; Yamashita, N.; Saito, S.; Morino, T. Novel neuritogenic activities of pseurotin A and penicillic acid. J. Antibiot. 1996, 49, 958-959. [CrossRef] 
76. Hayashi, A.; Fujioka, S.; Nukina, M.; Kawano, T.; Shimada, A.; Kimura, Y. Fumiquinones A and B, nematicidal quinones produced by Aspergillus fumigatus. Biosci. Biotechnol. Biochem. 2007, 71, 1697-1702. [CrossRef] [PubMed]

77. Ishikawa, M.; Ninomiya, T.; Akabane, H.; Kushida, N.; Tsujiuchi, G.; Ohyama, M.; Gomi, S.; Shito, K.; Murata, T. Pseurotin A and its analogues as inhibitors of immunoglobulin E [correction of immunoglobuline E] production. Bioorg. Med. Chem. Lett. 2009, 19, 1457-1460. [CrossRef] [PubMed]

78. Martinez-Luis, S.; Cherigo, L.; Arnold, E.; Spadafora, C.; Gerwick, W.H.; Cubilla-Rios, L. Antiparasitic and anticancer constituents of the endophytic fungus Aspergillus sp. strain F1544. Nat. Prod. Commun. 2012, 7, 165-168. [CrossRef] [PubMed]

79. Pinheiro, E.A.A.; Carvalho, J.M.; dos Santos, D.C.P.; Feitosa, A.d.O.; Marinho, P.S.B.; Guilhon, G.M.S.P.; de Souza, A.D.L.; da Silva, F.M.A.; Marinho, A.M.d.R. Antibacterial activity of alkaloids produced by endophytic fungus Aspergillus sp. EJC08 isolated from medical plant Bauhinia guianensis. Nat. Prod. Res. 2013, 27, 1633-1638. [CrossRef] [PubMed]

80. Mehedi, M.A.U.; Molla, A.H.; Khondkar, P.; Sultana, S.; Islam, M.A.; Rashid, M.A.; Chowdhury, R. Pseurotin A: An Antibacterial Secondary Metabolite from Aspergillus fumigatus. Asian J. Chem. 2010, 22, 2611-2614.

81. Lu, Q.Q.; Tian, J.M.; Wei, J.; Gao, J.M. Bioactive metabolites from the mycelia of the basidiomycete Hericium erinaceum. Nat. Prod. Res. 2014, 28, 1288-1292. [CrossRef]

82. Chen, K.; Qiu, P.; Yuan, Y.; Zheng, L.; He, J.; Wang, C.; Guo, Q.; Kenny, J.; Liu, Q.; Zhao, J.; et al. Pseurotin A Inhibits Osteoclastogenesis and Prevents Ovariectomized-Induced Bone Loss by Suppressing Reactive Oxygen Species. Theranostics 2019, 9, 1634-1650. [CrossRef]

83. Wang, Y.; Li, Z.; Bai, J.; Chen, Z.; Hua, H.; Liu, T. Alkaloids from the Marine-Derived Fungus Aspergillus fumigatus YK-7 and Their Antitumor Activities. Chin. Pharm. J. 2017, 52, 1308-1312.

84. Wang, F.-Z.; Li, D.-H.; Zhu, T.-J.; Zhang, M.; Gu, Q.-Q. Pseurotin A1 and A2, two new 1-oxa-7-azaspiro[4.4]non-2-ene-4,6-diones from the holothurian-derived fungus Aspergillus fumigatus WFZ-25. Can. J. Chem. 2011, 89, 72-76. [CrossRef]

85. Yamada, T.; Ohshima, M.; Yuasa, K.; Kikuchi, T.; Tanaka, R. Assignment of the CD Cotton Effect to the Chiral Center in Pseurotins, and the Stereochemical Revision of Pseurotin A (2). Mar. Drugs 2016, 14, 74. [CrossRef] [PubMed]

86. Wink, J. Pseurotin F1/F2, new metabolites from Aspergillus fumigatus, process for their preparation and their use as apomorphine antagonists. European Patent Application JP EP546474, 16 June 1993.

87. Ren, H.; Liu, R.; Chen, L.; Zhu, T.; Zhu, W.M.; Gu, Q.Q. Two new hetero-spirocyclic gamma-lactam derivatives from marine sediment-derived fungus Aspergillus sydowi D2-6. Arch. Pharm. Res. 2010, 33, 499-502. [CrossRef] [PubMed]

88. Tao, G.-Y.; Liu, J.; Jung, J.H.; Guo, W.; Wen, X.-Q.; Liu, Y. Compounds from a jellyfish-derived fungus Aspergillus fumigates. Nat. Prod. Sci. 2016, 22, 82-86. [CrossRef]

89. Copmans, D.; Rateb, M.; Tabudravu, J.N.; Perez-Bonilla, M.; Dirkx, N.; Vallorani, R.; Diaz, C.; Perez Del Palacio, J.; Smith, A.J.; Ebel, R.; et al. Zebrafish-Based Discovery of Antiseizure Compounds from the Red Sea: Pseurotin A2 and Azaspirofuran, A. ACS Chem. Neurosci. 2018, 9, 1652-1662. [CrossRef]

90. Wakefield, J.; Hassan, H.M.; Jaspars, M.; Ebel, R.; Rateb, M.E. Dual Induction of New Microbial Secondary Metabolites by Fungal Bacterial Co-cultivation. Front. Microbiol. 2017, 8, 1284-1293. [CrossRef]

91. Rischer, M.; Lee, S.R.; Eom, H.J.; Park, H.B.; Vollmers, J.; Kaster, A.-K.; Shin, Y.-H.; Oh, D.-C.; Kim, K.H.; Beemelmanns, C. Spirocyclic cladosporicin A and cladosporiumins I and J from a Hydractinia-associated Cladosporium sphaerospermum SW67. Org. Chem. Front. 2019, 6, 1084-1093. [CrossRef]

92. Yamada, T.; Imai, E.; Nakatuji, K.; Numata, A.; Tanaka, R. Cephalimysin A, a potent cytotoxic metabolite from an Aspergillus species separated from a marine fish. Tetrahedron Lett. 2007, 48, 6294-6296. [CrossRef]

93. Yamada, T.; Kitada, H.; Kajimoto, T.; Numata, A.; Tanaka, R. The relationship between the CD Cotton effect and the absolute configuration of FD-838 and its seven stereoisomers. J. Org. Chem. 2010, 75, 4146-4153. [CrossRef]

94. Yamada, T.; Kimura, H.; Arimitsu, K.; Kajimoto, T.; Kikuchi, T.; Tanaka, R. Absolute Configuration of Eight Cephalimysins Isolated from the Marine-Derived Aspergillus fumigatus. Chem. Sel. 2017, 2, 10936-10940. [CrossRef] 
95. Yamada, T.; Kajimoto, T.; Kikuchi, T.; Tanaka, R. Elucidation of the Relationship between CD Cotton Effects and the Absolute Configuration of Sixteen Stereoisomers of Spiroheterocyclic-Lactams. Mar. Drugs 2018, 16, 223. [CrossRef] [PubMed]

96. Mizoue, K.; Okazaki, T.; Hanada, K.; Amamoto, T.; Yamagishi, M.; Omura, S. Physiologically active substance FD-838 and process for preparing the same. Europe Patent EP0216607, 1 April 1987.

97. Xu, X.; Han, J.; Wang, Y.; Lin, R.; Yang, H.; Li, J.; Wei, S.; Polyak, S.W.; Song, F. Two New Spiro-Heterocyclic gamma-Lactams from A Marine-Derived Aspergillus fumigatus Strain CUGBMF170049. Mar. Drugs 2019, 17, 289. [CrossRef] [PubMed]

98. Wang, J.; Chen, F.; Liu, Y.; Liu, Y.; Li, K.; Yang, X.; Liu, S.; Zhou, X.; Yang, J. Spirostaphylotrichin x from a marine-derived fungus as an anti-influenza agent targeting RNA polymerase PB2. J. Nat. Prod. 2018, 81, 2722-2730. [CrossRef] [PubMed]

99. Xu, D.; Luo, M.; Liu, F.; Wang, D.; Pang, X.; Zhao, T.; Xu, L.; Wu, X.; Xia, M.; Yang, X. Cytochalasan and tyrosine-derived alkaloids from the marine sediment-derived fungus Westerdykella dispersa and their bioactivities. Sci. Rep. 2017, 7, 11956. [CrossRef]

100. Quezada, M.; Licona-Cassani, C.; Cruz-Morales, P.; Salim, A.A.; Marcellin, E.; Capon, R.J.; Barona-Gomez, F. Diverse cone-snail species harbor closely related Streptomyces species with conserved chemical and genetic profiles, including polycyclic tetramic acid macrolactams. Front. Microbiol. 2017, 8, 2305-2317. [CrossRef]

101. Li, Y.; Chen, H.; Ding, Y.; Xie, Y.; Wang, H.; Cerny, R.L.; Shen, Y.; Du, L. Iterative assembly of two separate polyketide chains by the same single-module bacterial polyketide synthase in the biosynthesis of HSAF. Angew. Chem. Int. Ed. Engl 2014, 53, 7524-7530. [CrossRef]

102. Blodgett, J.A.; Oh, D.C.; Cao, S.; Currie, C.R.; Kolter, R.; Clardy, J. Common biosynthetic origins for polycyclic tetramate macrolactams from phylogenetically diverse bacteria. Proc. Natl. Acad. Sci. USA 2010, 107, 11692-11697. [CrossRef]

103. Jomon, K.; Kuroda, Y.; Ajisaka, M.; Sakai, H. A new antibiotic, ikarugamycin. J. Antibiot. 1972, 25, $271-280$. [CrossRef]

104. Ito, S.; Hirata, Y. The structure of ikarugamycin, an acyltetramic acid antibiotic possessing a unique as-hydrindacene skeleton. Bull. Chem. Soc. Jpn. 1977, 50, 1813-1820. [CrossRef]

105. Bertasso, M.; Holzenkaempfer, M.; Zeeck, A.; Stackebrandt, E.; Beil, W.; Fiedler, H.-P. Ripromycin and other polycyclic macrolactams from Streptomyces sp. Tü 6239. J. Antibiot. 2003, 56, 364-371. [CrossRef]

106. Lacret, R.; Oves-Costales, D.; Gomez, C.; Diaz, C.; de la Cruz, M.; Perez-Victoria, I.; Vicente, F.; Genilloud, O.; Reyes, F. New ikarugamycin derivatives with antifungal and antibacterial properties from Streptomyces zhaozhouensis. Mar. Drugs 2014, 13, 128-140. [CrossRef] [PubMed]

107. Popescu, R.; Heiss, E.H.; Ferk, F.; Peschel, A.; Knasmueller, S.; Dirsch, V.M.; Krupitza, G.; Kopp, B. Ikarugamycin induces DNA damage, intracellular calcium increase, p38 MAP kinase activation and apoptosis in HL-60 human promyelocytic leukemia cells. Mutat. Res. Fund. Mol. Mech. Mutagen. 2011, 709, 60-66. [CrossRef] [PubMed]

108. Dhaneesha, M.; Hasin, O.; Sivakumar, K.C.; Ravinesh, R.; Naman, C.B.; Carmeli, S.; Sajeevan, T.P. DNA binding and molecular dynamic studies of polycyclic tetramate macrolactams (PTM) with potential anticancer activity isolated from a sponge-associated Streptomyces zhaozhouensis subsp. mycale subsp. nov. Mar. Biotechnol. 2019, 21, 124-137. [CrossRef] [PubMed]

109. Yu, H.L.; Jiang, S.H.; Bu, X.L.; Wang, J.H.; Weng, J.Y.; Yang, X.M.; He, K.Y.; Zhang, Z.G.; Ao, P.; Xu, J.; et al. Structural diversity of anti-pancreatic cancer capsimycins identified in mangrove-derived Streptomyces xiamenensis 318 and post-modification via a novel cytochrome P450 monooxygenase. Sci. Rep. 2017, 7, 40689. [CrossRef] [PubMed]

110. Zhang, W.; Zhang, G.; Zhang, L.; Liu, W.; Jiang, X.; Jin, H.; Liu, Z.; Zhang, H.; Zhou, A.; Zhang, C. New polycyclic tetramate macrolactams from marine-derived Streptomyces sp. SCSIO 40060. Tetrahedron 2018, 74, 6839-6845. [CrossRef]

111. Hasumi, K.; Shinohara, C.; Naganuma, S.; Endo, A. Inhibition of the uptake of oxidized low-density lipoprotein in macrophage J774 by the antibiotic ikarugamycin. Eur. J. Biochem. 1992, 205, 841-846. [CrossRef]

112. Luo, T.; Fredericksen, B.L.; Hasumi, K.; Endo, A.; Garcia, J.V. Human immunodeficiency virus type 1 Nef-induced CD4 cell surface downregulation is inhibited by ikarugamycin. J. Virol. 2001, 75, 2488-2492. [CrossRef] 
113. Moscatelli, A.; Ciampolini, F.; Rodighiero, S.; Onelli, E.; Cresti, M.; Santo, N.; Idilli, A. Distinct endocytic pathways identified in tobacco pollen tubes using charged nanogold. J. Cell. Sci. 2007, 120, 3804-3819. [CrossRef]

114. Kyeremeh, K.; Acquah, K.S.; Sazak, A.; Houssen, W.; Tabudravu, J.; Deng, H.; Jaspars, M. Butremycin, the 3-hydroxyl derivative of ikarugamycin and a protonated aromatic tautomer of 5 '-methylthioinosine from a Ghanaian Micromonospora sp. K310. Mar. Drugs 2014, 12, 999-1012. [CrossRef]

115. Aizawa, S.; Akutsu, H.; Satomi, T.; Nagatsu, T.; Taguchi, R.; Seino, A. Capsimycin, a new antibiotic. I. Production, isolation and properties. J. Antibiot. 1979, 32, 193-196. [CrossRef]

116. Fukuda, T.; Takahashi, M.; Kasai, H.; Nagai, K.; Tomoda, H. Chlokamycin, a New Chloride from the Marine-derived Streptomyces sp MA2-12. Nat. Prod. Commun. 2017, 12, 1223-1226. [CrossRef]

117. Mei, X.; Wang, L.; Wang, D.; Fan, J.; Zhu, W. Polycyclic Tetramate Macrolactams from the Marine-Derived Actinoalloteichus cyanogriseus WH1-2216-6. Chin. J. Org. Chem. 2017, 37, 2352-2360. [CrossRef]

118. Graupner, P.; Thornburgh, S.; Mathieson, J.; Chapin, E.; Kemmitt, G.; Brown, J.; Snipes, C. Dihydromaltophilin; A novel fungicidal tetramic acid containing metabolite from Streptomyces sp. J. Antibiot. 1997, 50, 1014-1019. [CrossRef] [PubMed]

119. Yu, F.; Zaleta-Rivera, K.; Zhu, X.; Huffman, J.; Millet, J.C.; Harris, S.D.; Yuen, G.; Li, X.C.; Du, L. Structure and biosynthesis of heat-stable antifungal factor (HSAF), a broad-spectrum antimycotic with a novel mode of action. Antimicrob. Agents Chemother. 2007, 51, 64-72. [CrossRef]

120. Saha, S.; Zhang, W.; Zhang, G.; Zhu, Y.; Chen, Y.; Liu, W.; Yuan, C.; Zhang, Q.; Zhang, H.; Zhang, L.; et al. Activation and characterization of a cryptic gene cluster reveals a cyclization cascade for polycyclic tetramate macrolactams. Chem. Sci. 2017, 8, 1607-1612. [CrossRef]

121. Shigemori, H.; Bae, M.A.; Yazawa, K.; Sasaki, T.; Kobayashi, J. Alteramide A, a new tetracyclic alkaloid from a bacterium Alteromonas sp. associated with the marine sponge Halichondria okadai. J. Org. Chem. 1992, 57, 4317-4320. [CrossRef]

122. Moree, W.J.; McConnell, O.J.; Nguyen, D.D.; Sanchez, L.M.; Yang, Y.L.; Zhao, X.; Liu, W.T.; Boudreau, P.D.; Srinivasan, J.; Atencio, L.; et al. Microbiota of healthy corals are active against fungi in a light-dependent manner. ACS Chem. Biol. 2014, 9, 2300-2308. [CrossRef]

123. Olano, C.; Garcia, I.; Gonzalez, A.; Rodriguez, M.; Rozas, D.; Rubio, J.; Sanchez-Hidalgo, M.; Brana, A.F.; Mendez, C.; Salas, J.A. Activation and identification of five clusters for secondary metabolites in Streptomyces albus J1074. Microb. Biotechnol. 2014, 7, 242-256. [CrossRef]

124. Bae, M.; Yamada, K.; Uemura, D.; Seu, J.-H.; Kim, Y.-H. Aburatubolactam C, a novel apoptosis-inducing substance produced by marine Streptomyces sp. SCRC A-20. J. Microbiol. Biotech. 1998, 8, 455-460.

125. Bae, M.-A.; Yamada, K.; Ijuin, Y.; Tsuji, T.; Yazawa, K.; Uemura, D. Aburatubolactam A, a novel inhibitor of superoxide anion generation from a marine microorganism. Heterocycl. Commun. 1992, 2, 315-318. [CrossRef]

126. Yamada, K.; Kuramoto, M.; Uemura, D. Aburatubolactams and Zoanthamines, naturally occurring bioactive alkaloids. Recent Res. Devel. Pure. Appl. Chem 1999, 3, 245-254.

127. Song, T.; Chen, M.; Chai, W.; Zhang, Z.; Lian, X.-Y. New bioactive pyrrospirones C-I from a marine-derived fungus Penicillium sp. ZZ380. Tetrahedron 2018, 74, 884-891. [CrossRef]

128. Song, T.; Chen, M.; Ge, Z.W.; Chai, W.; Li, X.C.; Zhang, Z.; Lian, X.Y. Bioactive Penicipyrrodiether A, an Adduct of GKK1032 Analogue and Phenol A Derivative, from a Marine-Sourced Fungus Penicillium sp. ZZ380. J. Org. Chem. 2018, 83, 13395-13401. [CrossRef] [PubMed]

129. Song, T.; Tang, M.; Ge, H.; Chen, M.; Lian, X.; Zhang, Z. Novel Bioactive Penicipyrroether A and Pyrrospirone J from the Marine-Derived Penicillium sp. ZZ380. Mar. Drugs 2019, 17, 292. [CrossRef] [PubMed]

130. Qi, X.; Li, X.; Zhao, J.; He, N.; Li, Y.; Zhang, T.; Wang, S.; Yu, L.; Xie, Y. GKK1032C, a new alkaloid compound from the endophytic fungus Penicillium sp. CPCC 400817 with activity against methicillin-resistant $S$. aureus. J. Antibiot. 2019, 72, 237-240. [CrossRef]

131. Chen, S.; Shen, H.; Zhang, P.; Cheng, H.; Dai, X.; Liu, L. Anti-glioma trichobamide A with an unprecedented tetrahydro-5H-furo[2,3-b]pyrrol-5-one functionality from ascidian-derived fungus Trichobotrys effuse 4729. Chem. Commun. 2019, 55, 1438-1441. [CrossRef]

132. Wijeratne, E.M.; He, H.; Franzblau, S.G.; Hoffman, A.M.; Gunatilaka, A.A. Phomapyrrolidones A-C, antitubercular alkaloids from the endophytic fungus Phoma sp. NRRL 46751. J. Nat. Prod. 2013, 76, 1860-1865. [CrossRef] 
133. Chen, Y.; Liu, Z.; Huang, Y.; Liu, L.; He, J.; Wang, L.; Yuan, J.; She, Z. Ascomylactams A-C, Cytotoxic 12or 13-Membered-Ring Macrocyclic Alkaloids Isolated from the Mangrove Endophytic Fungus Didymella sp. CYSK-4, and Structure Revisions of Phomapyrrolidones A and C. J. Nat. Prod. 2019, 82, 1752-1758. [CrossRef]

134. Luesch, H.; Harrigan, G.; Goetz, G.; Horgen, F. The cyanobacterial origin of potent anticancer agents originally isolated from sea hares. Curr. Med. Chem. 2002, 9, 1791-1806. [CrossRef]

135. Edwards, D.J.; Marquez, B.L.; Nogle, L.M.; McPhail, K.; Goeger, D.E.; Roberts, M.A.; Gerwick, W.H. Structure and biosynthesis of the jamaicamides, new mixed polyketide-peptide neurotoxins from the marine cyanobacterium Lyngbya majuscula. Chem. Biol. 2004, 11, 817-833. [CrossRef]

136. Boudreau, P.D.; Monroe, E.A.; Mehrotra, S.; Desfor, S.; Korobeynikov, A.; Sherman, D.H.; Murray, T.F.; Gerwick, L.; Dorrestein, P.C.; Gerwick, W.H. Expanding the Described Metabolome of the Marine Cyanobacterium Moorea producens JHB through Orthogonal Natural Products Workflows. PLoS ONE 2015, 10, e0133297. [CrossRef] [PubMed]

137. Koehn, F.E.; Longley, R.E.; Reed, J.K. Microcolins A and B, new immunosuppressive peptides from the blue-green alga Lyngbya majuscula. J. Nat. Prod. 1992, 55, 613-619. [CrossRef] [PubMed]

138. Meickle, T.; Matthew, S.; Ross, C.; Luesch, H.; Paul, V. Bioassay-guided isolation and identification of desacetylmicrocolin B from Lyngbya cf. polychroa. Plant. Med. 2009, 75, 1427-1430. [CrossRef] [PubMed]

139. Yu, H.B.; Glukhov, E.; Li, Y.; Iwasaki, A.; Gerwick, L.; Dorrestein, P.C.; Jiao, B.H.; Gerwick, W.H. Cytotoxic Microcolin Lipopeptides from the Marine Cyanobacterium Moorea producens. J. Nat. Prod. 2019, 82, 2608-2619. [CrossRef]

140. Takamatsu, S.; Nagle, D.G.; Gerwick, W.H. Secondary metabolites from marine cyanobacteria and algae inhibit LFA-1/ICAM-1 mediated cell adhesion. Plant. Med. 2004, 70, 127-131.

141. Zhang, L.H.; Longley, R.E.; Koehn, F.E. Antiproliferative and immunosuppressive properties of microcolin A, a marine-derived lipopeptide. Life Sci. 1997, 60, 751-762. [CrossRef]

142. Moore, R.E.; Entzeroth, M. Majusculamide D and deoxymajusculamide D, two cytotoxins from Lyngbya majuscula. Phytochemistry 1988, 27, 3101-3103. [CrossRef]

143. Caro-Diaz, E.J.E.; Valeriote, F.A.; Gerwick, W.H. Highly Convergent Total Synthesis and Assignment of Absolute Configuration of Majusculamide D, a Potent and Selective Cytotoxic Metabolite from Moorea sp. Org. Lett. 2019, 21, 793-796. [CrossRef]

144. Nagle, D.G.; Paul, V.J.; Roberts, M.A. Ypaoamide, a new broadly acting feeding deterrent from the marine cyanobacterium Lyngbya majuscula. Tetrahedron Lett. 1996, 37, 6263-6266. [CrossRef]

145. Sueyoshi, K.; Yamada, M.; Yamano, A.; Ozaki, K.; Sumimoto, S.; Iwasaki, A.; Suenaga, K.; Teruya, T. Ypaoamides B and C, Linear Lipopeptides from an Okeania sp. Marine Cyanobacterium. J. Nat. Prod. 2018, 81, 1103-1107. [CrossRef]

146. Pereira, A.R.; Etzbach, L.; Engene, N.; Muller, R.; Gerwick, W.H. Molluscicidal metabolites from an assemblage of Palmyra Atoll cyanobacteria. J. Nat. Prod. 2011, 74, 1175-1181. [CrossRef] [PubMed]

147. Cardellina, J.H.; Marner, F.J.; Moore, R.E. Malyngamide A, a novel chlorinated metabolite of the marine cyanophyte Lyngbya majuscula. J. Am. Chem. Soc. 1979, 101, 240-242. [CrossRef]

148. Dalietos, D.; Marner, F.-J.; Mynderse, J.S.; Moore, R.E. (-)-Trans-7 (S)-methoxytetradec-4-enoic acid and related amides from the marine cyanophyte Lyngbya majuscula. Phytochemistry 1978, 17, 2091-2095.

149. Simmons, C.J.; Marner, F.-J.; Cardellina II, J.H.; Moore, R.E.; Seff, K. Pukeleimide C, a novel pyrrolic compound from the marine cyanophyte Lyngbya majuscula. Tetrahedron Lett. 1979, 20, 2003-2006. [CrossRef]

150. Cardellina II, J.H.; Moore, R.E. The structures of pukeleimides A., B., D., E., F., and G. Tetrahedron Lett. 1979, 20, 2007-2010. [CrossRef]

151. Milligan, K.E.; Marquez, B.; Williamson, R.T.; Davies-Coleman, M.; Gerwick, W.H. Two new malyngamides from a Madagascan Lyngbya majuscula. J. Nat. Prod. 2000, 63, 965-968. [CrossRef]

152. Kan, Y.; Sakamoto, B.; Fujita, T.; Nagai, H. New malyngamides from the Hawaiian cyanobacterium Lyngbya majuscula. J. Nat. Prod. 2000, 63, 1599-1602. [CrossRef]

153. Shaala, L.A.; Youssef, D.T.A.; McPhail, K.L.; Elbandy, M. Malyngamide 4, a new lipopeptide from the Red Sea marine cyanobacterium Moorea producens (formerly Lyngbya majuscula). Phytochem Lett. 2013, 6, $183-188$. [CrossRef]

154. Chang, T.T.; More, S.V.; Lu, I.H.; Hsu, J.C.; Chen, T.J.; Jen, Y.C.; Lu, C.K.; Li, W.S. Isomalyngamide A, A-1 and their analogs suppress cancer cell migration in vitro. Eur. J. Med. Chem. 2011, 46, 3810-3819. [CrossRef] 
155. Jiang, W.; Zhou, W.; Othman, R.; Uchida, H.; Watanabe, R.; Suzuki, T.; Sakamoto, B.; Nagai, H. A new malyngamide from the marine cyanobacterium Moorea producens. Nat. Prod. Res. 2018, 32, 97-104. [CrossRef]

156. Luesch, H.; Toshida, W.Y.; Moore, R.E.; Paul, V.J. Structurally diverse new alkaloids from Palauan collections of the apratoxin-producing marine cyanobacterium Lyngbya sp. Tetrahedron 2002, 58, 7959-7966. [CrossRef]

157. Simmons, T.L.; McPhail, K.L.; Ortega-Barría, E.; Mooberry, S.L.; Gerwick, W.H. Belamide A, a new antimitotic tetrapeptide from a Panamanian marine cyanobacterium. Tetrahedron Lett. 2006, 47, 3387-3390. [CrossRef]

158. Gunasekera, S.P.; Imperial, L.; Garst, C.; Ratnayake, R.; Dang, L.H.; Paul, V.J.; Luesch, H. Caldoramide, a Modified Pentapeptide from the Marine Cyanobacterium Caldora penicillata. J. Nat. Prod. 2016, 79, 1867-1871. [CrossRef] [PubMed]

159. Taori, K.; Liu, Y.; Paul, V.J.; Luesch, H. Combinatorial strategies by marine cyanobacteria: Symplostatin 4, an antimitotic natural dolastatin 10/15 hybrid that synergizes with the coproduced HDAC inhibitor largazole. Chembiochem 2009, 10, 1634-1639. [CrossRef]

160. Conroy, T.; Guo, J.T.; Linington, R.G.; Hunt, N.H.; Payne, R.J. Total synthesis, stereochemical assignment, and antimalarial activity of gallinamide A. Chem. Eur. J. 2011, 17, 13544-13552. [CrossRef]

161. Conroy, T.; Guo, J.T.; Hunt, N.H.; Payne, R.J. Total synthesis and antimalarial activity of symplostatin 4. Org. Lett. 2010, 12, 5576-5579. [CrossRef]

162. Linington, R.G.; Clark, B.R.; Trimble, E.E.; Almanza, A.; Urena, L.D.; Kyle, D.E.; Gerwick, W.H. Antimalarial peptides from marine cyanobacteria: Isolation and structural elucidation of gallinamide A. J. Nat. Prod. 2009, 72, 14-17. [CrossRef]

163. Miller, B.; Friedman, A.J.; Choi, H.; Hogan, J.; McCammon, J.A.; Hook, V.; Gerwick, W.H. The marine cyanobacterial metabolite gallinamide A is a potent and selective inhibitor of human cathepsin L. J. Nat. Prod. 2014, 77, 92-99. [CrossRef]

164. Stolze, S.C.; Deu, E.; Kaschani, F.; Li, N.; Florea, B.I.; Richau, K.H.; Colby, T.; van der Hoorn, R.A.; Overkleeft, H.S.; Bogyo, M.; et al. The antimalarial natural product symplostatin 4 is a nanomolar inhibitor of the food vacuole falcipains. Chem. Biol. 2012, 19, 1546-1555. [CrossRef]

165. Uka, V.; Moore, G.G.; Arroyo-Manzanares, N.; Nebija, D.; De Saeger, S.; Di Mavungu, J.D. Unravelling the diversity of the cyclopiazonic acid family of mycotoxins in Aspergillus flavus by UHPLC triple-TOF HRMS. Toxins 2017, 9, 35. [CrossRef]

166. Ostry, V.; Toman, J.; Grosse, Y.; Malir, F. Cyclopiazonic acid: 50th anniversary of its discovery. World Mycotoxin J. 2018, 11, 135-148. [CrossRef]

167. Hymery, N.; Masson, F.; Barbier, G.; Coton, E. Cytotoxicity and immunotoxicity of cyclopiazonic acid on human cells. Toxicol. Vitr. 2014, 28, 940-947. [CrossRef] [PubMed]

168. Cui, R.; Wang, Y.; Wang, L.; Li, G.; Lan, K.; Altmeyer, R.; Zou, G. Cyclopiazonic acid, an inhibitor of calcium-dependent ATPases with antiviral activity against human respiratory syncytial virus. Antivir. Res. 2016, 132, 38-45. [CrossRef] [PubMed]

169. Lin, A.-Q.; Du, L.; Fang, Y.-C.; Wang, F.-Z.; Zhu, T.-J.; Gu, Q.-Q.; Zhu, W.-M. Iso- $\alpha$-Cyclopiazonic acid, a new natural product isolated from the marine-derived fungus Aspergillus flavus CF-3. Chem. Nat. Compd. 2009, 45, 677-680. [CrossRef]

170. Sun, K.; Li, Y.; Guo, L.; Wang, Y.; Liu, P.; Zhu, W. Indole diterpenoids and isocoumarin from the fungus, Aspergillus flavus, isolated from the prawn, Penaeus vannamei. Mar. Drugs 2014, 12, 3970-3981. [CrossRef]

171. Zhu, H.; Chen, C.; Wang, J.; Li, X.N.; Wei, G.; Guo, Y.; Yao, G.; Luo, Z.; Zhang, J.; Xue, Y. Penicamedine A, a highly oxygenated hexacyclic indole alkaloid from Penicillium camemberti. Chem. Biodivers. 2015, 12, 1547-1553. [CrossRef]

172. Kwon, Y.; Kim, S.H.; Shin, Y.; Bae, M.; Kim, B.Y.; Lee, S.K.; Oh, K.B.; Shin, J.; Oh, D.C. A new benzofuran glycoside and indole alkaloids from a sponge-associated rare actinomycete, Amycolatopsis sp. Mar. Drugs 2014, 12, 2326-2340. [CrossRef]

173. Lan, W.-J.; Wang, K.-T.; Xu, M.-Y.; Zhang, J.-J.; Lam, C.-K.; Zhong, G.-H.; Xu, J.; Yang, D.-P.; Li, H.-J.; Wang, L.-Y. Secondary metabolites with chemical diversity from the marine-derived fungus Pseudallescheria boydii F19-1 and their cytotoxic activity. RSC Adv. 2016, 6, 76206-76213. [CrossRef]

174. Cao, T.; Ling, J.; Liu, Y.; Chen, X.; Tian, X.; Meng, D.; Pan, H.; Hu, J.; Wang, N. Characterization and abolishment of the cyclopiazonic acids produced by Aspergillus oryzae HMP-F28. Biosci. Biotechnol. Biochem. 2018, 82, 1832-1839. [CrossRef] 
175. Tsuda, M.; Mugishima, T.; Komatsu, K.; Sone, T.; Tanaka, M.; Mikami, Y.; Shiro, M.; Hirai, M.; Ohizumi, Y.; Kobayashi, J.I. Speradine A, a new pentacyclic oxindole alkaloid from a marine-derived fungus Aspergillus tamarii. Tetrahedron 2003, 59, 3227-3230. [CrossRef]

176. Wang, N.; Hu, J.C.; Liu, W.; Wang, S.J. Cyclopiazonic Acid Compound, and Preparation and Application Thereof. Chinese Patent CN103183666A, 3 July 2013.

177. Zhang, Q.-Q.; Chen, L.; Hu, X.; Xia, Q.-W.; Zhao, Y.-Y.; Zheng, Q.-H.; Liu, Q.-Y. Speradines B-E, Four Novel Tetracyclic Oxindole Alkaloids from the Marine-Derived Fungus Aspergillus oryzae. Heterocycles 2014, 89, 1662-1669.

178. Hu, X.; Xia, Q.W.; Zhao, Y.Y.; Zheng, Q.H.; Liu, Q.Y.; Chen, L.; Zhang, Q.Q. Speradines F-H, three new oxindole alkaloids from the marine-derived fungus Aspergillus oryzae. Chem. Pharm. Bull. 2014, 62, 942-946. [CrossRef]

179. Ma, X.; Peng, J.; Wu, G.; Zhu, T.; Li, G.; Gu, Q.; Li, D. Speradines B-D, oxygenated cyclopiazonic acid alkaloids from the sponge-derived fungus Aspergillus flavus MXH-X104. Tetrahedron 2015, 71, 3522-3527. [CrossRef]

180. Wang, D.; Bao, Y.-R.; Yang, X.-X.; Meng, X.-S.; Chen, G. A New Alkaloid from Penicillium Dipodomyicola. Chem. Nat. Compd. 2015, 51, 733-735. [CrossRef]

181. Xu, X.; Zhang, X.; Nong, X.; Wei, X.; Qi, S. Oxindole alkaloids from the fungus Penicillium commune DFFSCS026 isolated from deep-sea-derived sediments. Tetrahedron 2015, 71, 610-615. [CrossRef]

182. Zhou, M.; Miao, M.M.; Du, G.; Li, X.N.; Shang, S.Z.; Zhao, W.; Liu, Z.H.; Yang, G.Y.; Che, C.T.; Hu, Q.F.; et al. Aspergillines A-E, highly oxygenated hexacyclic indole-tetrahydrofuran-tetramic acid derivatives from Aspergillus versicolor. Org. Lett. 2014, 16, 5016-5019. [CrossRef]

183. Zhang, D.; Zhao, L.; Wang, L.; Fang, X.; Zhao, J.; Wang, X.; Li, L.; Liu, H.; Wei, Y.; You, X.; et al. Griseofulvin Derivative and Indole Alkaloids from Penicillium griseofulvum CPCC 400528. J. Nat. Prod. 2017, 80, 371-376. [CrossRef]

184. Asiri, I.A.M.; Badr, J.M.; Youssef, D.T.A. Penicillivinacine, antimigratory diketopiperazine alkaloid from the marine-derived fungus Penicillium vinaceum. Phytochem. Lett. 2015, 13, 53-58. [CrossRef]

185. Hiort, J.; Maksimenka, K.; Reichert, M.; Perović-Ottstadt, S.; Lin, W.; Wray, V.; Steube, K.; Schaumann, K.; Weber, H.; Proksch, P. New Natural Products from the Sponge-Derived Fungus Aspergillus niger. J. Nat. Prod. 2004, 67, 1532-1543. [CrossRef]

186. Schlingmann, G.; Taniguchi, T.; He, H.; Bigelis, R.; Yang, H.Y.; Koehn, F.E.; Carter, G.T.; Berova, N. Reassessing the structure of pyranonigrin. J. Nat. Prod. 2007, 70, 1180-1187. [CrossRef]

187. Meng, L.-H.; Li, X.-M.; Liu, Y.; Wang, B.-G. Polyoxygenated dihydropyrano [2, 3-c] pyrrole-4, 5-dione derivatives from the marine mangrove-derived endophytic fungus Penicillium brocae MA-231 and their antimicrobial activity. Chin. Chem. Lett. 2015, 26, 610-612. [CrossRef]

188. Miyake, Y.; Mochizuki, M.; Ito, C.; Itoigawa, M.; Osawa, T. Antioxidative pyranonigrins in rice mold starters and their suppressive effect on the expression of blood adhesion molecules. Biosci. Biotechnol. Biochem. 2008, 72, 1580-1585. [CrossRef] [PubMed]

189. Miyake, Y.; Ito, C.; Tokuda, H.; Osawa, T.; Itoigawa, M. Evaluation of flavoglaucin, its derivatives and pyranonigrins produced by molds used in fermented foods for inhibiting tumor promotion. Biosci. Biotechnol. Biochem. 2010, 74, 1120-1122. [CrossRef] [PubMed]

190. Miyake, Y.; Ito, C.; Itoigawa, M.; Osawa, T. Isolation of the antioxidant pyranonigrin-A from rice mold starters used in the manufacturing process of fermented foods. Biosci. Biotechnol. Biochem. 2007, 71, 2515-2521. [CrossRef]

191. Riko, R.; Nakamura, H.; Shindo, K. Studies on pyranonigrins-isolation of pyranonigrin E and biosynthetic studies on pyranonigrin A. J. Antibiot. 2014, 67, 179-181. [CrossRef]

192. Dong, J.-J.; Bao, J.; Zhang, X.-Y.; Xu, X.-Y.; Nong, X.-H.; Qi, S.-H. Alkaloids and citrinins from marine-derived fungus Nigrospora oryzae SCSGAF 0111. Tetrahedron Lett. 2014, 55, 2749-2753. [CrossRef]

193. Hosoe, T.; Fukushima, K.; Takizawa, K. A new pyrrolidine-2, 4-dione derivative, vermelhotin, isolated from unidentified fungus IFM 52672. Heterocycles 2006, 68, 1949-1953.

194. Kasettrathat, C.; Ngamrojanavanich, N.; Wiyakrutta, S.; Mahidol, C.; Ruchirawat, S.; Kittakoop, P. Cytotoxic and antiplasmodial substances from marine-derived fungi, Nodulisporium sp. and CRI247-01. Phytochemistry 2008, 69, 2621-2626. [CrossRef] 
195. Leyte-Lugo, M.; Gonzalez-Andrade, M.; Gonzalez Mdel, C.; Glenn, A.E.; Cerda-Garcia-Rojas, C.M.; Mata, R. (+)-Ascosalitoxin and vermelhotin, a calmodulin inhibitor, from an endophytic fungus isolated from Hintonia latiflora. J. Nat. Prod. 2012, 75, 1571-1577. [CrossRef]

196. Pansanit, A.; Park, E.J.; Kondratyuk, T.P.; Pezzuto, J.M.; Lirdprapamongkol, K.; Kittakoop, P. Vermelhotin, an anti-inflammatory agent, suppresses nitric oxide production in RAW 264.7 cells via p38 inhibition. J. Nat. Prod. 2013, 76, 1824-1827. [CrossRef]

197. Ganihigama, D.U.; Sureram, S.; Sangher, S.; Hongmanee, P.; Aree, T.; Mahidol, C.; Ruchirawat, S.; Kittakoop, P. Antimycobacterial activity of natural products and synthetic agents: Pyrrolodiquinolines and vermelhotin as anti-tubercular leads against clinical multidrug resistant isolates of Mycobacterium tuberculosis. Eur. J. Med. Chem. 2015, 89, 1-12. [CrossRef]

198. Zhu, G.; Kong, F.; Wang, Y.; Fu, P.; Zhu, W. Cladodionen, a Cytotoxic Hybrid Polyketide from the Marine-Derived Cladosporium sp. OUCMDZ-1635. Mar. Drugs 2018, 16, 71. [CrossRef]

199. Wu, G.; Sun, X.; Yu, G.; Wang, W.; Zhu, T.; Gu, Q.; Li, D. Cladosins A-E, hybrid polyketides from a deep-sea-derived fungus, Cladosporium sphaerospermum. J. Nat. Prod. 2014, 77, 270-275. [CrossRef] [PubMed]

200. Yu, G.H.; Wu, G.W.; Zhu, T.J.; Gu, Q.Q.; Li, D.H. Cladosins F and G, two new hybrid polyketides from the deep-sea-derived Cladosporium sphaerospermum 2005-01-E3. J. Asian Nat. Prod. Res. 2015, 17, 120-124. [CrossRef]

201. Zhang, Z.; He, X.; Wu, G.; Liu, C.; Lu, C.; Gu, Q.; Che, Q.; Zhu, T.; Zhang, G.; Li, D. Aniline-tetramic acids from the deep-sea-derived fungus Cladosporium sphaerospermum L3P3 cultured with the hdac inhibitor saha. J. Nat. Prod. 2018, 81, 1651-1657. [CrossRef]

202. Chen, S.C.; Liu, Z.M.; Tan, H.B.; Chen, Y.C.; Li, S.N.; Li, H.H.; Guo, H.; Zhu, S.; Liu, H.X.; Zhang, W.M. Tersone A-G, New Pyridone Alkaloids from the Deep-Sea Fungus Phomopsis tersa. Mar. Drugs 2019, 17, 394. [CrossRef] [PubMed]

203. Manam, R.R.; Teisan, S.; White, D.J.; Nicholson, B.; Grodberg, J.; Neuteboom, S.T.; Lam, K.S.; Mosca, D.A.; Lloyd, G.K.; Potts, B.C. Lajollamycin, a Nitro-tetraene Spiro- $\beta$-lactone- $\gamma$-lactam Antibiotic from the Marine Actinomycete Streptomyces nodosus. J. Nat. Prod. 2005, 68, 240-243. [CrossRef]

204. Ko, K.; Lee, S.H.; Kim, S.H.; Kim, E.H.; Oh, K.B.; Shin, J.; Oh, D.C. Lajollamycins, nitro group-bearing spiro-beta-lactone-gamma-lactams obtained from a marine-derived Streptomyces sp. J. Nat. Prod. 2014, 77, 2099-2104. [CrossRef]

205. Shin, H.J.; Kim, T.S.; Lee, H.S.; Park, J.Y.; Choi, I.K.; Kwon, H.J. Streptopyrrolidine, an angiogenesis inhibitor from a marine-derived Streptomyces sp. KORDI-3973. Phytochemistry 2008, 69, 2363-2366. [CrossRef]

206. Fu, P.; La, S.; MacMillan, J.B. 1,3-Oxazin-6-one Derivatives and Bohemamine-Type Pyrrolizidine Alkaloids from a Marine-Derived Streptomyces spinoverrucosus. J. Nat. Prod. 2016, 79, 455-462. [CrossRef]

207. Kakeya, H.; Takahashi, I.; Okada, G.; Isono, K.; Osada, H. Epolactaene, a novel neuritogenic compound in human neuroblastoma cells, produced by a marine fungus. J. Antibiot. 1995, 48, 733-735. [CrossRef] [PubMed]

208. Mizushina, Y.; Kobayashi, S.; Kuramochi, K.; Nagata, S.; Sugawara, F.; Sakaguchi, K. Epolactaene, a novel neuritogenic compound in human neuroblastoma cells, selectively inhibits the activities of mammalian DNA polymerases and human DNA topoisomerase II. Biochem. Biophys. Res. Commun. 2000, 273, 784-788. [CrossRef] [PubMed]

209. Nagumo, Y.; Kakeya, H.; Shoji, M.; Hayashi, Y.; Dohmae, N.; Osada, H. Epolactaene binds human Hsp60 Cys442 resulting in the inhibition of chaperone activity. Biochem. J. 2005, 387, 835-840. [CrossRef]

210. Nagumo, Y.; Kakeya, H.; Yamaguchi, J.; Uno, T.; Shoji, M.; Hayashi, Y.; Osada, H. Structure-activity relationships of epolactaene derivatives: Structural requirements for inhibition of Hsp60 chaperone activity. Bioorg. Med. Chem. Lett. 2004, 14, 4425-4429. [CrossRef]

211. Alvi, K.A.; Casey, A.; Nair, B.G. Pulchellalactam: A CD45 protein tyrosine phosphatase inhibitor from the marine fungus Corollospora pulchella. J. Antibiot. 1998, 51, 515-517. [CrossRef] [PubMed]

212. Ogawa, H.; Iwasaki, A.; Sumimoto, S.; Iwatsuki, M.; Ishiyama, A.; Hokari, R.; Otoguro, K.; Omura, S.; Suenaga, K. Isolation and Total Synthesis of Hoshinolactam, an Antitrypanosomal Lactam from a Marine Cyanobacterium. Org. Lett. 2017, 19, 890-893. [CrossRef] 
213. Sangnoi, Y.; Plubrukarn, A.; Arunpairojana, V.; Kanjana-Opas, A. A new antibacterial amino phenyl pyrrolidone derivative from a novel marine gliding bacterium Rapidithrix thailandica. World J. Microbiol. Biotechnol. 2014, 30, 1135-1139. [CrossRef]

214. Needham, J.; Kelly, M.T.; Ishige, M.; Andersen, R.J. Andrimid and moiramides A-C, metabolites produced in culture by a marine isolate of the bacterium Pseudomonas fluorescens: Structure elucidation and biosynthesis. J. Org. Chem. 1994, 59, 2058-2063. [CrossRef]

215. Freiberg, C.; Brunner, N.A.; Schiffer, G.; Lampe, T.; Pohlmann, J.; Brands, M.; Raabe, M.; Habich, D.; Ziegelbauer, K. Identification and characterization of the first class of potent bacterial acetyl-CoA carboxylase inhibitors with antibacterial activity. J. Biol. Chem. 2004, 279, 26066-26073. [CrossRef]

216. Pohlmann, J.; Lampe, T.; Shimada, M.; Nell, P.G.; Pernerstorfer, J.; Svenstrup, N.; Brunner, N.A.; Schiffer, G.; Freiberg, C. Pyrrolidinedione derivatives as antibacterial agents with a novel mode of action. Bioorg. Med. Chem. Lett. 2005, 15, 1189-1192. [CrossRef]

(C) 2020 by the authors. Licensee MDPI, Basel, Switzerland. This article is an open access article distributed under the terms and conditions of the Creative Commons Attribution (CC BY) license (http://creativecommons.org/licenses/by/4.0/). 